\title{
Fostering self-regulated learning
}

Citation for published version (APA):

Hui, L. (2021). Fostering self-regulated learning: the role of perceived mental effort. [Doctoral Thesis, Maastricht University]. Ipskamp. https://doi.org/10.26481/dis.20211206lh

Document status and date:

Published: 01/01/2021

DOI:

$10.26481 /$ dis.20211206lh

Document Version:

Publisher's PDF, also known as Version of record

\section{Please check the document version of this publication:}

- A submitted manuscript is the version of the article upon submission and before peer-review. There can be important differences between the submitted version and the official published version of record.

People interested in the research are advised to contact the author for the final version of the publication, or visit the DOI to the publisher's website.

- The final author version and the galley proof are versions of the publication after peer review.

- The final published version features the final layout of the paper including the volume, issue and page numbers.

Link to publication

\footnotetext{
General rights rights.

- You may freely distribute the URL identifying the publication in the public portal. please follow below link for the End User Agreement:

www.umlib.nl/taverne-license

Take down policy

If you believe that this document breaches copyright please contact us at:

repository@maastrichtuniversity.nl

providing details and we will investigate your claim.
}

Copyright and moral rights for the publications made accessible in the public portal are retained by the authors and/or other copyright owners and it is a condition of accessing publications that users recognise and abide by the legal requirements associated with these

- Users may download and print one copy of any publication from the public portal for the purpose of private study or research.

- You may not further distribute the material or use it for any profit-making activity or commercial gain

If the publication is distributed under the terms of Article $25 \mathrm{fa}$ of the Dutch Copyright Act, indicated by the "Taverne" license above, 


\section{Fostering Self-Regulated Learning: the Role of Perceived Mental Effort}

Luotong Hui 
The studies presented in this thesis were carried out at

\section{Maastricht University}

in the School of Health Professions Education

\section{SHE}

in the context of the research school (Interuniversity Center for Educational Research)

\section{ico}

Title: Fostering Self-Regulated Learning: the Role of Perceived Mental Effort

Luotong Hui

Design and layout by Rowen Aker | persoonlijkproefschrift.nl

Printed by Ipskamp Printing | proefschriften.net

ISBN: 978-94-6421-534-2

Copyright 2021 @ Luotong Hui

The Netherlands. All rights reserved. No parts of this thesis may be reproduced, stored in a retrieval system or transmitted in any form or by any means without permission of the author. 


\title{
Fostering Self-Regulated Learning: The Role of Perceived Mental Effort
}

\author{
DISSERTATION \\ To obtain the degree of Doctor at Maastricht University, \\ on the authority of the Rector Magnificus, \\ Prof. Dr. Rianne M. Letschert \\ in accordance with the decision of the Board of Deans, \\ to be defended in public \\ on Monday $6^{\text {th }}$ December 2021, at 10.00 hours
}




\section{Supervisor(s)}

Prof. dr. A. B. H. de Bruin

Prof. dr. J. J. G. van Merriënboer

\section{Co-Supervisor}

Dr. J. Donkers

\section{Assessment committee}

Prof. dr. H. H. C. M. Savelberg (Chair)

Prof. dr. C. M. G. Haelermans

Prof. dr. S. Heeneman

Dr. V. Hoogerheide (Utrecht University)

Prof. dr. A. Renkl (University of Freiburg, Germany) 


\section{Contents}

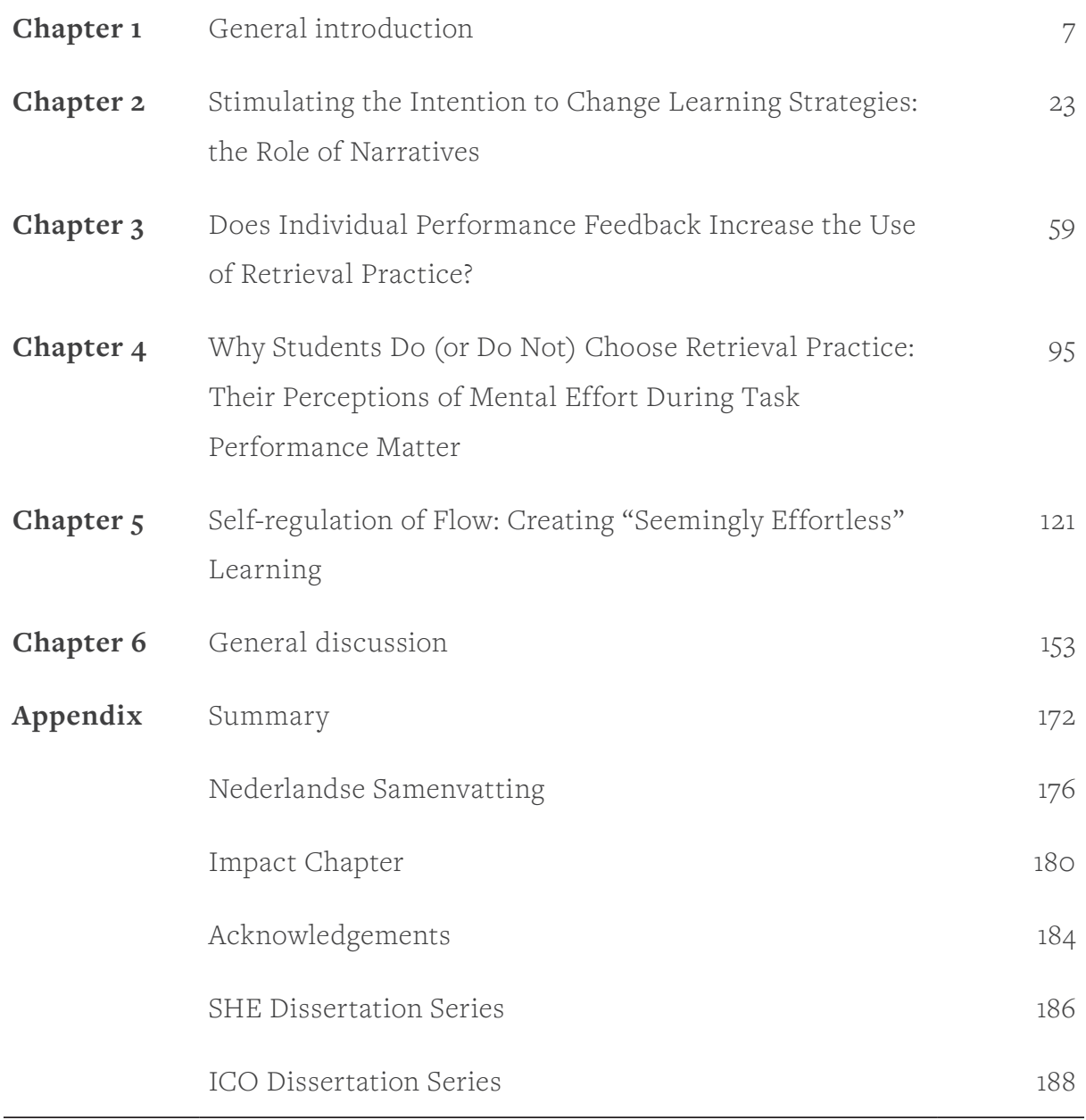

\section{Gatefolds}

Front: $\quad$ Propositions

Back: About the Author 



\section{Chapter 1}

General Introduction 


\section{Introduction}

Self-regulated learning skills are crucial to achieve academic success, especially for higher education students who spend ample time studying on their own, at their own place or in the university library. To be able to adapt to a rapidly changing world, people must become lifelong learners, which requires them to develop self-regulated learning skills in formal education. Being a self-regulated learner can be seen, in large part, as the capacity to use effective learning strategies (Wolters \& Benzon, 2013). Two learning strategies, that is, retrieval practice and distributed practice, have been found to be particularly effective in fostering long-term learning and transfer (Bjork, Dunlosky, \& Kornell, 2013; Dunlosky, Rawson, Marsh, Nathan, \& Willingham, 2013). Although students often perceive these strategies as problematic for the high investment of mental effort they require, they have positive learning effects and are therefore said to produce “desirable difficulties" (Biwer, Oude Egbrink, Aalten, \& de Bruin, 2020; Bjork \& Bjork, 2011; Rovers, Stalmeijer, van Merriënboer, Savelberg, \& de Bruin, 2018).

Despite the effectiveness of both strategies, learners often prefer strategies that are less effortful (but also less effective), such as restudy (Geller et al., 2018; Hartwig \& Dunlosky, 2012; Kornell \& Bjork, 2007; Yan, Thai, \& Bjork, 2014) and massed practice (McCabe, 2011; Wissman, Rawson, \& Pyc, 2012). To enhance academic success and prepare our students to be lifelong learners, it is crucial to help them use such effective learning strategies even though they require more mental effort. Additionally, it is crucial to help them to reach a "flow state" when wielding these strategies, meaning that they experience learning as inherently enjoyable and rewarding, without noticing the effort invested.

The main aim of the studies reported in this dissertation was to investigate how we can encourage higher education students to optimize their self-regulated learning, either by promoting the uptake of more effective learning strategies or by helping them to self-regulate factors that lead to a flow state. This Introduction section will first give a description of effective learning strategies and of the research conducted to date to enhance their use. Then, it will briefly present theory about flow, including current research about how to self-regulate into a state of flow. I will conclude by specifying the research questions that each study in this dissertation addresses, followed by a description of each chapter. 


\section{Enhancing the Uptake of Effective Learning Strategies}

Ample research has shown that retrieval practice and distributed practice are particularly effective in enhancing long-term retention and transfer of acquired knowledge (Bjork et al., 2013; Cepeda, Pashler, Vul, Wixted, \& Rohrer, 2006; Dunlosky et al., 2013; KirkJohnson, Galla, \& Fraundorf, 2019; Roediger III \& Pyc, 2012; Rowland, 2014). The first strategy, retrieval practice or practice testing, refers to any form of self-testing or taking practice tests on to-be-learned material where students answer representative questions without having access to the learning materials. The strategy is often praised for its allegedly superior effectiveness, which proponents have coined "the testing effect." Two mechanisms have been proposed to explain the testing effect. First, the process of elaborative retrieval prompts learners to activate information related to the learning materials in long-term memory (Carpenter, 2009), thereby creating multiple memory traces that facilitate later access. Second, effortful processing may also explain its high effectiveness, as the testing effect increases with the level of complexity and effort invested during the process of active retrieval of information from memory (Kang, McDermott, \& Roediger III, 2007; Rowland, 2014).

When learners wield distributed practice as their learning strategy, they implement a schedule of practice that includes the spreading out of study activities over time and structured repetition of learning materials (Dunlosky et al., 2013). This strategy is effective because the time interval between an initial and second learning opportunity reduces "feelings of familiarity" and/or "feelings of ease" toward the tobe-learned material. Consequently, learners are likely to work harder during the second learning opportunity compared to massed practice that does not have such intervals (Bahrick \& Hall, 2005; Benjamin \& Tullis, 2010; Dunlosky et al., 2013). Moreover, the delayed learning activity presents an opportunity to retrieve the to-be-learned material from memory, thereby increasing its effectiveness (Benjamin \& Tullis, 2010; Dunlosky et al., 2013).

Although the said learning strategies have been proven to be effective, oftentimes their benefits become manifest not immediately after learning but after a delay of several days (Roediger III \& Karpicke, 2006b; Rovers et al., 2018) and after learners have actively invested cognitive effort to process the learning materials (Kirk-Johnson et al., 2019; Roediger III \& Pyc, 2012). Both characteristics might limit their uptake, for instance because the delayed effectiveness and the high perceived mental effort required when wielding the strategies could lead students to believe that the strategies have no learning 
gains (i.e., low perceived learning) (Baars, Wijnia, de Bruin, \& Paas, 2020; Bjork et al., 2013; Kirk-Johnson et al., 2019).

Passive and ineffective learning strategies such as restudy and massed practice, in contrast, require less active engagement efforts, thereby creating a more fluent and smooth learning experience. Students often mistake this subjective state of ease and fluency for signs of better learning (i.e., high perceived learning) (Yan, Bjork, \& Bjork, 2016). The perceived learning versus actual learning paradox that results further discourages students from wielding strategies that are effective (Biwer et al., 2020). In their study, Kirk-Johnson et al. (2019) corroborated these findings by concluding that participants perceived more mental effort when using effective strategies (e.g., retrieval practice) as opposed to ineffective strategies (e.g., restudy), in turn feeding perceptions of limited learning, which further impeded the uptake of effective learning strategies and demonstrated the mediating role of perceived learning.

Although the foregoing explains students' reluctance to wield effective learning strategies, we still do not fully understand how we can encourage students to engage in them. Among the limited number of available studies, some have sought to enhance students' knowledge of these strategies and of their effects (see review studies Donker, De Boer, Kostons, Van Ewijk, \& van der Werf, 2014; Hattie, Biggs, \& Purdie, 1996). To promote retrieval practice uptake, for instance, Ariel and Karpicke (2018) instructed students about its mnemonic benefits and on how to use it. Other studies provided feedback about the actual learning outcomes of effective learning strategies to promote their use. Einstein, Mullet, and Harrison (2012), for instance, let students compare average test scores of the whole class after using retrieval practice versus restudy, in the hope that higher test scores following retrieval practice would stimulate them to switch to this strategy. In a similar fashion, Carpenter et al. (2017) exposed students to optional online review questions that could be studied by either retrieval practice or restudy. After students had learned that the average actual outcomes were higher after retrieval practice than after restudy, the proportion of students taking up retrieval practice significantly increased in the subsequent review phase.

After having practiced certain learning strategies for years, students in higher education may have developed their own particular behaviors for wielding these strategies, regardless of them being effective or not (Fiorella, 2020). Hence, if we wish to promote the uptake of effective learning strategies by changing students' behaviors that have become so ingrained, it could be helpful to adopt a behavioral change perspective 
(Fiorella, 2020). To our knowledge, however, research in this domain has not yet taken such approach. I therefore presume that the research presented in this dissertation is the first to use insights from the behavioral-change literature as a starting point for interventions that aim to promote the uptake of effective learning strategies. From this literature on behavioral change, for instance on ways to promote a healthy diet or physical exercise, I have learned that "narratives" have the potential to significantly change beliefs, stimulate intentions to change, and change behaviors in the long run (Appel \& Richter, 2007; Green, 2006; Murphy, Frank, Chatterjee, \& Baezconde-Garbanati, 2013). By narratives we mean presentations of connected events and human characters that have an identifiable structure, are bounded in space and time, and contain implicit or explicit messages about the topic being addressed (Kreuter et al., 2007; Shen, Sheer, \& $\mathrm{Li}, 2 \mathrm{O} 15)$. They are a basic mode of human interaction and a comfortable and familiar way of giving and receiving information (Graaf, Sanders, \& Hoeken, 2016; Kreuter et al., 2007). As such, they can be presented in text, audio, or video format (Murphy et al., 2013). To increase regular breast screening, for instance, McQueen, Kreuter, Kalesan, and Alcaraz (2011) presented videos in which breast cancer survivors told their stories about the benefits of breast screening. I deem it plausible that presenting a story about a student who switched to effective learning strategies and benefited from doing so might equally convince learners to adopt more effective learning strategies.

I also argue that the interventions discussed in the penultimate paragraph could have been more powerful had learners been presented with their individual rather than their average learning outcomes (e.g., test scores). Although the interventions did improve participants' uptake of effective strategies to a certain degree, we should not discount the fact that perceived learning remains an experience that is inherently subjective and individual. As such, presenting learners with the group's average learning results may not address an individual's perceived learning versus actual learning paradox. I therefore contend that presenting learners with their individual learning outcomes might be more powerful a strategy to promote the uptake of more effective learning strategies than presenting them with average group scores.

Finally, in my review of the studies discussed above, I identified a missed opportunity to focus on the domain-specific tasks that the learning strategies target. Instead, these studies focused on specific aspects of the strategies, such as their effectiveness, effort investment, and perceived learning. Other studies have shown that learners also base their learning strategy decisions about whether and how to study a 
task on their perception of how well they learned that particular task (Karpicke, 2009; Thiede \& Dunlosky, 1999). Perceived learning at the learning task level is known to be influenced by how much effort was necessary to learn the task (Baars et al., 2020). It seems that factors at the learning task level influence decisions to wield particular learning strategies. For these reasons, I deemed a more thorough exploration of this issue appropriate.

\section{Flow: The Seemingly Effortless Learning State}

Using effective learning strategies requires the investment of mental effort. Interestingly, under specific circumstances, learners are capable of self-regulating their learning in such a way that they enter a "flow state", in which little to no effort is experienced, despite the application of effortful learning strategies (Lee \& Choi, 2013). In this state of flow, students are completely involved in learning to the point of forgetting time, fatigue, and everything but the learning activity itself (Craig, Graesser, Sullins, \& Gholson, 2004; Csikszentmihalyi, 2000; Nakamura \& Csikszentmihalyi, 2014). Some people have described this experience as being focused on activities without needing to invest effort in order to be focused. Moreover, they perceived their involvement in the activities as enjoyable and requiring little effort. Some reported that they felt rested even though they were investing a great deal of effort in the activities (Swann, Jackman, Schweickle, \& Vella, 2019; Swann, Keegan, Crust, \& Piggott, 2016). Jackson and Wrigley (2004) associated this flow experience with enjoyment and self-fulfillment, for learners put in effort without experiencing it as such. Hence, when in a flow state, learners seem to invest a great deal of effort, while in fact they regulate learning-related factors in such a way that their perceived effort is reduced, for instance by strongly focusing their attention on the task only. Although learners perceive this flow state as effortless, rather than being harmed, their learning and performance are actually improved in the process (Nakamura \& Csikszentmihalyi, 2014).

Researchers have emphasized the dynamic nature of flow, by describing it as "a subjective experience of engaging just-manageable challenges by tackling a series of goals, continuously processing feedback about progress, and adjusting action based on this feedback" (Nakamura \& Csikszentmihalyi, 2014, p. 2). This characterization suggests that the flow experience is shaped by interactions between an individual and the environment, in turn implying that an individual's self-regulation into a state of flow depends on personal and environmental conditions (Nakamura \& Csikszentmihalyi, 2014). 
Under specific circumstances, learners seem to be able to self-regulate learning factors that increase the occurrence of flow, yielding an optimal experience of enhanced learning and performance (MacLaren, Tran, \& Chiappe, 2017; Nakamura \& Csikszentmihalyi, 2014). For example, learners may deliberately remove any distractors in the environment (e.g., by switching off their phones) so that they can better focus on the task at hand. This is beneficial, as focused attention can be conducive to a flow experience (RodriguezArdura \& Meseguer-Artola, 2017).

Although the aforesaid suggests that learners can, to some degree, self-regulate flow-facilitating factors by creating optimal learning situations, studies in this domain have mainly concentrated on the factors that directly influence flow. For example, Khan, Hameed, Yu, and Khan (2017) have investigated the factors that influence flow in an eLearning environment, while Li, Meng, Tian, Zhang, and Xiao (2019) did the same in a game-based learning setting. None of these studies, however, have looked into the factors that learners can self-regulate to increase the chance of achieving flow, and it remains unclear how they can regulate these factors to create optimal learning conditions and enter a flow state.

\section{Research Questions}

Based on previous research findings and gaps in the available literature, in this dissertation I aim to answer the following research questions (RQs):

RQ1: Does a behavior change intervention using narrative communication influence the intention to wield more effortful and effective learning strategies?

RQ2: Does the provision of individual feedback on actual learning outcomes increase the uptake of an effortful and effective learning strategy, namely retrieval practice?

RQ3: What role do factors at the learning task level - perceived effort and perceived learning - play in students' learning strategy decisions both before and after receiving individual feedback on actual learning outcomes?

RQ4: Which factors known to promote flow can be self-regulated by learners, and how can these factors be self-regulated?

As presented in Figure 1.1, the four aforementioned questions aim to address the central problem of this dissertation and, in doing so, take two different approaches. The first 
approach is to work from the problem toward possible solutions and will be described in Chapters 2 to 4 . I will first explain why students are not inclined to wield effective learning strategies, and then propose a potential solution. Chapter 2 applied narratives to change higher education students' behaviors and optimize their self-regulated learning skills, so that they would replace their use of non-effective strategies by more effective strategies. Chapters 3 and 4 aimed to optimize students' self-regulated learning by addressing the perceived learning versus actual learning paradox. While students received individual feedback on their actual learning outcomes in both chapters, Chapter 4 went a step further by investigating students' learning strategy decision process at the learning task level, which offers future studies a foundation for optimizing self-regulated learning.

The second approach is to work from a possible solution back to the problem and will be described in Chapter 5. I will start from the concept of "flow state", which is seen as a solution to the reduced uptake of effective and effort-demanding learning strategies. In a flow state, students experience their learning as enjoyable and effortless, even when they apply effective and effort-demanding strategies. I will identify flow-facilitating factors that can possibly be self-regulated and, finally, describe self-regulatory processes that might help students to enter a flow state.

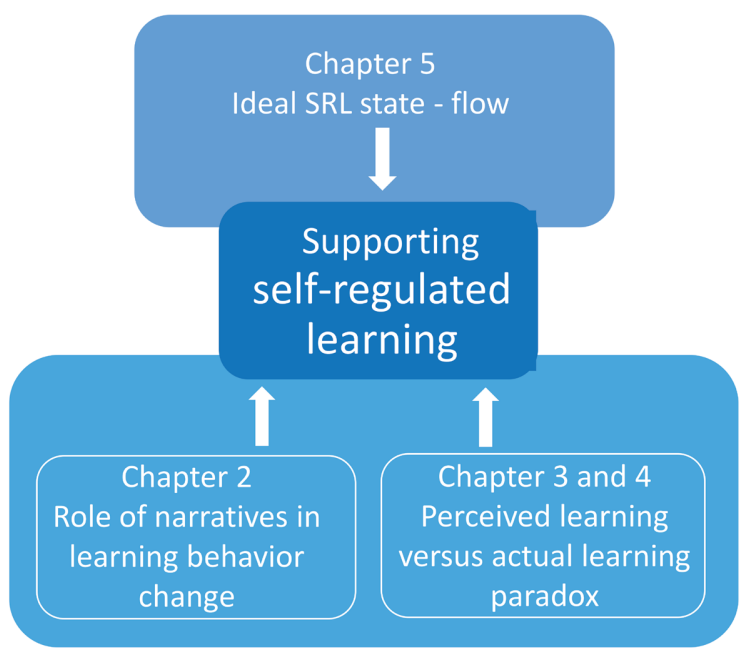

Figure 1.1. Overview of this dissertation. 


\section{Outline of the Dissertation}

In this dissertation, I will report on five separate studies that were conducted to address the four above-listed questions. In the first study (Chapter 2), I conducted an experiment to answer RQ1. Since the reduced uptake of effective learning strategies can be seen as a behavioral problem (Fiorella, 2020), I investigated the effects of a widely used behavior change strategy (i.e., narrative communication) on students' intention to switch to effective and effort-demanding learning strategies. To this end, I recorded videos that used either a narrative or a didactic approach with the aim to promote learning strategy change. I presented the narrative videos to one student group and the didactic videos to another. A third control group received videos that were irrelevant. Afterwards, I measured and compared students' intention to change from less effective to more effective learning strategies, including their awareness of desirable difficulties.

Chapter 3 addressed RQ2 by means of two experiments that aimed to promote the uptake of retrieval practice. In the first experiment, participants were asked to use an effective strategy (i.e., retrieval practice) and an ineffective strategy (i.e., restudy) to study two series of anatomical image-name pairs. In their subsequent learning of new image-name pairs, participants were free to choose either one of these strategies for each pair. After a 7-day interval, participants took a test and were subsequently informed of their actual individual learning outcomes demonstrating the effectiveness of each learning strategy. Finally, participants were again free to choose a strategy to study new anatomical image-name pairs. In the second experiment, I added another experimental group that received general feedback about group learning outcomes after retrieval practice and after restudy. This allowed us to compare the effects of individual performance feedback versus general feedback on the uptake of retrieval practice.

Chapter 4 presents the results of a study conducted to answer RQ3. In addition to providing individual feedback on learning outcomes as in Chapter 3 to increase the uptake of retrieval practice, students also rated the perceived mental effort that learning each anatomical image-name pair required as well as their perceived learning of each pair. After collecting these ratings for each image-name pair, they chose either retrieval practice or restudy to memorize each pair again. With these data, I built models to measure how students' perceptions of the tasks, their mental effort, and of their learning influence their learning strategy decisions and how this decision process changes following individual feedback on actual learning outcomes after each strategy. 
To answer RQ4 on how students can self-regulate the occurrence of a flow state, I conducted a systematic review study in Chapter 5 . To this end, I searched five databases for peer-reviewed articles published between 1990 and 2020. Articles investigating the factors that are conducive to a flow state during self-regulated learning were included in the initial set, while those that only investigated factors that cannot be self-regulated (e.g., instructional design features of learning materials) were excluded. From the final set of articles remaining I extracted and summarized the factors that can be self-regulated, subjecting our data to an exploration of how these factors can be self-regulated.

Chapter 6 is reserved for a General Discussion of this dissertation, in which I will discuss the combined findings from the studies mentioned above, give suggestions for further research, and present the studies' strengths and limitations. The chapter is followed by an Impact chapter that addresses the scientific and societal impact of the research undertaken in this dissertation. 


\section{References}

Appel, M., \& Richter, T. (2007). Persuasive effects of fictional narratives increase over time. Media Psychology, 10(1), 113-134.

Ariel, R., \& Karpicke, J. D. (2018). Improving self-regulated learning with a retrieval practice intervention. Journal of Experimental Psychology: Applied, 24(1), 43.

Baars, M., Wijnia, L., de Bruin, A., \& Paas, F. (2020). The relation between students' effort and monitoring judgments during learning: A meta-analysis. Educational Psychology Review.

Bahrick, H. P., \& Hall, L. K. (2005). The importance of retrieval failures to long-term retention: A metacognitive explanation of the spacing effect. Journal of Memory and Language, 52(4), 566-577.

Benjamin, A. S., \& Tullis, J. (2010). What makes distributed practice effective? Cognitive Psychology, $61(3), 228-247$.

Biwer, F., Oude Egbrink, M. G., Aalten, P., \& de Bruin, A. B. (2020). Fostering Effective Learning Strategies in Higher Education-A Mixed-Methods Study. Journal of Applied Research in Memory and Cognition.

Bjork, E., \& Bjork, R. (2011). Making things hard on yourself, but in a good way: Creating desirable difficulties to enhance learning. Psychology and the real world: Essays illustrating fundamental contributions to society, 2(59-68).

Bjork, R. A., Dunlosky, J., \& Kornell, N. (2013). Self-Regulated Learning: Beliefs, Techniques, and Illusions. Annual Review of Psychology, 64(1), 417-444. doi:10.1146/annurev-psych-113011-143823

Carpenter, S. K. (2009). Cue strength as a moderator of the testing effect: the benefits of elaborative retrieval. Journal of Experimental Psychology: Learning, Memory, and Cognition, 35(6), 1563.

Carpenter, S. K., Rahman, S., Lund, T. J., Armstrong, P. I., Lamm, M. H., Reason, R. D., \& Coffman, C. R. (2017). Students' use of optional online reviews and its relationship to summative assessment outcomes in introductory biology. CBE—Life Sciences Education, 16(2), ar23.

Cepeda, N. J., Pashler, H., Vul, E., Wixted, J. T., \& Rohrer, D. (2006). Distributed practice in verbal recall tasks: A review and quantitative synthesis. Psychological Bulletin, 132(3), 354.

Craig, S., Graesser, A., Sullins, J., \& Gholson, B. (2004). Affect and learning: an exploratory look into the role of affect in learning with AutoTutor. Journal of Educational Media, 29(3), 241-250.

Csikszentmihalyi, M. (2000). Beyond boredom and anxiety: Jossey-Bass.

Donker, A. S., De Boer, H., Kostons, D., Van Ewijk, C. D., \& van der Werf, M. P. (2014). Effectiveness of learning strategy instruction on academic performance: A meta-analysis. Educational Research Review, 11, 1-26. 
Dunlosky, J., Rawson, K. A., Marsh, E. J., Nathan, M. J., \& Willingham, D. T. (2013). Improving students' learning with effective learning techniques: Promising directions from cognitive and educational psychology. Psychological Science in the Public Interest, 14(1), 4-58.

Einstein, G. O., Mullet, H. G., \& Harrison, T. L. (2012). The testing effect: Illustrating a fundamental concept and changing study strategies. Teaching of Psychology, 39(3), 190-193.

Fiorella, L. (2020). The Science of Habit and Its Implications for Student Learning and Well-being. Educational Psychology Review, 1-23.

Geller, J., Toftness, A. R., Armstrong, P. I., Carpenter, S. K., Manz, C. L., Coffman, C. R., \& Lamm, M. H. (2018). Study strategies and beliefs about learning as a function of academic achievement and achievement goals. Memory, 26(5), 683-690.

Graaf, A. d., Sanders, J., \& Hoeken, H. (2016). Characteristics of narrative interventions and health effects: A review of the content, form, and context of narratives in health-related narrative persuasion research. Review of Communication Research, 4, 88-131.

Green, M. C. (2006). Narratives and cancer communication. Journal of Communication, 56, S163S183.

Hartwig, M. K., \& Dunlosky, J. (2012). Study strategies of college students: Are self-testing and scheduling related to achievement? Psychonomic Bulletin \& Review, 19(1), 126-134.

Hattie, J., Biggs, J., \& Purdie, N. (1996). Effects of learning skills interventions on student learning: A meta-analysis. Review of Educational Research, 66(2), 99-136.

Jackson, S. A., \& Wrigley, W. J. (2004). Optimal experience in sport: Current issues and future directions.

Kang, S. H., McDermott, K. B., \& Roediger III, H. L. (2007). Test format and corrective feedback modify the effect of testing on long-term retention. European Journal of Cognitive Psychology, $19(4-5), 528-558$.

Karpicke, J. D. (2009). Metacognitive control and strategy selection: Deciding to practice retrieval during learning. Journal of Experimental Psychology: General, 138(4), 469.

Khan, I. U., Hameed, Z., Yu, Y., \& Khan, S. U. (2017). Assessing the determinants of flow experience in the adoption of learning management systems: The moderating role of perceived institutional support. Behaviour \& Information Technology, 36(11), 1162-1176. doi:10.1080/0144 929X.2017.1362475

Kirk-Johnson, A., Galla, B. M., \& Fraundorf, S. H. (2019). Perceiving effort as poor learning: The misinterpreted-effort hypothesis of how experienced effort and perceived learning relate to study strategy choice. Cognitive Psychology, 115, 101237.

Kornell, N., \& Bjork, R. A. (2007). The promise and perils of self-regulated study. Psychonomic Bulletin \& Review, 14(2), 219-224. 
Kreuter, M. W., Green, M. C., Cappella, J. N., Slater, M. D., Wise, M. E., Storey, D., . . Holmes, K. (2007). Narrative communication in cancer prevention and control: a framework to guide research and application. Annals of Behavioral Medicine, 33(3), 221-235.

Lee, Y., \& Choi, J. (2013). A structural equation model of predictors of online learning retention. Internet and Higher Education, 16, 36-42. doi:10.1016/j.iheduc.2012.01.005

Li, R., Meng, Z., Tian, M., Zhang, Z., \& Xiao, W. (2019). Modelling Chinese EFL learners' flow experiences in digital game-based vocabulary learning: the roles of learner and contextual factors. Computer Assisted Language Learning, 1-22.

MacLaren, R., Tran, V. H., \& Chiappe, D. (2017). Effects of motivation orientation on schoolwork enjoyment and achievement and study habits. Thinking Skills and Creativity, 24, 199-227. doi:10.1016/j.tsc.2017.03.003

McCabe, J. (2011). Metacognitive awareness of learning strategies in undergraduates. Memory \& Cognition, 39(3), 462-476. doi:10.3758/s13421-010-0035-2

McQueen, A., Kreuter, M. W., Kalesan, B., \& Alcaraz, K. I. (2011). Understanding narrative effects: the impact of breast cancer survivor stories on message processing, attitudes, and beliefs among African American women. Health Psychology, 30(6), 674.

Murphy, S. T., Frank, L. B., Chatterjee, J. S., \& Baezconde-Garbanati, L. (2013). Narrative versus nonnarrative: The role of identification, transportation, and emotion in reducing health disparities. Journal of Communication, 63(1), 116-137.

Nakamura, J., \& Csikszentmihalyi, M. (2014). The concept of flow. In Flow and the foundations of positive psychology (pp. 239-263): Springer.

Rodriguez-Ardura, I., \& Meseguer-Artola, A. (2017). Flow in e-learning: What drives it and why it matters. British Journal of Educational Technology, 48(4), 899-915. doi:10.1111/bjet.12480

Roediger III, H. L., \& Karpicke, J. D. (2006b). Test-enhanced learning: Taking memory tests improves long-term retention. Psychological Science, 17(3), 249-255.

Roediger III, H. L., \& Pyc, M. A. (2012). Inexpensive techniques to improve education: Applying cognitive psychology to enhance educational practice. Journal of Applied Research in Memory and Cognition, 1(4), 242-248.

Rovers, S. F. E., Stalmeijer, R. E., van Merriënboer, J. J. G., Savelberg, H., \& de Bruin, A. B. H. (2018). How and Why Do Students Use Learning Strategies? A Mixed Methods Study on Learning Strategies and Desirable Difficulties With Effective Strategy Users. Frontiers in Psychology, 9, 2501. doi:10.3389/fpsyg.2018.02501

Rowland, C. A. (2014). The effect of testing versus restudy on retention: A meta-analytic review of the testing effect. Psychological Bulletin, 140(6), 1432.

Shen, F., Sheer, V. C., \& Li, R. (2015). Impact of narratives on persuasion in health communication: A meta-analysis. Journal of Advertising, 44(2), 105-113. 
Swann, C., Jackman, P. C., Schweickle, M. J., \& Vella, S. A. (2019). Optimal experiences in exercise: A qualitative investigation of flow and clutch states. Psychology of Sport and Exercise, 40, 87-98.

Swann, C., Keegan, R., Crust, L., \& Piggott, D. (2016). Psychological states underlying excellent performance in professional golfers:"Letting it happen” vs. "making it happen”. Psychology of Sport and Exercise, 23, 101-113.

Thiede, K. W., \& Dunlosky, J. (1999). Toward a general model of self-regulated study: An analysis of selection of items for study and self-paced study time. Journal of Experimental Psychology: Learning, Memory, and Cognition, 25(4), 1024.

Wissman, K. T., Rawson, K. A., \& Pyc, M. A. (2012). How and when do students use flashcards? Memory, 20(6), 568-579.

Wolters, C. A., \& Benzon, M. B. (2013). Assessing and predicting college students' use of strategies for the self-regulation of motivation. The Journal of Experimental Education, 81(2), 199-221.

Yan, V. X., Bjork, E. L., \& Bjork, R. A. (2016). On the difficulty of mending metacognitive illusions: A priori theories, fluency effects, and misattributions of the interleaving benefit. Journal of Experimental Psychology: General, 145(7), 918.

Yan, V. X., Thai, K.-P., \& Bjork, R. A. (2014). Habits and beliefs that guide self-regulated learning: Do they vary with mindset? Journal of Applied Research in Memory and Cognition, 3(3), 140-152. 



\title{
Chapter 2
}

\section{Stimulating the Intention to Change Learning Strategies: the Role of Narratives}

This chapter has been published as Hui, L., de Bruin, A. B., Donkers, J., \& van Merriënboer, J. J. (2021). Stimulating the intention to change learning strategies: The role of narratives. International Journal of Educational Research, 107, 101753.

\begin{abstract}
Practice testing and distributed practice are effective in enhancing learning outcomes and long-term retention. Yet, many students use ineffective learning strategies instead and are reluctant to change them because they hold erroneous beliefs about practice testing and distributed practice. This intervention study examined whether narratives, compared to traditional didactic communication, can change learning strategy-beliefs, stimulate intentions to change ineffective strategy use, and raise awareness of desirable difficulties (i.e., difficulties produced by strategies that slow down the acquisition process but enhance long-term retention and transfer). Narratives and didactic communication did not differ in their change of erroneous beliefs and stimulate intentions to change, but narratives led to a higher awareness of the importance of desirable difficulties for learning.
\end{abstract}

Keywords: learning strategies, narratives, identification, desirable difficulties, practice testing, distributed practice 


\section{Introduction}

Many students struggle to develop and implement effective strategies to achieve learning goals. This is not surprising, since they rarely receive any training in what effective learning strategies are or how to implement them (Geller et al., 2018; Hartwig \& Dunlosky, 2012; Kornell \& Bjork, 2007). As a result, students often continue to use ineffective learning strategies, such as rereading and highlighting, that on average lead to poorer learning outcomes (Dunlosky et al., 2013). Such strategies typically appeal to students because they are simple to use, low in effort and do not require much time investment (Kirk-Johnson et al., 2019; Rowland, 2014). In addition, by connecting with short-term memory, these strategies generate a feeling of familiarity or perceptual fluency, making students think that they remember more after learning, and, consequently, that these strategies are effective (Bjork et al., 2013; Finn \& Tauber, 2015).

The aforesaid raises the question: What learning strategies are effective in promoting long-term learning? Several studies have pointed to two learning strategies in particular, specifically 'practice testing' and 'distributed practice' (Benjamin \& Tullis, 2010; Dunlosky et al., 2013; Roediger III \& Karpicke, 2006a). Whereas practice testing refers to self-testing or taking practice tests with or without feedback on the correct answer (Dunlosky et al., 2013; Roediger III \& Karpicke, 2006a), distributed practice means that students implement a schedule of practice that spreads out study activities over time, incorporating rehearsal of material previously studied (Benjamin \& Tullis, 2010; Dunlosky et al., 2013). These two strategies benefit learners of different ages and abilities and have been shown to boost students' performance across many criterion tasks (Dunlosky et al., 2013).

Practice testing and distributed practice are effective because they introduce difficulties into the learning phase and, although they slow down the process of acquisition, these difficulties enhance long-term retention and transfer, hence their name 'desirable difficulties' (Bjork \& Bjork, 2011; Rovers et al., 2018). Since many students associate a smooth learning process with better learning (Yan et al., 2016), they do not believe that these two strategies benefit their learning, because they increase the difficulty of the learning phase and slow down learning. When students, for instance, reread a textbook, they immediately get a subjective feeling of familiarity or fluency that they may mistake for actual understanding or retention. When applying practice testing and distributed practice, on the other hand, they experience no or less fluency 
(Kornell, 2009; Kornell \& Bjork, 2007; Tullis, Finley, \& Benjamin, 2013). Moreover, the effects of practice testing and distributed practice on learning are long-term rather than immediate, which altogether leads to erroneous beliefs about these effective strategies, in turn inhibiting their actual use (Kirk-Johnson et al., 2019). Without awareness of desirable difficulties, the perceived costs of using practice testing and distributed practice are too high (Berger \& Karabenick, 2011). Furthermore, more and more studies showed that when students do hold proper beliefs about which learning strategies are effective, they may not persist in using them because they are not aware of the importance of desirable difficulties (Biwer et al., 2020; Carpenter, Witherby, \& Tauber, 2020; Kirk-Johnson et al., 2019; Yan et al., 2016).

Enhancing the use of effective learning strategies is an important factor in improving educational outcomes, including academic achievement (Carpenter et al., 2016; Dunlosky et al., 2013). We therefore need interventions that discourage the use of ineffective learning strategies. Existing interventions to improve the use of effective learning strategies usually target students' motivation and knowledge, two related aspects (Donker et al., 2014). In the case of motivation, the strategies aim to influence a student's approach to a task, while in the latter case they seek to enhance knowledge of cognitive strategies, metacognitive strategies and management strategies (Donker et al., 2014; Hattie et al., 1996). These aims are usually pursued by offering training, direct skills teaching and/or instruction, without considering students' use of learning strategies as a habitual behavior (Fiorella, 2020). To our knowledge, no intervention exists to date that focuses on behavior change with a view to changing the use of ineffective learning strategies. In this study, an intervention focusing on behavior change is conducted with 117 students in X University in the Netherlands. In the following paragraphs of the Introduction section, we will first present the theoretical background, and then introduce factors that are relevant to behavior change.

\section{Behavior Change and Narratives}

In the behavior change domain, the theory of planned behavior is one of the most widely tested models for changing behavior and is well supported by many experimental studies (Ajzen, 1991, 2006; Armitage \& Conner, 2001). This theory is nowadays also known as the 'reasoned action model' (Fishbein \& Ajzen, 2011). It clearly maps out how to change from undesirable to desirable behavior in a step by step fashion. According to this theory, the first step is to change erroneous beliefs, which includes beliefs about 
the likely consequences of the behavior (behavioral beliefs), beliefs about the normative expectations of others (normative beliefs), and beliefs about factors that can help or impede their attempts to carry out the behavior (control beliefs). Respectively, behavioral beliefs produce a positive or negative attitude toward the behavior, normative beliefs create a social pressure to engage or not engage in the behavior, and control beliefs result in a sense of high or low self-efficacy or perceived behavioral control. Together, these three factors lead to intentions to change which is also the most important predictor of behavior (Ajzen, 2006; Eldredge et al., 2016). The behavioral intention is a decisive factor for showing desirable behaviors and the relation between behavioral intentions and behaviors is impacted by the actual behavioral control. From previous research it is known that to accomplish behavioral change procedure, gaining appropriate knowledge is a necessary but insufficient prerequisite condition (Fishbein \& Ajzen, 1975b).

One promising approach to change one's behavior is the use of so-called narratives. Narratives are presentations of connected events and characters that have an identifiable structure, are bounded in space and time, and contain implicit or explicit messages about the topic being addressed (Kreuter et al., 2007; Shen et al., 2015). As the basic mode of human interaction and a comfortable and familiar way of giving and receiving information, they are widely used in the domain of behavioral change, for instance to promote a healthy diet or more exercise (Graaf et al., 2016; Kreuter et al., 2007). Studies have confirmed that narratives significantly change beliefs, stimulate intentions to change, and may also change behaviors in the long term (Appel \& Richter, 2007; Green, 2006; Murphy et al., 2013). In its video-based form, they have even more advantages, such as providing vivid, concrete images, which is why they are currently gaining more and more popularity (Brownson, Eyler, Harris, Moore, \& Tabak, 2018; Hurtado-de-Mendoza et al., 2020).

When students use ineffective learning strategies, they, in effect, must also change behavior that they have performed and reinforced over a number of years and, as such, has become habitual (Fiorella, 2020). Consequently, they must take similar steps to change their learning strategies. The main aim of the present study was therefore to investigate whether narratives can help students to change erroneous beliefs and stimulate the intention to change ineffective learning strategies. This study is, to our knowledge, the first to adopt a behavior change perspective in the learning strategy change domain. 
Narrative communication differs from other styles such as didactic communication in that it uses personal stories to convey points to or to receive information from another party (Hinyard \& Kreuter, 2007). Didactic communication, on the other hand, is more expository in nature, as it presents propositions in the form of reasons and evidence to support a claim (Kreuter et al., 2007). More specifically, it relies on empirical and experimental methods to discover, describe or elucidate facts. Instead of using stories, didactic communication uses scientific truth or statistical results to convey information or explain facts. Several studies have shown that narratives have a stronger potential to improve health-related behavior than didactic communication (De Wit, Das, \& Vet, 2008; Green, 2006; Kreuter et al., 2010; Murphy et al., 2013). One reason for this advantage is that narratives have the ability to transport individuals into the storyline (Braverman, 2008; Green \& Brock, 2000; Kim, Bigman, Leader, Lerman, \& Cappella, 2012).

\section{Transportation and Identification}

Transportation into a narrative world has been defined as an integrative melding of attention, imagery and feelings sparked by the narrative that is associated with increased positivity towards sympathetic characters and a reduction in negative cognitive resistance (Gebbers, De Wit, \& Appel, 2017; Green \& Brock, 2000). Three factors affect an individual's transportation into the narrative (Green, 2006), specifically the extent of: 1) identification, or the individual's tendency to create connections with the narrative characters; 2) realism, or the extent to which narrative events resemble real experiences, causing increased attentional focus (Green, 2006); and 3) cognitive engagement, which goes hand in hand with a reduction in the individuals' ability to counter narratives' assertions. A coherent story that presents in a logical sequence by a similar character (e.g., study at same university) increases identification to the character, the realism of the story, and the engagement to this story, further increase transportation (Green, 2006; Kim et al., 2012; Kreuter et al., 2010). It has been shown that the extent of transportation into narratives determines the amount of change (Braverman, 2008; Green \& Brock, 2000). Didactic communication does not cause transportation, even though individuals may become less cognizant of things happening around them. This makes narratives a relatively subtle method to change beliefs and to stimulate the intention to change, also because they are less likely to cause resistance which is a key obstacle to belief and behavior change (Green, 2006). 
Of these three factors, identification with narrative characters is increasingly being seen as of utmost importance and some studies even indicated that identification is a mediator in narrative communication (De Graaf, Hoeken, Sanders, \& Beentjes, 2012; Hoeken \& Fikkers, 2014; Hoeken, Kolthoff, \& Sanders, 2016). Identification consists of the ability to experience characters' feelings, to adopt characters' point of view, to internalize characters' goals, and potentially to have the sensation of becoming the character (Hoeken \& Fikkers, 2014; Tal-Or \& Cohen, 2010), which positively impact individuals' behavioral beliefs and control beliefs (self-efficacy) (Hinyard \& Kreuter, 2007; Moyer-Gusé, Chung, \& Jain, 2011). We assume that identification with narrative characters probably is the most crucial one for achieving learning strategy change. When students identify with the characters, they may care about them and put themselves in their place (Green, 2006), which may make students easily impacted by characters' behavioral beliefs. Besides, as the characters serve as role models (Bandura, 2009; De Graaf et al., 2012), seeing the characters successfully changing their ineffective learning strategies, students' self-efficacy increases which further facilitates the use of effective strategies (Geitz, Joosten-ten Brinke, \& Kirschner, 2016). Furthermore, such characters may serve as templates for 'possible selves' (Markus \& Nurius, 1986) who experience the same desirable difficulties that certain learning conditions present and the same benefits from using effective learning strategies. This may make students more receptive to the desirable difficulties information and may generate the strongest intention to change. More specifically, a higher level of identification could cause more students to generate awareness of desirable difficulties and a stronger intention to change their own ineffective learning strategies.

\section{Need for Cognition}

Personality traits are essential in both theories of planned behavior (Picazo-Vela, Chou, Melcher, \& Pearson, 2010; Rhodes, Courneya, \& Jones, 2005) and narrative communication (Golke, Hagen, \& Wittwer, 2019; Green et al., 2008). As a result, personality traits should be considered when behavioral interventions are organized (Rhodes et al., 2005). Studies have found that the 'need for cognition' (NFC) strongly impacts individuals' resistance to information they receive, which further impacts their construction of beliefs and behavior (Haugtvedt \& Petty, 1992; Linvill, Mazer, \& Boatwright, 2016; Verplanken, 1989). NFC refers to 'an individual's tendency to engage in and enjoy effortful endeavors' (Cacioppo, Petty, Feinstein, Blair, \& Jarvis, 1996, p. 197). 
High-NFC individuals enjoy being involved in the processes and outcomes of cognitively demanding comprehension activities (Dai \& Wang, 2007). They tend to use elaborative processing that takes place at a deeper, semantic-associative level. NFC impacts the effect of narratives by influencing the extent to which individuals are transported into narratives, and further causes changes in beliefs and/or intentions to change (Green et al., 2008; Verplanken, 1989). Since narratives are normally smooth and effortless to process (Golke et al., 2019), low-NFC individuals are more likely to be attracted by them. Therefore, NFC should be taken into account. We assume that NFC may be a covariate in the narrative intervention, with low-NFC students potentially being more attracted by and more transported into the narratives than their high-NFC counterparts.

\section{Current Study}

This study investigated whether a behavior change technique, in particular the use of narratives, helped students diminish erroneous learning strategy beliefs and generate intentions to change. Moreover, it investigated individual factors that may influence the effect narratives have on students' transition to more effective learning strategies. To this end, we first informed all participants about effective learning strategies to help them gain learning strategy knowledge. We subsequently showed two experimental groups either a narrative or a didactic video about changing learning strategies to investigate the potential of these videos to diminish erroneous beliefs and stimulate the intention to change to effective learning strategies (it was beyond the scope of the current study to measure actual strategy use, which would require a longitudinal study design). To equate time on task, a video unrelated to learning strategies was shown to the control group. The main research questions are: (1) how do the narrative, didactic and control group differ in their changes in beliefs about practice testing and distributed practice and in their intentions to change ineffective learning strategies? (2) To what extent does a stronger identification with the characters and more transportation predicts a higher intention to change? (3) To what extent are participants in the narrative group more aware of desirable difficulties than participants in the didactic group? (4) To what extent do participants with lower NFC show stronger identification with narrative characters than participants with higher NFC? Based on the discussion above, we hypothesized that: 
1. the narrative group changes its beliefs about practice testing and distributed practice more than the didactic group and the didactic group changes more than the control group (H1);

2. there will be a similar effect to $\mathrm{H}_{1}$ for intentions to change learning strategies (H2a); more identification with the narrative characters and more transportation into the narrative predicts a higher intention to change (H2b);

3. more participants in the narrative group generate awareness of desirable difficulties compared to the didactic group ( $\left.\mathrm{H}_{3}\right)$; and, finally

4. participants with a lower NFC identify more with the characters in the narrative video $\left(\mathrm{H}_{4}\right)$.

\section{Materials and Methods}

\section{Participants and Study Design}

To reach a medium effect size for intentions to change across three groups $\left(\eta^{2}=.30\right)$, 111 participants were required to achieve a power of at least .80 based on power analysis with G*Power 3.1.9.2 (Faul, Erdfelder, Buchner, \& Lang, 2014). Since we expected a high drop-out rate due to the duration of the study (two weeks), we oversampled to 119 participants. They were first-year students (35\% male) from the faculties of medicine (56\%) and business (44\%) of Maastricht University who voluntarily signed up after receiving flyers or short announcements during courses they participated in. We randomly assigned them to one of three groups: a narrative, a didactic and a control group. In the pre-intervention phase, we gave all three groups information about learning strategies commonly used, what they look like, how to use them and why they are effective or not. In the intervention phase, the narrative group watched videos about learning behavior change that conveyed information in a narrative style. The didactic group watched similar videos conveying the same information but in a didactic style. The control group watched an emotionally neutral video that was unrelated to learning strategy change. The data from two participants had to be discarded for noncompliance with instructions (they finished the study at their own home). This resulted in a final sample of 117 participants ( $M$ age $=19.35 \mathrm{yrs}, S D=2.01$ ). Across all 117 participants, one did not fill in the age and one's learning strategy belief about practice testing before the 
intervention was not recorded due to technical issues (missing completely at random, thus these missing data were neglected).

\section{Materials}

\section{Pre-intervention Materials (learning strategy introduction)}

We showed participants a 260 -second video introducing them to seven learning strategies commonly used, which are: practice testing, rereading, self-explanation, summarization, imagery, highlighting and distributed practice. These strategies have been reviewed extensively by Dunlosky and colleagues (2013). The video provided an explanation and examples of these seven strategies and had been developed at Maastricht University as part of a university-wide learning strategy training project. To help participants fully understand these learning strategies, we provided them with additional computer-based reading materials about their definitions and more examples of the strategies in real learning that we had developed based on the comprehensive review study of Dunlosky and colleagues (2013).

To inform students in the best way possible about the learning strategies before starting the experiment, we gave them the task to sort the seven strategies from the video into three piles: highly effective, moderately effective and minimally effective. We then provided participants with feedback on the effectiveness of the respective learning strategies and the reasons why they were effective or not (e.g. practice testing: highly effective; it forces students to actively retrieve information from memory and it facilitates the learning in the next study session.). We based this feedback on Dunlosky and colleagues (2013).

\section{The Narrative, Didactic and Control Videos}

The narrative video consisted of two parts of 134 seconds, each involving one student (a male, 'Max', and a female, 'Linda') who shared their experiences of changing their learning strategies when entering university. In both parts, the students first introduced themselves as students and subsequently explained how they had struggled at first when applying practice testing and distributed practice, how they felt they did not learn that much compared with rereading, and ended describing the positive results they had obtained after using these strategies. These experiences were real stories from students 
who joined a university-wide learning strategy training project of Maastricht University. The narrative video was made following the instruction of Thompson and Kreuter (2014).

The didactic video also consisted of two parts (112 and 126 seconds; 238 seconds in total) showing the same two students, but this time presenting scientific research results to explain the benefit of learning strategy change. As in the narrative video, the students first introduced themselves, though this time as researchers, and subsequently explained research findings on the desirable difficulties inherent in practice testing and distributed practice, ending with a description of the positive results obtained from using these strategies.

The aforementioned videos both presented the following main information: (1) practice testing and distributed practice are effective learning strategies, (2) changing ineffective learning strategies is essential, and (3) learning with effective learning strategies is difficult but worth the effort. Point 1 repeated the information presented in the pre-intervention phase and served to ensure that participants had understood the two learning strategies; point 2 conveyed the information that students should change, and point 3 was included to raise awareness of desirable difficulties. These key messages were identical in both videos, the only difference being the style of presentation (narrative or didactic). The full scripts of both videos are presented in the Appendix 2.1.

Finally, the control group watched a handcrafting video about 'how to make a box' (258 seconds) from YouTube (https://www.youtube.com/watch?v=R6TUvYCrdvM), as videos about handcrafting are considered emotionally neutral.

\section{Learning Strategy Beliefs Questionnaire}

To measure students' beliefs about the effectiveness of learning strategies before and after the intervention, we administered a 5-point rating questionnaire ( 1 = not effective at all, 5 = extremely effective) to participants containing the seven learning strategies including crammed learning, considering the popularity of this strategy. The description of each learning strategy (e.g. distributed practice: spread your study over time) in this questionnaire was based on Dunlosky and colleagues (2013) and Morehead and colleagues (2016). This questionnaire contains one question per learning strategy, so the internal consistency reliability coefficient of this questionnaire is not reported here. The change of learning strategy beliefs before and after the intervention was determined by calculating the difference in rating before and after the 


\section{Intention to Change Scale}

After the intervention, we measured the extent to which participants intended to change their ineffective learning strategies using the intention to change scale. This scale was an adaptation of the readiness to change questionnaire (Carey, Purnine, Maisto, \& Carey, 1999), which is used in the field of addiction (e.g. the original question 'sometimes I think I should cut down on my drinking' was adapted to 'sometimes I think I should change my learning strategies'). From the original 9-item, 5-point rating scale (1 = strongly disagree, 5 = strongly agree), three questions were reversely scored. We deleted one confusing question ('I may use ineffective learning strategies now'), leaving eight items (Cronbach's $\alpha=.65$, McDonald's $\left.\omega_{t}=.76\right)$ to measure participants' intention to change.

\section{Self-report Transportation Scale}

We measured the extent to which participants were transported into the narrative world using the self-report transportation scale developed by Williams and colleagues (2011). We adapted this scale to fit the theme of our study (e.g. the original question 'I was mentally involved in the story while watching it' was adapted to 'I was mentally involved in the videos while watching them'). This scale contained 8 items to be rated on a 5 -point rating scale ( 1 = strongly disagree, 5 = strongly agree) (Cronbach's $\alpha=.79$, McDonald's $\left.\omega_{\mathrm{t}}=.87\right)$. It included three subscales, specifically a 3 -item engagement subscale (Cronbach's $\alpha=.75$, McDonald's $\omega_{\mathrm{t}}=.76$ ), a 2 -item realism subscale (Cronbach's $\alpha=.66$, McDonald's $\omega_{\mathrm{t}}=.67$ ), and a 3 -item identification subscale (Cronbach's $\alpha=.69$, McDonald's $\left.\omega_{t}=.73\right)$. Although the internal consistency coefficients were not very high, as an initial study trying to change ineffective learning strategies by adopting a behaviorchange method we decided to follow previous studies with using these already available scales.

\section{Need for Cognition Scale}

Before the intervention, we measured students' disposition to engage in and enjoy effortful cognitive activities using a shortened version of the need for cognition scale (Cacioppo, Petty, \& Feng Kao, 1984). This scale contained 18 items (e.g. 'I prefer my life to be filled with puzzles that I must solve') to be rated on a 9-point scale ( -4 = very strong disagreement, 4 = very strong agreement) (Cronbach's $\alpha=.82$, McDonald's $\omega_{\mathrm{t}}=.84$ ). 


\section{Learning Strategy Knowledge Questionnaire}

After the intervention, we asked participants three open questions (e.g. 'Why is summarizing not effective?') to measure their knowledge about learning strategies. The answers were coded from 1 to 5 ( 1 = omission or completely incorrect; 5 = completely correct). The first researcher initially coded all answers, and a second researcher also coded $20 \%$ of the answers of the three questions (interrater-reliability Kappa $=.80$ ). Disagreement was discussed. The first researcher made the final decision and consensus was reached between these two researchers.

\section{Knowledge Gained from the Narrative and Didactic videos}

To measure what kind of knowledge participants had gained from the narrative and didactic videos, we asked them the open question 'Did you learn from Linda and Max? What did you learn?' The answers were classified as: (1) nothing (when participants' answers indicated they had not learnt anything, contained comments about the videos but without mentioning videos' contents, or were left blank); (2) knowledge of effective learning strategies (when answers included descriptions of what effective learning strategies are); (3) I should change my learning strategies (when participants' answers indicated they should change their learning strategies), and (4) awareness of desirable difficulties (when answers reflected the understanding that more effective strategies take effort and time but are worth it). The classification number ( 1 to 4 ) indicated the level of knowledge participants had gained from the videos from low (1) to high (4). If participants' answer contained multiple levels of information, it was coded to the highest level. The first researcher initially coded all answers, whereas a second researcher coded $20 \%$ of answers (interrater-reliability Kappa $=.81$ ). Disagreement was discussed. The first researcher made the final decision and consensus was reached between these two researchers.

\section{Procedure}

The study consisted of four phases. First, all participants answered the learning strategy beliefs questionnaire and need for cognition scale online from home (phase 1). To prevent these scales from affecting the intervention effect, this phase was finished two weeks before the remaining phases. The second to fourth phase were conducted in a single session where participants worked individually on computers in a computer lab (in groups of 4 to 15 students). In the pre-intervention phase (phase 2), all participants 
watched the learning strategy introduction video. After this, they studied the definitions and examples of each learning strategy. Participants then performed the sorting task and received feedback on the effectiveness of the strategies sorted. In the intervention phase (phase 3), the three different groups watched the narrative video, the didactic video or the how-to-make-a-box video. Finally, all participants filled in the intention to change scale, the transportation scale and the learning strategy knowledge questionnaire, in addition to answering the open question about knowledge gained from the videos (the narrative videos, the didactic videos, or the how to make a box video) and the learning strategy beliefs questionnaire again (phase 4). All procedures were approved by the ethical review board of the Netherlands Association for Medical Education (NVMO, reference number 1055).

\section{Data Analysis}

We analyzed the data using SPSS, version 25, and R, version 3.6.0 (2019) . For answering research question 1, we performed Kruskal-Wallis $H$ tests in SPSS to compare how the three groups differ in their change in beliefs about practice testing and distributed practice, and how they differ in learning-strategy knowledge. Also for answering research question 1, we performed a one-way ANOVA to measure any differences in intentions to change between the three groups. For answering research question 2, we first used independent-samples $t$-tests or Mann-Whitney U-tests to compare differences in transportation and its three associated factors (identification, realism and engagement) between the narrative and didactic group; then, simple linear regressions were used to predict intentions to change based on identification and transportation, respectively. For answering research question 3, we ran a Pearson's Chi-Square analysis to check for differences in the knowledge that participants had gained from the narrative and didactic videos. For answering research question 4, we used simple linear regression to predict identification/transportation based on the need for cognition. Finally, we performed a mediation analysis with $\mathrm{R}$ to test whether identification was a mediator between narratives and the intention to change. The significance level chosen was .05. Bonferroni-adjusted alpha level for learning strategy belief change was set to .006 considering there were eight parallel Kruskal-Wallis $H$ tests. 


\section{Results}

\section{Learning Strategy Beliefs and Learning Strategy Knowledge}

Means and standard deviations of the analyses are presented in Table 2.1. For interested readers, we also present the learning strategy belief scores of the moderately and minimally effective learning strategies in Table 2.1 and we briefly report how the three groups differ in their change in beliefs for these strategies (i.e. rereading, selfexplanation, summarization, imagery, highlighting and crammed learning). Preliminary data analysis showed that transportation, need for cognition and intentions to change scores of the three groups met the analysis assumptions, but this was not the case for scores of learning strategy knowledge and learning strategy beliefs. The subscales of transportation, identification from the two experimental groups, and engagement from the didactic group met the analysis assumptions, but the other subscales or groups did not. Based on these results, we chose appropriate analysis methods.

The Kruskal-Wallis $H$ tests partly confirmed Hypothesis 1. For practice testing, there was a significant difference in belief change before and after the intervention between the three groups, $H(2)=12.82, p=.002$, with a mean rank belief change of 66.26 for the narrative group, 64.97 for the didactic group, and 44.44 for the control group. Then pairwise comparisons showed that the learning strategy beliefs changed significantly more in the narrative $(p<.01)$ and didactic groups $(p<.01)$ than in the control group. However, the belief change difference between the narrative and didactic group was not significant $(p=1.00)$. For distributed practice, there was no significant difference in belief change across the three groups, $H(2)=1.48, p=.48$, with a mean rank belief change of 58.77 for the narrative group, 63.14 for the didactic group, and 55.09 for the control group. Fig 1 depicts the learning strategy beliefs of the two highly effective strategies of the three groups before and after the intervention. The Kruskal-Wallis $H$ tests showed that the belief changes of other learning strategies (i.e. rereading, selfexplanation, summarization, imagery, highlighting and crammed learning) were not significantly different between the three groups, indicating that the intervention did not impact these beliefs. This is expected as these strategies were not emphasized in the narrative/didactic videos. More importantly, this shows that the learning strategy knowledge participants gained from the pre-intervention section did not significantly influence their learning strategy beliefs. 
Table 2.1 Means (standard deviations) of measures in this study.

\begin{tabular}{|c|c|c|c|}
\hline & $\begin{array}{l}\text { Narrative group } \\
(\mathrm{n}=39)\end{array}$ & $\begin{array}{l}\text { Didactic group } \\
(\mathrm{n}=39)\end{array}$ & $\begin{array}{l}\text { Control group } \\
(\mathrm{n}=39)\end{array}$ \\
\hline LS knowledge questionnaire & $3.92(.66)$ & $3.88(.73)$ & $3.71(.87)$ \\
\hline \multicolumn{4}{|c|}{ LS beliefs (about highly effective LSs) } \\
\hline Practice testing (before) & $4.23(.90)$ & $4.26(.76)$ & $4.59(.50)$ \\
\hline Practice testing (after) & $4.74(.44)$ & $4.74(.45)$ & $4.51(.76)$ \\
\hline Distributed practice (before) & $4.44(.68)$ & $4.23(.87)$ & $4.54(.64)$ \\
\hline Distributed practice (after) & $4.74(.50)$ & $4.69(.61)$ & $4.72(.56)$ \\
\hline \multicolumn{4}{|c|}{ LS beliefs (about moderately effective LS) } \\
\hline Self-explanation (before) & $4.38(.96)$ & $4.23(.87)$ & $4.33(.81)$ \\
\hline Self-explanation (after) & $3.64(.81)$ & $3.92(.87)$ & $3.95(.92)$ \\
\hline \multicolumn{4}{|c|}{ LS beliefs (about minimally effective LSs) } \\
\hline Rereading (before) & $3.76(.96)$ & $3.69(1.03)$ & $3.72(.94)$ \\
\hline Rereading (after) & $2.84(1.09)$ & $2.82(.89)$ & $2.97(1.06)$ \\
\hline Summarization (before) & $4.28(.86)$ & $4.00(.69)$ & $4.18(.87)$ \\
\hline Summarization (after) & $3.85(.81)$ & $3.23(.78)$ & $3.24(1.03)$ \\
\hline Cramming (before) & $1.97(.74)$ & $1.90(.82)$ & $1.72(.89)$ \\
\hline Cramming (after) & $1.79(.77)$ & $1.54(.72)$ & $1.62(.99)$ \\
\hline Highlighting (before) & $3.59(1.04)$ & $3.41(1.09)$ & $3.62(1.09)$ \\
\hline Highlighting (after) & $2.69(1.03)$ & $2.31(.92)$ & $2.44(1.05)$ \\
\hline Imagery (before) & $4.32(.84)$ & $4.15(.99)$ & $4.13(.80)$ \\
\hline Imagery (after) & $3.03(1.17)$ & $2.95(1.08)$ & $2.95(1.19)$ \\
\hline Intention to change & $4.21(.35)$ & $4.24(.35)$ & $4.06(.40)$ \\
\hline \multicolumn{4}{|l|}{ Transportation } \\
\hline Transportation total & $3.42(.46)$ & $3.37(.47)$ & \\
\hline Identification & $3.06(.68)$ & $2.50(.66)$ & \\
\hline Realism & $3.73(.86)$ & $4.06(.74)$ & \\
\hline Engagement & $3.46(.69)$ & $3.55(.57)$ & \\
\hline
\end{tabular}

Note. 'LS' means learning strategy; 'before' and 'after' indicate before and after the intervention. 
Since the additional belief change about practice testing may be due to the narrative and didactic group gaining extra knowledge from the narrative and didactic videos, we performed a Kruskal-Wallis $H$ test to compare the three groups in terms of their learning strategy knowledge. The learning strategy knowledge scores did not differ significantly between the three groups, $H(2)=1.58, p=.45$, with a mean rank knowledge of 62.90 for the narrative group, 60.41 for the didactic group, and 53.69 for the control group. This shows that the three groups gained the same amount of learning strategy knowledge, even though the narrative and didactic group watched extra videos about learning strategies.

\section{Intentions to Change}

In the next step, we performed a one-way ANOVA to examine Hypothesis 2a. The mean scores on the intention to change did not differ significantly across the three groups, $F(2,114)=2.53, p=.08$. This result did not confirm H2a, although the narrative and didactic groups numerically had higher mean intention to change scores.
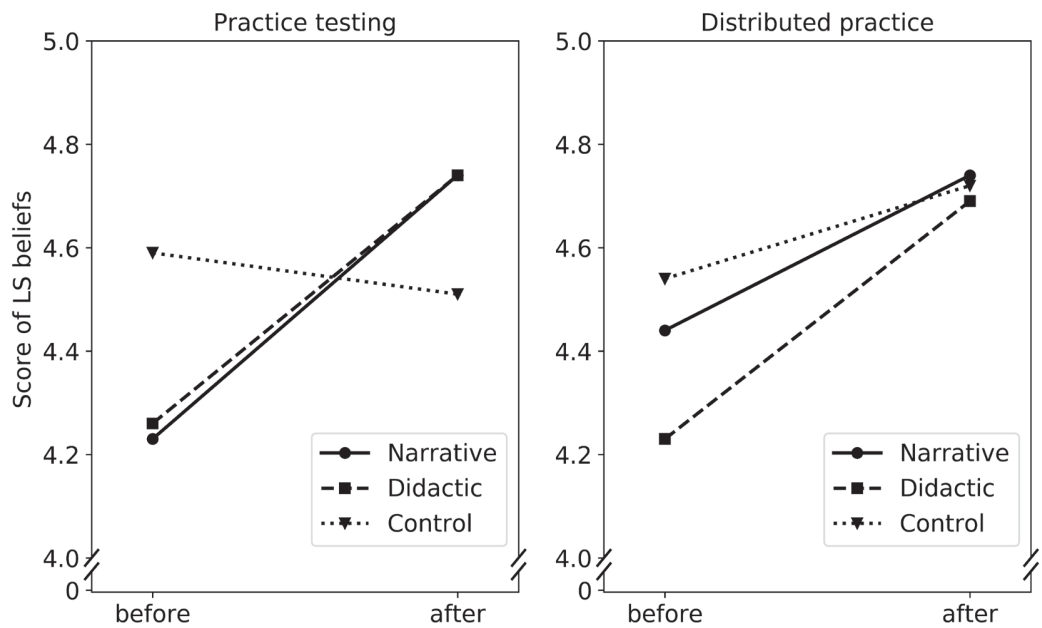

Figure 2.1. Learning strategy (LS) beliefs of practice testing (left) and distributed practice (right) of the three groups before and after the intervention. 


\section{The Relation between Transportation Factors and the Narrative Effect}

Independent-samples t-tests or Mann-Whitney tests were used to investigate which factors of transportation (engagement, realism, identification) were affected by the narrative video compared to the didactic video. There was a significant difference in identification between the narrative and didactic groups, $t(76)=3.73, p<.001$, Cohen's $d=.84$, indicating that participants from the narrative group identified more with the characters than those from the didactic group. There was no significant difference in engagement $(U=733.00, p=.78)$, nor in the total transportation score $(t(76)=.46$, $p=.65)$. There was no significant difference in realism either $(U=588.50, p=.08)$, but there was a tendency among participants to consider the narrative video less real than the didactic video.

Table 2.2 The results of regression analyses in this study. Model 1 is the regression model using identification to predict intentions to change; model 2 is using transportation to predict intentions to change; model 3 is using need for cognition to predict identification.

\begin{tabular}{|c|c|c|c|c|c|c|}
\hline & \multirow[t]{2}{*}{ Variable } & \multicolumn{2}{|c|}{$\begin{array}{l}\text { Unstandardized } \\
\text { Coefficients }\end{array}$} & \multirow{2}{*}{$\begin{array}{l}\text { Standardized } \\
\text { Coefficients }\end{array}$} & \multirow[t]{2}{*}{$\mathrm{t}$} & \multirow[t]{2}{*}{$p$} \\
\hline & & B & $\mathrm{SE}$ & & & \\
\hline \multirow[t]{2}{*}{ Model 1} & Constant & 3.67 & .25 & & $14.88^{* * *}$ & .00 \\
\hline & Identification & .18 & .08 & .35 & $2.27^{*}$ & .03 \\
\hline \multirow[t]{2}{*}{ Model 2} & Constant & 3.81 & .42 & & $9.08^{* * * *}$ & .00 \\
\hline & Transportation & .12 & .12 & .16 & .96 & .34 \\
\hline \multirow[t]{2}{*}{ Model 3} & Constant & 3.29 & .17 & & $19.08^{* * * *}$ & .00 \\
\hline & Need for cognition & -.01 & .01 & -.27 & -1.69 & .10 \\
\hline
\end{tabular}

${ }^{*} p \leq .05,{ }^{* * *} p \leq .001$

Hypothesis $2 \mathrm{~b}$ was tested by simple linear regression. This test only included the narrative group, because the nature of the narratives but not the nature of didactic communication is expected to affect identification/transportation (Green, 2006; Murphy et al., 2013). We first conducted an assumption check for identification and intention to change. An analysis of standard residuals was carried out, which showed that the data contained no influential outliers (Std. Residual Min = -2.15, Std. Residual Max =2.23). The data met 
the assumption of independent errors (Durbin-Watson value =1.69). The histogram of standardized residuals and the normal P-P plot indicated that the data contained normally distributed errors. Assumptions check for transportation and intentions to change showed similar results. The simple linear regression analysis confirms $\mathrm{H} 2 \mathrm{~b}$, $F(1,37)=5.17, p=.03, \eta^{2}=.12$, meaning that identification with the characters in the narrative video had an impact on participants' intention to change. Their intention to change increased by .18 for each 1-point increase in the identification score. For details, see Model 1 in Table 2.2. However, the total transportation score could not predict the intention to change score, $F(1,37)=.93, p=.34$, suggesting that total transportation was unrelated to the intention to change one's learning strategy. For details, see Model 2 in Table 2.2.

As identification has been found to be a factor in mediating narrative effects in some studies (De Graaf, Hoeken, Sanders, \& Beentjes, 2012; Hoeken \& Fikkers, 2014), we therefore performed an exploratory analysis to investigate the relation between narratives and the intention to change one's learning strategy. Using the R package mediation (Tingley, Yamamoto, Hirose, Keele, \& Imai, 2014), we ran causal mediation analyses to investigate whether identification was a potential variable mediating the effect of our narratives intervention compared to didactic communication. The intervention variable (narrative or didactic communication) and covariates of age and gender were used to predict the extent of identification, which, in turn, served to predict the overall intention to change. The results showed that intervention, age and gender were significantly impacting the extent of identification, $F(3,74)=6.32, p<.001, \eta^{2}=.20$. However, we did not find a total effect on the intention to change in the narrative group, 95\% CIs $[-.13, .19]$, nor did we find an average direct effect (narratives $\rightarrow$ intention to change), 95\% CIs [-.10, .25]. We also did not find an average causal mediation effect either (narratives $\rightarrow$ identification $\rightarrow$ intention to change), 95\% CIs [-.15, .01]. The mediation results are presented in Fig 2.2. As expected in $\mathrm{H} 2 \mathrm{~b}$, identification with the characters in the narratives had an impact on intentions to change but was not a mediator of the narrative effect. 


\section{Awareness of Desirable Difficulties Stimulated by the Narrative Video}

Hypothesis 3 was tested by Chi-square test. There was a significant association between the type of group on the one hand and the types of knowledge gained from the video on the other, $\chi^{2}(3)=25.47, p<.001$, Cramér's $V=.57$. The results indicate that participants' focus on the information elements included in the narrative or didactic videos differed between the groups (Table 2.3), even though the only difference was the style in which the content was conveyed. For the narrative group, 21 participants became aware that more effective learning strategies come with desirable difficulties, as opposed to only three participants from the didactic group. These results confirm Hypothesis 3. As described under Materials, information about desirable difficulties and changing learning strategies were new in the narrative and didactic videos. Factual knowledge about effective learning strategies was already included in the pre-intervention phase. From Table 2.3 we can infer that $82.1 \%$ of the participants in the narrative group actually received this new information. In the didactic group, this percentage was only $30.8 \%$, while the majority (59.0\%) indicated they had learnt factual knowledge about effective learning strategies by watching the video. This means that the narrative video had more power to convey information than the didactic video, especially the information about desirable difficulties.

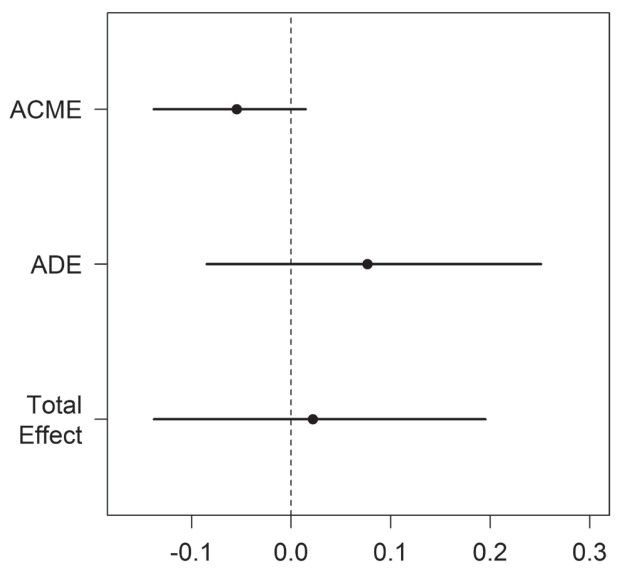

Figure 2.2. Mediation analysis results. $A C M E=$ average causal mediation effect, $A D E=a v-$ erage direct effect. 
Table 2.3. Numbers of participants reporting what they learnt from the narrative/didactic video,

\begin{tabular}{lll}
\hline & $\begin{array}{l}\text { Narrative } \\
(\mathrm{N}=39)\end{array}$ & $\begin{array}{l}\text { Didactic } \\
(\mathrm{N}=39)\end{array}$ \\
\hline Awareness of desirable difficulties & $21(53.9 \%)$ & $3(7.7 \%)$ \\
Should change learning strategies & $11(28.2 \%)$ & $9(23.1 \%)$ \\
Effective learning strategies & $6(15.4 \%)$ & $23(59.0 \%)$ \\
Nothing & $1(0.03 \%)$ & $4(10.3 \%)$ \\
\hline
\end{tabular}

\section{Need for Cognition and Identification}

We performed a simple linear regression analysis to test Hypothesis 4. We first conducted an assumption check for the data. An analysis of standard residuals was carried out, which showed that the data contained no outliers (Std. Residual Min $=-2.11$, Std. Residual Max = 2.03). The data met the assumption of independent errors (DurbinWatson value $=2.04)$. The histogram of standardized residuals and the normal P-P plot indicated that the data contained normally distributed errors. The regression results do not confirm $\mathrm{H}_{4}$ that the lower NFC participants have a higher level of identification, although there was a tendency in this direction, $F(1,37)=2.85, p=.10$. For details, see Model 3 in Table 2.2.

\section{Discussion}

This study investigated the applicability of a narrative video for diminishing erroneous beliefs and increasing the intention to change ineffective learning strategies. We found that both the narrative and didactic videos helped diminish erroneous learning strategy beliefs of practice testing, but the narrative video did not change beliefs nor stimulate the intention to change learning strategies more than the didactic video. Participants who identified more with the narrative characters had a greater intention to change. Moreover, more participants in the narrative group generated awareness of desirable difficulties. Need for cognition showed a tendency to affect identification with the narrative characters. 
Our findings confirm the hypothesis that the video explanations about changing learning strategies have the potential to diminish erroneous learning strategy beliefs of practice testing, over and above only providing information about effective learning strategy knowledge. To be able to apply the correct learning strategies, students must possess adequate knowledge about these strategies (Donker et al., 2014). University students often did not acquire this type of knowledge in high school, which may be explained by the fact that teacher education books do not fully cover this information (Surma, Vanhoyweghen, Camp, \& Kirschner, 2018). According to our results, however, students need an incentive other than knowledge acquisition to change erroneous beliefs and improve their use of effective learning strategies. This incentive is provided in the form of a narrative or didactic video about changing ineffective learning strategies. Future research should investigate to what extent the effect we found is due to the content of the video or the presentation style. However, we failed to find the same effect of the narrative and the didactic videos on diminishing erroneous beliefs of distributed practice. This is probably because Maastricht University uses problem-based learning (PBL). In this curriculum, students are grouped in small tutorials and actively participate in multiple tutorial meetings that are equally distributed over each study period (Budé, Imbos, van de Wiel, \& Berger, 2011; Dolmans, Wolfhagen, Van Der Vleuten, \& Wijnen, 2001). During the initial brainstorming phase in tutorial PBL meetings, students activate their prior knowledge and discover issues they need to study for the next tutorial meeting taking place a few days later (Dolmans et al., 2001). Because of the time interval and the distribution of learning activities, students might take ample time to construct their knowledge and also retrieve and elaborate on their knowledge during the postdiscussion. Participants from our study were taught these benefits of PBL immediately after they entered Maastricht University. It is therefore possible that these students already learned that distributed practice is effective and, therefore, it is important to test the generalizability of the results in non-PBL settings.

However, the results failed to support previous research in the health domain demonstrating that narratives are superior to didactic communication in changing beliefs and stimulating intentions. One reason could be that the using of actors instead of actual events from their own protagonists might have influenced the narrative effect. Indeed, our results showed that students tended to consider the narrative video less real. To minimize differences between the two videos, we used the same actors to act in both the narrative and didactic video. Research has shown that a narrative becomes 
more plausible and impactful when it bears more resemblance to an actual event (Potter, 1986). Our use of actors therefore may have reduced the effect of narratives in general. To resolve this matter, we suggest that future researchers record cases of real students who changed their learning strategies to investigate their influence on learning strategy use. However, since the realism rating was sufficient for both videos and the difference was small, it is not likely to explain the lack of a difference between the two video groups. Another reason may be a ceiling effect. Both the narrative and didactic groups scored relatively high on both the learning strategy beliefs of practice testing and the intention to change scales (both rated on a 5-point Likert scale). For the two experimental groups, the lowest average group score on the learning strategy beliefs of practice testing questionnaire was 4.74, while the lowest average group score on the intention to change scale was 4.21, leaving little room for improvement. Moreover, we measured the intentions to change for the two effective strategies on average. Since the behavioral beliefs of distributed practice were not impacted, this may have hindered us to find significant results on the intentions to change (Ajzen, 1991; Fishbein \& Ajzen, 2011). The intentions to use practice testing may have been significantly stimulated. We welcome future research to investigate the effect of narratives based on a single learning strategy.

Another finding flowing from our study was that the narrative video impacted identification. Moreover, our hypothesis that participants who identified more with the narrative characters have a higher intention to change was confirmed. More identification with the narrative characters means more identification with the characters' opinions, attitudes and experienced events (Green, 2006). Consequently, students may have been more motivated and inspired to emulate the characters' behavior. In addition, seeing the characters successfully change their learning strategies, may have increased students' self-efficacy (Bandura, 2009; De Graaf et al., 2012). Taken together, these considerations could explain the higher intention to change. We also found that total transportation was unrelated to the intention to change. A potential explanation is offered by Murphy and colleagues (2013, p. 131) who stated that 'although transportation and identification with a specific character ... are related constructs, they do not entirely overlap in their effects'. Hence, our results imply that identification may be more important than transportation in effecting learning strategy change. The power of narratives may lie in the extent to which students can 'see themselves' in the characters (Murphy et al., 2013) and increased similarity will increase identification (Hoffner \& Buchanan, 2005). We did 
not confirm that identification is a mediator of the narrative effect, possibly because the level of identification with the narrative was not sufficient and therefore the influence of narratives on intentions to change through identification was not significant. Future studies could explore what kind of similarity increases identification, for instance similar study problems and study topic.

Our results also showed that more participants in the narrative group generated awareness of desirable difficulties than their counterparts in the didactic group. A reason could be that they identified more with the narrative characters who stressed the importance of desirable difficulties and explained how to deal with them, causing these participants to be more affected by them. Watching a character that resembles their own struggle with certain events may have made participants more receptive to the information about desirable difficulties. Awareness of desirable difficulties is valuable as it helps students to adopt effective learning strategies and persist in using them. According to the expectancy-value theory (Berger \& Karabenick, 2011), this is because such awareness reduces the perceived cost or effort of using these effective strategies, in turn influencing their use in the long run. In addition, students are reluctant to use effective learning strategies maybe not because they lack awareness of the effectiveness, but because of the high effort these strategies evoke (Biwer et al., 2020; Carpenter, Witherby, et al., 2020; Kirk-Johnson et al., 2019). In line with Biwer and colleagues (2020), we found the effectiveness rating for practice testing and distributed practice was higher than those for ineffective ones, such as rereading and cramming, both before and after the intervention. This is similar to findings in the health behavior change domain. For example, an individual knows that doing sports and a healthy diet is good, but does not act accordingly because of high costs (Hofmann, Friese, \& Wiers, 2008; Mann, De Ridder, \& Fujita, 2013). As a result, although we did not find narratives to stimulate the intention to change in this study, the finding that they did raise awareness of desirable difficulties suggests that narratives are preferable to didactic communication in the learning strategy change domain. The awareness of the importance of desirable difficulties (high effort, but followed by positive results) could be a promising coping strategy for starting and persisting a new desirable behavior.

Finally, our results did not confirm the hypothesis that low-NFC participants identify more with the characters, and hence have a greater intention to change, but there was a tendency for this group towards enhanced identification. Although these results should be interpreted with caution, they echo previous research findings showing 
that students with a lower need for cognition were more involved in the narratives and focused more on the storyline (Golke et al., 2019). A potential reason for this lack of a significant relation between the need for cognition and identification is the using of actors in the narrative video might have influenced identification. Hence, also in this case we suggest that future researchers record cases of real students changing their learning strategies to measure the relationship between the need for cognition and identification, and how these influence the effect of narratives.

Although this study provides insight into the use of narratives in the learning strategy change domain, it has some limitations. The main limitation is that the reliabilities of the intention to change and the transportation scale were suboptimal. This was the first study trying to change ineffective learning strategies from a behavior-change perspective, and therefore we adapted scales used in the behavioral-change domain, which may explain the relatively low internal consistencies. The used scales might not be the best option for measuring changes in learning behavior. To our knowledge, there exist no specific scales for the learning behavior change domain. Therefore, developing a transportation scale and an intention to change scale in the learning behavior change domain could be a valuable direction for future research. Another limitation of this study is that the long-term effect of narratives on learning strategy use was not measured. Studies have shown that narratives can have a long-term effect on behavior change (e.g. Kreuter et al., 2010). In this study, however, the principal aim was to measure the direct effect of a short narrative video on the most important predictor of behavior change, that is, the intention to change. We welcome future research into the effect of narratives on learning strategy change in the long run, measured, for instance, three or six months after the intervention. 


\section{Conclusion}

The present study underscores the value of narrative and didactic videos in diminishing erroneous beliefs about learning strategies and stimulating intentions to change these, especially the power of the narrative video to convey information about desirable difficulties. Educationalists could use narratives to convey information about desirable difficulties. This study also shows that, in addition to helping students gain learning strategy knowledge, educationalists should offer students more support in changing ineffective learning strategy use. Last but not least, higher identification with narrative characters suggests a higher intention to change. Given the importance of using effective learning strategies to enhancing learning outcomes, the results of this study encourage researchers and practitioners aiming for learning strategy change to develop narratives with highly identifiable characters to improve the effectiveness of their interventions. 


\section{References}

Ajzen, I. (1991). The theory of planned behavior. Organizational Behavior and Human Decision Processes, 50(2), 179-211.

Ajzen, I. (2006). Constructing a theory of planned behavior questionnaire. Retrieved from https:// people.umass.edu/ aizen/pdf/tpb.measurement.pdf

Appel, M., \& Richter, T. (2007). Persuasive effects of fictional narratives increase over time. Media Psychology, 10(1), 113-134.

Armitage, C. J., \& Conner, M. (2001). Efficacy of the theory of planned behaviour: A meta-analytic review. British journal of Social Psychology, 40 (4), 471-499.

Bandura, A. (2009). Social cognitive theory of mass communication. In Media effects (pp. 110-140): Routledge.

Bell, K. E., \& Limber, J. E. (2009). Reading skill, textbook marking, and course performance. Literacy Research and Instruction, 49(1), 56-67.

Benjamin, A. S., \& Tullis, J. (2010). What makes distributed practice effective? Cognitive Psychology, 61(3), 228-247.

Berger, J.-L., \& Karabenick, S. A. (2011). Motivation and students' use of learning strategies: Evidence of unidirectional effects in mathematics classrooms. Learning and Instruction, 21(3), 416-428.

Biwer, F., Oude Egbrink, M. G., Aalten, P., \& de Bruin, A. B. (2020). Fostering Effective Learning Strategies in Higher Education-A Mixed-Methods Study. Journal of Applied Research in Memory and Cognition.

Bjork, E., \& Bjork, R. (2011). Making things hard on yourself, but in a good way: Creating desirable difficulties to enhance learning. Psychology and the real world: Essays illustrating fundamental contributions to society, 2(59-68).

Bjork, R. A., Dunlosky, J., \& Kornell, N. (2013). Self-Regulated Learning: Beliefs, Techniques, and Illusions. Annual Review of Psychology, 64(1), 417-444. doi:10.1146/annurev-psych-113011-143823

Braverman, J. (2008). Testimonials versus informational persuasive messages: The moderating effect of delivery mode and personal involvement. Communication Research, 35(5), 666-694.

Brownson, R. C., Eyler, A. A., Harris, J. K., Moore, J. B., \& Tabak, R. G. (2018). Getting the Word Out: New Approaches for Disseminating Public Health Science. Journal of Public Health Management and Practice: JPHMP, 24(2), 102-111. doi:10.1097/PHH.0000000000000673

Budé, L., Imbos, T., van de Wiel, M. W., \& Berger, M. P. (2011). The effect of distributed practice on students' conceptual understanding of statistics. Higher Education, 62(1), 69-79. 
Cacioppo, Petty, \& Feng Kao. (1984). The efficient assessment of need for cognition. Journal of Personality Assessment, 48(3), 306-307. Retrieved from https://www.tandfonline.com/doi/ abs/10.1207/s15327752jpa4803_13

Cacioppo, J. T., Petty, R. E., Feinstein, J. A., Blair, W., \& Jarvis, G. (1996). Dispositional differences in cognitive motivation: The life and times of individuals varying in need for cognition. Psychological Bulletin, 119(2), 197-253. doi:10.1037/0033-2909.119.2.197

Carey, K. B., Purnine, D. M., Maisto, S. A., \& Carey, M. P. (1999). Assessing readiness to change substance abuse: A critical review of instruments. Clinical Psychology: Science and Practice, $6(3), 245-266$.

Carpenter, S. K., Lund, T. J., Coffman, C. R., Armstrong, P. I., Lamm, M. H., \& Reason, R. D. (2016). A classroom study on the relationship between student achievement and retrieval-enhanced learning. Educational Psychology Review, 28(2), 353-375.

Carpenter, S. K., Witherby, A. E., \& Tauber, S. K. (2020). On Students'(Mis) judgments of Learning and Teaching Effectiveness. Journal of Applied Research in Memory and Cognition.

Dai, D. Y., \& Wang, X. L. (2007). The role of need for cognition and reader beliefs in text comprehension and interest development. Contemporary Educational Psychology, 32(3), 332347. doi:10.1016/j.cedpsych.2006.05.002

De Graaf, A., Hoeken, H., Sanders, J., \& Beentjes, J. W. (2012). Identification as a mechanism of narrative persuasion. Communication Research, 39(6), 802-823.

De Wit, J. B., Das, E., \& Vet, R. (2008). What works best: objective statistics or a personal testimonial? An assessment of the persuasive effects of different types of message evidence on risk perception. Health Psychology, 27(1), 110.

Dolmans, D. H., Wolfhagen, I. H., Van Der Vleuten, C. P., \& Wijnen, W. H. (2001). Solving problems with group work in problem-based learning: hold on to the philosophy. Medical Education, 35(9), 884-889.

Donker, A. S., De Boer, H., Kostons, D., Van Ewijk, C. D., \& van der Werf, M. P. (2014). Effectiveness of learning strategy instruction on academic performance: A meta-analysis. Educational Research Review, 11, 1-26.

Dunlosky, J., Rawson, K. A., Marsh, E. J., Nathan, M. J., \& Willingham, D. T. (2013). Improving students' learning with effective learning techniques: Promising directions from cognitive and educational psychology. Psychological Science in the Public Interest, 14(1), 4-58.

Eldredge, L. K. B., Markham, C. M., Ruiter, R. A., Kok, G., Fernandez, M. E., \& Parcel, G. S. (2016). Planning health promotion programs: an intervention mapping approach: John Wiley \& Sons.

Faul, F., Erdfelder, E., Buchner, A., \& Lang, A. (2014). G* Power Version 3.1. 9.2. Germany: University of Kiel. 
Finn, B., \& Tauber, S. K. (2015). When confidence is not a signal of knowing: How students' experiences and beliefs about processing fluency can lead to miscalibrated confidence. Educational Psychology Review, 27(4), 567-586.

Fiorella, L. (2020). The Science of Habit and Its Implications for Student Learning and Well-being. Educational Psychology Review, 1-23.

Fishbein, M., \& Ajzen, I. (1975b). Intention and Behavior: An introduction to theory and research: Addison-Wesley, Reading, MA.

Fishbein, M., \& Ajzen, I. (2011). Predicting and changing behavior: The reasoned action approach: Taylor \& Francis.

Gebbers, T., De Wit, J. B., \& Appel, M. (2017). Health Communication| Transportation Into Narrative Worlds and the Motivation to Change Health-Related Behavior. International Journal of Communication, 11, 21.

Geitz, G., Joosten-ten Brinke, D., \& Kirschner, P. A. (2016). Changing learning behaviour: Selfefficacy and goal orientation in PBL groups in higher education. International Journal of Educational Research, 75, 146-158.

Geller, J., Toftness, A. R., Armstrong, P. I., Carpenter, S. K., Manz, C. L., Coffman, C. R., \& Lamm, M. H. (2018). Study strategies and beliefs about learning as a function of academic achievement and achievement goals. Memory, 26(5), 683-690.

Golke, S., Hagen, R., \& Wittwer, J. (2019). Lost in narrative? The effect of informative narratives on text comprehension and metacomprehension accuracy. Learning and Instruction, 60, 1-19.

Graaf, A. d., Sanders, J., \& Hoeken, H. (2016). Characteristics of narrative interventions and health effects: A review of the content, form, and context of narratives in health-related narrative persuasion research. Review of Communication Research, 4, 88-131.

Green, M. C. (2006). Narratives and cancer communication. Journal of Communication, 56, S163$\mathrm{S} 183$.

Green, M. C., \& Brock, T. C. (2000). The role of transportation in the persuasiveness of public narratives. Journal of Personality and Social Psychology, 79(5), 701.

Green, M. C., Kass, S., Carrey, J., Herzig, B., Feeney, R., \& Sabini, J. (2008). Transportation across media: Repeated exposure to print and film. Media Psychology, 11(4), 512-539.

Hartwig, M. K., \& Dunlosky, J. (2012). Study strategies of college students: Are self-testing and scheduling related to achievement? Psychonomic Bulletin \& Review, 19(1), 126-134.

Hattie, J., Biggs, J., \& Purdie, N. (1996). Effects of learning skills interventions on student learning: A meta-analysis. Review of Educational Research, 66(2), 99-136. 
Haugtvedt, C. P., \& Petty, R. E. (1992). Personality and persuasion: Need for cognition moderates the persistence and resistance of attitude changes. Journal of Personality and Social Psychology, 63(2), 308.

Hinyard, L. J., \& Kreuter, M. W. (2007). Using narrative communication as a tool for health behavior change: a conceptual, theoretical, and empirical overview. Health Education \& Behavior, 34(5), 777-792.

Hoeken, H., \& Fikkers, K. M. (2014). Issue-relevant thinking and identification as mechanisms of narrative persuasion. Poetics, 44, 84-99.

Hoeken, H., Kolthoff, M., \& Sanders, J. (2016). Story perspective and character similarity as drivers of identification and narrative persuasion. Human Communication Research, 42(2), 292-311.

Hoffner, C., \& Buchanan, M. (2005). Young adults' wishful identification with television characters: The role of perceived similarity and character attributes. Media Psychology, 7(4), 325-351.

Hofmann, W., Friese, M., \& Wiers, R. W. (2008). Impulsive versus reflective influences on health behavior: A theoretical framework and empirical review. Health Psychology Review, 2(2), 111-137.

Hurtado-de-Mendoza, A., Graves, K. D., Gómez-Trillos, S., Song, M., Anderson, L., Campos, C., . . . Schwartz, M. D. (2020). Developing a culturally targeted video to enhance the use of genetic counseling in Latina women at increased risk for hereditary breast and ovarian cancer. Journal of Community Genetics, 11(1), 85-99.

Kim, H. S., Bigman, C. A., Leader, A. E., Lerman, C., \& Cappella, J. N. (2012). Narrative health communication and behavior change: The influence of exemplars in the news on intention to quit smoking. Journal of Communication, 62(3), 473-492.

Kirk-Johnson, A., Galla, B. M., \& Fraundorf, S. H. (2019). Perceiving effort as poor learning: The misinterpreted-effort hypothesis of how experienced effort and perceived learning relate to study strategy choice. Cognitive Psychology, 115, 101237.

Kornell, N. (2009). Optimising learning using flashcards: Spacing is more effective than cramming. Applied Cognitive Psychology: The Official Journal of the Society for Applied Research in Memory and Cognition, 23(9), 1297-1317.

Kornell, N., \& Bjork, R. A. (2007). The promise and perils of self-regulated study. Psychonomic Bulletin \& Review, 14(2), 219-224.

Kreuter, M. W., Green, M. C., Cappella, J. N., Slater, M. D., Wise, M. E., Storey, D., . . Holmes, K. (2007). Narrative communication in cancer prevention and control: a framework to guide research and application. Annals of Behavioral Medicine, 33(3), 221-235.

Kreuter, M. W., Holmes, K., Alcaraz, K., Kalesan, B., Rath, S., Richert, M., . . Clark, E. M. (2010). Comparing narrative and informational videos to increase mammography in low-income African American women. Patient Education and Counseling, 81, S6-S14. 
Linvill, D. L., Mazer, J. P., \& Boatwright, B. C. (2016). Need for cognition as a mediating variable between aggressive communication traits and tolerance for disagreement. Communication Research Reports, 33(4), 363-369.

Mann, T., De Ridder, D., \& Fujita, K. (2013). Self-regulation of health behavior: social psychological approaches to goal setting and goal striving. Health Psychology, 32(5), 487.

Markus, H., \& Nurius, P. (1986). Possible selves. American Psychologist, 41(9), 954.

Morehead, K., Rhodes, M. G., \& DeLozier, S. (2016). Instructor and student knowledge of study strategies. Memory, 24(2), 257-271.

Moyer-Gusé, E., Chung, A. H., \& Jain, P. (2011). Identification with characters and discussion of taboo topics after exposure to an entertainment narrative about sexual health. Journal of Communication, 61(3), 387-406.

Murphy, S. T., Frank, L. B., Chatterjee, J. S., \& Baezconde-Garbanati, L. (2013). Narrative versus nonnarrative: The role of identification, transportation, and emotion in reducing health disparities. Journal of Communication, 63(1), 116-137.

Picazo-Vela, S., Chou, S. Y., Melcher, A. J., \& Pearson, J. M. (2010). Why provide an online review? An extended theory of planned behavior and the role of Big-Five personality traits. Computers in Human Behavior, 26(4), 685-696.

Potter, W. J. (1986). Perceived reality and the cultivation hypothesis. Journal of Broadcasting \& Electronic Media, 30(2), 159-174.

R Core Team (2019). R: A language and environment for statistical computing. R Foundation for Statistical Computing, Vienna, Austria. URL https://www.R-project.org/.

Rhodes, R. E., Courneya, K. S., \& Jones, L. W. (2005). The theory of planned behavior and lowerorder personality traits: Interaction effects in the exercise domain. Personality and Individual Differences, 38(2), 251-265.

Roediger III, H. L., \& Karpicke, J. D. (2006a). The power of testing memory: Basic research and implications for educational practice. Perspectives on Psychological Science, 1(3), 181-210.

Rovers, S. F. E., Stalmeijer, R. E., van Merriënboer, J. J. G., Savelberg, H., \& de Bruin, A. B. H. (2018). How and Why Do Students Use Learning Strategies? A Mixed Methods Study on Learning Strategies and Desirable Difficulties With Effective Strategy Users. Frontiers in Psychology, 9, 2501. doi:10.3389/fpsyg.2018.02501

Rowland, C. A. (2014). The effect of testing versus restudy on retention: A meta-analytic review of the testing effect. Psychological Bulletin, 140(6), 1432.

Shen, F., Sheer, V. C., \& Li, R. (2015). Impact of narratives on persuasion in health communication: A meta-analysis. Journal of Advertising, 44(2), 105-113. 
Surma, T., Vanhoyweghen, K., Camp, G., \& Kirschner, P. A. (2018). The coverage of distributed practice and retrieval practice in Flemish and Dutch teacher education textbooks. Teaching and Teacher Education, 74, 229-237.

Tal-Or, N., \& Cohen, J. (2010). Understanding audience involvement: Conceptualizing and manipulating identification and transportation. Poetics, 38(4), 402-418.

Team, R. C. (2019). A language and environment for statistical computing. Vienna, Austria: R Foundation for Statistical Computing; 2012. URL https://www. R-project. org.

Thompson, T., \& Kreuter, M. W. (2014). Peer Reviewed: Using Written Narratives in Public Health Practice: A Creative Writing Perspective. Preventing Chronic Disease, 11.

Tingley, D., Yamamoto, T., Hirose, K., Keele, L., \& Imai, K. (2014). Mediation: R package for causal mediation analysis.

Tullis, J. G., Finley, J. R., \& Benjamin, A. S. (2013). Metacognition of the testing effect: Guiding learners to predict the benefits of retrieval. Memory \& Cognition, 41(3), 429-442.

Verplanken, B. (1989). Involvement and need for cognition as moderators of beliefs-attitudeintention consistency. British journal of Social Psychology, 28(2), 115-122.

Williams, J. H., Green, M. C., Kohler, C., Allison, J. J., \& Houston, T. K. (2011). Stories to communicate risks about tobacco: Development of a brief scale to measure transportation into a video story-The ACCE Project. Health Education Journal, 70 (2), 184-191.

Yan, V. X., Bjork, E. L., \& Bjork, R. A. (2016). On the difficulty of mending metacognitive illusions: A priori theories, fluency effects, and misattributions of the interleaving benefit. Journal of Experimental Psychology: General, 145(7), 918. 


\section{Appendix 2.1}

\section{The Narrative Videos}

\section{Actor 1: Linda}

Hi, I'm Linda. I am a second-year student at X University. I chose this university because of the problem-based learning. Er, I think that is really interesting, because you get to really understand the materials' full problems, and you get to choose when to study. So, back in high school, I did rereading and highlighting. And that really worked. And, and I got good grades. But now in university, er, it doesn't seem to be working anymore. And I got really frustrated about this.

Then I took study-skills training. And I actually learnt that practice testing and distributed practice were a really good idea. And actually a lot more effective than rereading and highlighting, so I thought I could maybe study using flashcards and make myself a schedule when to study and also to rehearse what I had already studied.

So then I decided to implement these strategies. So I made myself a schedule, and I also started trying to test myself. So then, I used, like, I looked at the questions at the end of the book chapter and also used an App to ask myself questions. And something I found it's really frustrating. It's, it just took me a lot of time, and I felt like, I wasn't remembering that much. And, I don't know, it was just, it's really, I got annoyed basically. Because I felt I wasn't learning. And it was taking so much more time. So it was kind of unsure whether it was worth it.

But then I remembered that in the training they really emphasized its worth, that even though it's quite difficult, it really improves your learning in the long term. So, I decided to stick to my distributed learning plan and also kept retesting myself with those practice questions.

And then, it's about a half year later, I really saw improvement. My grades got, went up, and I was just a lot happier, because it's really effective. So that also my mentor asked me, like, what's going on, right? And I told him about going to the training. And he told me I should tell others, the mentor group, share my way of learning with the rest of our mentor group. So I'm just really proud of myself. 


\section{Actor 2: Max}

Hi, I am Max. I am a second-year student at X University. And to be honest, I was actually never really one of the good students. So I would just cram my own learning in the last days before the exam. I was literally one of these people that you see in the library around midnight. Sometimes it worked, sometimes it didn't, but in general, I never really remembered anything after the exam.

So then I asked myself 'do you really just study to get a good grade, to pass the exams?'. And of course, that was not the case. Right? So, I decided to do something about it. I read some literature and I stumbled upon this article that was about effective learning. And it said that there are two methods, distributed practice and practice testing, that are really effective. And are actually fixing this memory into your longterm memory. And, and, that then is also good for getting grades. When I read that, I decided, hey, I'll just give a try.

So what I did was, when using distributed practice, I would make schedules to spread my learning over time. So take for an example, I had 8 hours to learn for an exam, so instead of just cramming these eight hours the day just before the exam, I would split them over eight days, and also use the time to rehearse the things that I already knew. And for practice testing, I looked up some practice questions online, which I could then use to practice the things that I knew, to rehearse things I knew, and also to fill the gaps and to re-practice the things I didn't know.

However, sometimes I had the impression that these methods, distributed practice and practice testing, were really time-consuming. So I had the impression that I was putting more effort and time into it than when I was cramming learning before. And, I didn't really know how to deal with that. But the article I had read said that this was a normal thing to have and that the effort would get less overtime, so I decided to just hang in there.

And actually the cool thing was, that I found out that I could just share way more things in the tutorial, and I remembered way more details and could give more detailed accounts of what I'd read and that really then paid off in the sessions. I also found that my grades were getting better. So, as afterwards now, I would say I will never go back to cram learning again. 


\section{The Didactic Videos}

\section{Actor 1: Linda}

Hi, I am Linda. I am a researcher at X University in the department of education. When students go from high school to university, they often notice that the old strategies they used, such as highlighting and rereading, don't work.

Ample scientific research shows that distributed practice and practice testing are more effective learning strategies than rereading and highlighting. A review study showed that study-skills training teaches and explains to students how to use these effective strategies and this helps in the long-term retention of knowledge and has a positive effect on students' grades. Educational psychologists at X University are conducting such a study-skills training. They explain to students that they should use the questions at the end of book chapters and use Apps to test themselves. And also to make schedules to distribute their learning and also to review what they already studied. This study-skills training shows again what positive effect it has.

Research also shows that using effective learning strategies is a difficult process that requires time and effort, especially at the beginning. But positive results will be noticed after at least a few weeks. So it's worth doing from a long-term perspective. The complexity and difficulty experienced when using these effective learning strategies are termed 'desirable difficulties', which means that it takes an effort but it benefits in the long run for the learning. Also, the time and effort required will diminish as students keep using these strategies.

Students who stuck to these strategies improved and their grades went up significantly. Therefore, my advice is to use distributed practice and practice testing as much as possible when preparing for tutorials and exams. 


\section{Actor 2: Max}

Hi, I am Max. I work here in the educational development lab at X University. And researchers have found that many university libraries have extended opening hours during or shortly before the exams and these hours are filled with students doing cram learning. X University, as you know, also has these XX opening hours. Now, while research has found that this, the crammed learning strategy, is not effective for the long-term retention of knowledge.

The aim of self-study is to retain knowledge for the long run, so as to be able to use what you have learnt in the future. Now research has found that two strategies, distributed practice and practice testing, are very effective for long-term retention, and actually can also boost grades. So students should give these two a try.

A large review study by John Dunlosky and colleagues has shown that when using distributed practice, a schedule should be made to spread learning over time and to review the knowledge that has already been learnt. So for example, if you have eight hours before an exam, instead of putting all your learning in one day, so the eight hours exactly before the exam, you should take eight days before the exam and study for one hour per day. And remember to also review the things that you already learnt. Now when you use practice testing, it is essential to look at the book only once and then put it away, to test your understanding with, for example, practice questions.

Research has shown that when using distributed practice and practice testing, students can get the impression that these methods are more time-consuming and cost much more effort than crammed learning. This can lead one to distrust the effectiveness of these methods. But, keep in mind, that these methods are better for long-term retention, so they are worth the effort. Also, research has shown that when using these methods repeatedly, effort and time investment will get less.

Because numerous studies have confirmed that these two methods help students to remember content for the long term, and that they also lead to better grades, I would advise that you never go back to crammed learning, but instead, focus on distributed practice and practice testing. 



\title{
Chapter 3
}

\section{Does Individual Performance Feedback Increase the Use of Retrieval Practice?}

This chapter has been published as Hui, L., de Bruin, A. B., Donkers, J., \& van Merriënboer, J. J. (2021). Does Individual Performance Feedback Increase the Use of Retrieval Practice? Educational Psychology Review, () 1-23.

\begin{abstract}
The testing effect - the power of retrieval practice to enhance long-term knowledge retention more than restudying does - is a well-known phenomenon in learning. However, retrieval practice is hardly appreciated by students and underutilized when studying. One of the reasons is that learners usually do not experience immediate benefits of such practice which often present only after a delay. We therefore conducted 2 experiments to examine whether students choose retrieval practice more often as their learning strategy after having experienced its benefits. In Experiment 1, students received individual feedback about the extent to which their 7-day delayed test scores after retrieval practice differed from their test scores after restudy. Those students who had actually experienced the benefits of retrieval practice appreciated the strategy more and used it more often after receiving feedback. In Experiment 2, we compared the shortterm and long-term effects on retrieval practice use of individual performance feedback and general instruction about the testing effect. Although both interventions enhanced its use in the short term, only the individual feedback led to enhanced use in the long term by those who had actually experienced its benefits, demonstrating the superiority of the individual feedback in terms of its ability to promote retrieval practice use.
\end{abstract}

Keywords: retrieval practice, testing effect, feedback, mental effort, perceived learning, perceived utility 


\section{Introduction}

Retrieval practice has been confirmed to significantly enhance learning compared with repeated study (or "restudy"). This phenomenon is known as "the testing effect" (Carpenter, 2009; Grimaldi \& Karpicke, 2014; Rawson \& Dunlosky, 2012; Roediger III $\&$ Karpicke, 2006a). The testing effect has been found not only in laboratory settings during the study of word pairs (Pyc \& Rawson, 2010; Runquist, 1983), face-name pairs (Carpenter \& DeLosh, 2005), symbols or features (Coppens, Verkoeijen, \& Rikers, 2011; Jacoby, Wahlheim, \& Coane, 2010), and text (Endres \& Renkl, 2015), but also in real course settings across different age groups (Carpenter et al., 2017; McDaniel, Anderson, Derbish, \& Morrisette, 2007).

Although studies have shown that some students use retrieval practice, they mostly do so to assess their knowledge level at the end of a study phase rather than during this phase to maximize learning (Geller et al., 2018; Hartwig \& Dunlosky, 2012; Kornell \& Bjork, 2007). Indeed, when making learning strategy decisions, students do not always prefer retrieval practice to restudy, despite the powerful memory benefits it can bring when used as a study tool (Ariel \& Karpicke, 2018; Clark \& Svinicki, 2015; Tullis et al., 2013). This is probably because learners base their learning strategy decisions on perceived learning (also called judgments of learning, JOLs), which can differ greatly from actual learning (Kirk-Johnson et al., 2019; Koriat, 1997; Schwartz, Benjamin, \& Bjork, 1997). More specifically, as students cannot objectively gauge their future learning outcomes, they judge their learning through the subjective feelings generated by the learning strategy used to study the learning material (e.g., feelings of familiarity/fluency) (Bjork et al., 2013; Kirk-Johnson et al., 2019; Yan et al., 2016). Students do not experience immediate feelings of fluency from retrieval practice use, and its long-term memory benefits often present after a delay. Consequently, they do not feel that the strategy has enhanced their learning as much as it actually did (i.e., low JOLs after retrieval practice) (Bjork et al., 2013; Finn \& Tauber, 2015). During restudy, on the other hand, students do experience immediate feelings of fluency which they mistake for actual learning, leading to the misconception that the strategy has enhanced their learning (i.e., high JOLs after restudy) (Bjork et al., 2013; Finn \& Tauber, 2015). As a result of such erroneous retrieval practice beliefs and ensuing perceptions of reduced utility, learners are disinclined to use retrieval practice (Kirk-Johnson et al., 2019). This tendency is confirmed by the expectancyvalue model, which predicts that perceived utility influences an individual's behavior to 
produce positive end states (Rokeach, 1973). Hence, reduced perceived utility may pose an additional barrier to retrieval practice use.

Over the last decade, researchers have actively promoted the use of effective learning strategies such as retrieval practice to enhance learning. However, rather than concentrating on perceived learning as its fundamental factor, these studies focused on how to change erroneous beliefs (see studies Donker et al., 2014; Hattie et al., 1996; Tullis et al., 2013). Since students did not actually experience the benefits of retrieval practice in these studies, it is doubtful whether they would use this strategy more frequently, even after changing their beliefs. This is probably because their perceived learning after retrieval practice is low, and this low perceived learning still dominates their decisions on retrieval practice.

According to Toppino et al. (2018), the underuse of retrieval practice could be down to a metacognitive bias in which learners do not adequately balance the risks of retrieval failure against the potential benefits of retrieval practice. If students experience benefits from retrieval practice use (i.e., the testing effect), for instance by observing performance feedback shows that this strategy leads to better learning compared to restudy, they might use it more often (Einstein et al., 2012) because their actual learning affects their perceived learning. Similarly, students' actual learning could impact their beliefs in retrieval practice. In light of these considerations, we expect that students who have not experienced the benefit of retrieval practice will stick to their previous strategies. In the current study, experiencing the benefits of retrieval practice means that (a) students profit from the testing effect, and (b) are actually aware of this profit.

Although experiencing the benefit of retrieval practice may have the potential to enhance its use, only a handful of studies have been conducted to investigate this. In an effort to enhance retrieval practice use, DeWinstanley and Bjork (2004) asked students the following question about their actual learning after retrieval practice and restudy: "What did you notice about your performance on the previous memory test?" Some students reported results that were at odds with their actual learning outcomes, which demonstrates that they had not effectively experienced the benefits of retrieval practice. Nevertheless, students did become more engaged in retrieval practice after noticing the testing effect. In a similar fashion, Einstein et al. (2012) asked students to take a delayed test after retrieval practice and restudy, and subsequently presented them with the test scores of the whole class for comparison. After they had explained the testing effect to students and gave them the average actual scores of the class which showed a 
testing effect, $82 \%$ of students reported that they were more or much more likely to use retrieval practice. Likewise, Dobson and Linderholm (2015) found that students who had been exposed to the testing effect and encouraged to use retrieval practice performed better on a subsequent test, supposedly because they applied more retrieval practice. Finally, Carpenter et al. (2017) exposed students in an introductory biology course to optional online review questions that could be studied by either retrieval practice or restudy. After students had learned that the average actual scores after retrieval practice were higher than the scores after restudy, the proportion of students choosing retrieval practice increased significantly in the following review phase.

None of the studies discussed above had students experience the benefit of retrieval practice by having them compare their personal learning outcomes after retrieval practice and after restudy, in order to increase their actual strategy use. We therefore conducted two experiments to investigate how the provision of feedback about actual learning outcomes, showing that retrieval practice outperforms restudy, affects learning strategy decisions, i.e., retrieval practice decisions. In Experiment 1, we measured whether students use retrieval practice more often after being given individual feedback about their actual learning outcomes showing that retrieval practice outperforms restudy. In Experiment 2, we investigated whether individual feedback about the testing effect has a stronger impact on retrieval practice decisions than general feedback about the testing effect. To our knowledge, this study is the first to promote the use of retrieval practice by letting students directly experience its benefits.

\section{Experiment 1}

The aim of Experiment 1 was twofold. First, we sought to investigate whether students would use retrieval practice more often after experiencing its benefits by receiving individual feedback about their actual learning outcomes showing that retrieval practice outperforms restudy. Our second aim was to explore the relationship between mental effort and the testing effect, because previous studies have been inconclusive in this regard. It is suggested that retrieval practice requires higher mental effort than restudy, in turn leading to better learning. Such enhanced effort, as mentioned above, might also prevent students from actually using the strategy (Karpicke \& Roediger III, 2007; KirkJohnson et al., 2019; Rowland, 2014). In his review study, Rowland indeed argued that 
effortful processing contributed to the testing effect (2014). At the same time, Endres and Renkl (2015) found that retrieval practice did not require any more investment from students than restudy did. With Experiment 1 we hoped to bring more clarity in this regard.

Participants studied half of the images of human anatomical structures with their Latin name using retrieval practice, the other half using restudy. In the subsequent study of new image-name pairs, participants were free to choose either one of these strategies. After a 7-day interval, a test was taken and participants were informed of their performance after each learning strategy use. Finally, participants were again free to choose a strategy to study new image-name pairs. We hypothesized that:

1. Students' scores for the delayed test would be higher after retrieval practice than after restudy (the testing effect);

2. Students would have higher JOLs after restudy than after retrieval practice (JOLs);

3. Students who had experienced the testing effect would significantly change their beliefs about retrieval practice (retrieval practice beliefs);

4. Students who had experienced the testing effect would more often select retrieval practice compared to those who had not (retrieval practice decisions).

\section{Method}

\section{Participants}

Participants were 68 university students from non-medical faculties ( $M$ age $=20.6 \mathrm{yrs}$, $S D=2.5,56 \%$ female), 29 of whom had studied some human anatomy before university and 39 never had. 56 students were non-native English speakers. Since 54 students had never studied Latin and 65 had never studied ancient Greek, the majority was not familiar with the anatomical names which are often closely related to Latin and/or ancient Greek.

\section{Memory Materials}

Seventy-two image-name pairs of human anatomical structures were used. Images were obtained from a human anatomy study website for medical students (www. anatomylearning.com). The structure names counted 7 to 10 letters. These 72 anatomical image-name pairs were organized into 18 units. Thus, each unit consists of four image- 
name pairs. In a restudying unit, these image-name pairs were shown in four consecutive rounds and participants were asked to memorize them. In a retrieval practice unit, the image-name pairs were only shown in two consecutive rounds, followed by two rounds of retrieval practice (cued recall). The 18 units were displayed in the same order to all participants.

\section{Design}

We used a single-factor, within-subjects design. The single factor was "learning strategy" (retrieval practice vs. restudy). Each participant studied half of the units 1-10 in the restudy condition (restudy units), the other half in the retrieval practice condition (retrieval practice units), and the outcome variable was delayed recall performance after two conditions. For units 11-18, participants were free to choose one of the strategies, and the outcome variable was the percentage of retrieval practice choice.

\section{Measures}

\section{Delayed Recall Test}

As a measure of recall performance, we used the percentage of anatomical names answered correctly at the 7-day delayed test after restudy and retrieval practice.

\section{Mental Effort}

We measured mental effort after each restudy unit and retrieval practice unit by asking the question: "You studied four image-name pairs by restudy/self-testing. How much mental effort did you invest from 1 to 9?", using Paas' 9-point rating scale ( 1 = very, very little mental effort, 9 = very, very much mental effort; see Figure 3.1a) (Paas, 1992). We preferred the term "self-testing" in communicating with participants as this is more common language than "retrieval practice". We consequently calculated the average mental effort that students had rated for restudy units and retrieval practice units.

\section{JOLS}

Students judged their learning after each restudy unit and retrieval practice unit by answering the question: "How many pairs do you think you will still remember after one week?" (see Figure 3.1b). We consequently calculated the average percentage of pairs that students had entered for restudy units and retrieval practice units. 


\section{Retrieval Practice Beliefs}

We measured students' beliefs about retrieval practice by asking the question: "How effective is self-testing in helping you to memorize the anatomic image-name pairs from 1 (extremely ineffective) to 7 (extremely effective)?" (see Figure 3.1c).

\section{Retrieval Practice Decisions}

To measure students' learning strategy decisions on retrieval practice, we asked the multiple-choice question: "Now that you have studied this item twice, do you want to: A. continue restudying, or B. continue self-testing?” Students were free to choose a learning strategy to study the image-name pairs. We consequently calculated the percentage of retrieval practice choice.

\section{Effort Beliefs}

We measured participants' effort beliefs using Blackwell's 7-point Likert scale ( 1 = strongly disagree, 7 = strongly agree) (2003). This scale contains four positive items (e.g., "When something is hard, it just makes me want to work more on it, not less") and five negative items (e.g., "If you're not good at a subject, working hard won't make you good at it”). To create a measure of positive effort beliefs, we reversely scored the negative items and merged them with the positive ones (McDonald's $\omega_{\mathrm{t}}=.74, \mathrm{M}=4.96$, $S D=.66)$.

\section{Procedure}

The procedure is depicted in Figure 1d. The experiment consisted of two parts (Day 1 and Day 8) that were separated by a 7-day interval. Participants were seated in a computer room in groups of 5 to 15 students. They answered questions about demographics, knowledge of Greek and Latin, and prior knowledge of anatomy at the start of the first day. Then they were informed to study the names of human anatomical images and informed that they will be tested for image-name pairs they learned during each phase, and those who performed at the top 50\% would receive a small additional financial compensation. Task difficulty and learning strategy sequence were counterbalanced. As shown in Figure 3.1d, 50\% of the participants started with restudy condition for unit 1 followed by retrieval practice condition for the next unit and another 50\% started with retrieval practice condition for unit 1 followed by restudy condition. 
You studied four image-name pairs by RESTUDYING. How much mental effort did you invest from 1 (very, very low mental effort) to 9 (very, very high mental effort)?

\begin{tabular}{|c|c|c|c|c|c|c|c|c|c|}
\hline (ely, vel & mo & . & $=171$ & (1) & (U) & & & & \\
\hline & 1 & 2 & 3 & 4 & 5 & 6 & 7 & 8 & 9 \\
\hline $\begin{array}{l}\text { Mental } \\
\text { effort }\end{array}$ & • & 당 & - & - & ㅇ & • & - & • & • \\
\hline
\end{tabular}

a. ME (mental effort judgment)

You studied four image-name pairs by RESTUDYING. How many pairs do you think you will still remember after one week?

$b$. JOLs (judgments of learning)

How effective is self-testing in helping you to memorize the anatomic image-name pairs from 1 (extremely ineffective) to 7 (extremely effective)?

\begin{tabular}{l|ccccccc} 
& 1 & 2 & 3 & 4 & 5 & 6 & 7 \\
\hline Self-testing & $\bullet$ & $\bullet$ & $\bullet$ & $\bullet$ & $\bullet$ & $\bullet$ & $\bullet$
\end{tabular}

c. Retrieval practice beliefs measure

Your score of items studied by restudying is: $\mathbf{X}$ out of 8

Your score of items studied by self-testing is: $Y$ out of 8.

Educational researchers have found that selftesting is generally a more effective learning strategy than restudying for enhancing learning performance (scores) and long-term memory.

The score of items that you studied by selftesting is: $(\mathrm{Y}-\mathrm{X}) / \mathbf{8} * \mathbf{1 0 0} \%$ higher than the score of items that you studied by restudying. See a visual depiction of your results in the figure below. Based on these results, we highly recommend that you use self-testing, because this strategy enhances long-term memory (>1 week) best.

$\%$ score

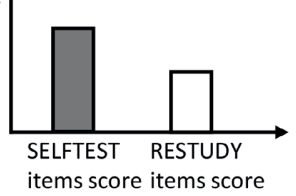

$e$. Individual performance feedback
Demographics and prior knowledge measure

$50 \%$ participants $\quad 50 \%$ participants

learning strategy orientation phase
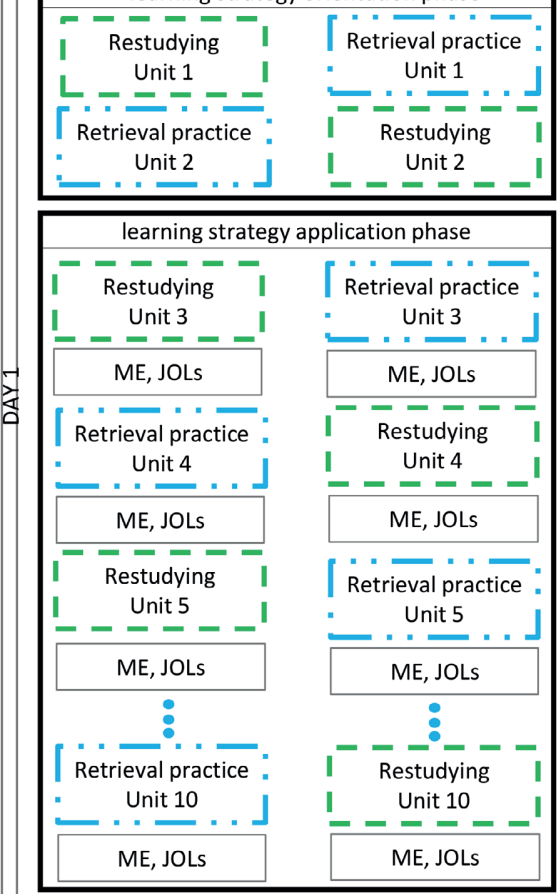

Retrieval practice beliefs measure phase

3 mins distracter

Immediate test phase

(Half of the pairs in Units 3-10)

Learning strategy decisions phase 1 Units 11-14

7 days interval

Performance measure phase (delayed test) (Remaining pairs in Units 3-10)

Individual performance feedback phase

Learning strategy decisions phase 2 Units 15-18

Effort beliefs,

Retrieval practice beliefs measure phase

d. Procedure 
(Left) Figure 3.1. $a$. mental effort measure, $b$. JOLs measure $c$. retrieval practice beliefs measure, $d$. procedure of Experiment $1, e$. individual performance feedback for students who had benefited from retrieval practice. $\mathrm{X}$ and $\mathrm{Y}$ indicate their actual scores after restudy and retrieval practice respectively. (Y-X)/8*100 shows how the score difference was calculated across two strategies. All those values were calculated automatically according to participants' delayed test performance. $\mathrm{ME}=$ mental effort, JOLs = Judgments of learning.

Participants started with a learning strategy orientation phase in which they practiced in the restudy and retrieval practice conditions on units 1 and 2. As Figure 3.2 shows, for a unit under the restudy condition (a restudy unit), four image-name pairs appeared for 8 s on the computer screen in a serial order. The presentation was repeated for four rounds. Participants completed a 15s distracter activity after the second learning round for each unit, in which they were required to write down as many country names as possible that are located in different regions of the world (e.g., "Let's play a game by writing down the names of the countries that surround the Arctic Ocean. You have 15 s to write down as many as you can. We will count the number of countries that you know"). The four image-name pairs in each unit were randomized in a Latin square across the four learning rounds. For a unit under the retrieval practice condition (a retrieval practice unit), four image-name pairs appeared for $8 \mathrm{~s}$ in a serial order for two repeated presentation rounds. Followed by a 15s distracter, participants received two rounds of presentation of the images with the first letter of its anatomical name. Here, they had 8s to complete the name of each image in learning round 3 and 4 . No feedback was provided.

This orientation phase was followed by a learning strategy application phase in which participants studied eight units (units 3-10), four in the restudy condition and another four in the retrieval practice condition (see Figure 3.1d). After each unit, we asked participants to rate their mental effort and provide JOL ratings. Upon completion of this application phase, we first administered the retrieval practice beliefs scale to participants, after which a 3 mins distracter was shown in which they were asked to watch cartoon videos from the Boomerang UK YouTube channel. Participants then took an immediate test consisting of 16 image-name pairs in total (eight from the restudy units, two out of each unit; eight from the retrieval practice units, also two out of each unit). These pairs were randomly chosen from the units and all participants received the same pairs. During this test, 16 images were displayed one by one together with the first letter of their name which participants had to complete. This test had no time limits, nor did 
we provide participants with information about the correct answer. The day ended with the first learning strategy decisions phase in which they studied new image-name pairs from units 11-14. Participants first studied unit 11. Four image-name pairs from this unit appeared for $8 \mathrm{~s}$ in a serial order for two repeated presentation rounds. After the second round of each image-name pair, participants were asked to select a strategy for continuing study by answering: "Now that you have studied this item twice, do you want to: A. continue restudying, or B. continue self-testing?" Hence, after the 15 s distracter in learning rounds 3 and 4 they used the chosen strategy to study each pair. For example, if a participant chose "A. continue restudy" for an image-name pair, this image together with its name would be presented in learning rounds 3 and 4 . If a participant chose "B. continue self-testing", the image with the first letter of its name would be presented in learning rounds 3 and 4 . He or she had $8 \mathrm{~s}$ to complete the name. This process was repeated until participants finished all units from this phase (units 12-14).

On Day 8, participants first took a delayed test consisting of 16 image-name pairs that had not been used in the immediate test to measure their delayed recall performance. The procedure of this delayed test was the same as for the immediate test. We then provided them with individual feedback which showed their 7-day delayed test scores (their actual learning) pertinent to retrieval practice and restudy and how these scores differed across the two learning strategies used. Figure 3.1e shows feedback for students who had obtained a higher score after retrieval practice. For students who had obtained the same or a higher score after restudy, the last sentence of the feedback was changed to "However, based on scientific results, we still highly recommend that you use self-testing, because this strategy enhances long-term memory (>1 week) best."

A second learning strategy decisions phase followed in which participants selected a strategy to study the image-name pairs of units 15-18. This phase was identical with the learning strategy decisions phase 1. As a last step, students completed the effort beliefs and again the retrieval practice beliefs scales. 

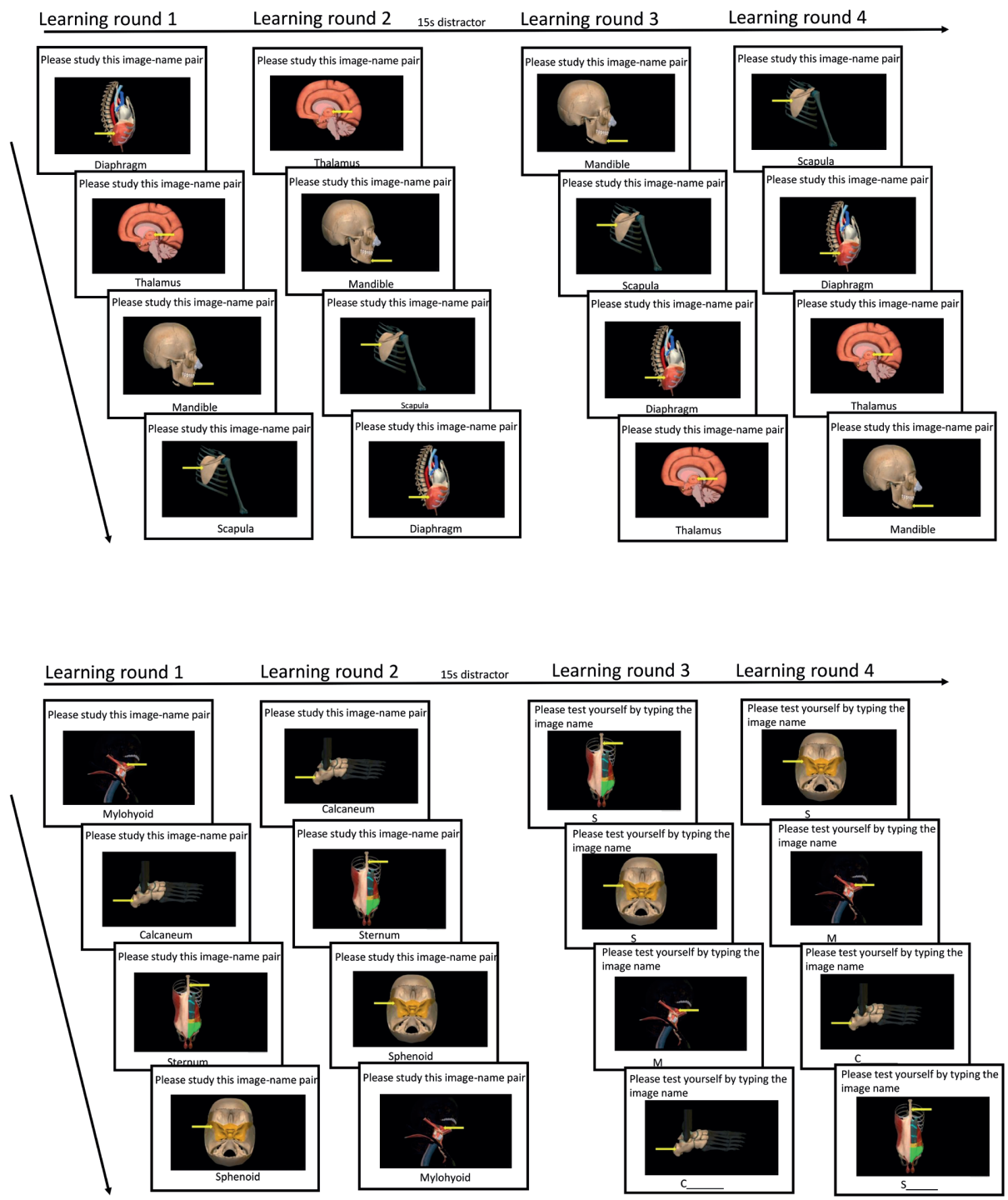

Figure 3.2. Display of the Latin square across four learning rounds of a restudy unit (above) and a retrieval practice unit (below).

All images were obtained from www.anatomylearning.com. 


\section{Data Analysis}

We used SPSS, version 25, to analyze the data. To compare performance between the two learning strategies as well as the retrieval practice beliefs before and after the individual feedback, we ran paired-samples t-tests. A simple linear regression was used to predict the delayed test score based on participants' invested mental effort. Finally, we performed repeated-measures Analyses of Variance (ANOVAs) to compare the retrieval practice decisions before and after receiving feedback. The significance level was set at .05.

\section{Results}

We had to delete the 7-day delayed test data of five participants due to programming errors. In addition, we had to remove all JOLs data of five students because they typed in the incorrect answer to one or more questions (e.g., they typed in "e" rather than a number). Due to time conflicts or illness, three participants dropped out of the 7-day delayed test. See Table 3.1 for a summary of the results. Our preliminary analyses showed that the learning strategy order, knowledge of Greek and Latin, and prior knowledge of anatomy did not affect delayed test scores.

\section{Testing Effect and Mental Effort}

Hypothesis 1 predicted that students' scores for the delayed test would be higher after retrieval practice than after restudy. A paired-samples $t$-test revealed that students indeed performed significantly better after retrieval practice than after restudy $(t(59)=1.99$, $p=.05, d=.25$ ) (see Table 3.1), confirming the testing effect.

As mental effort may play a role in the testing effect, we performed an exploratory analysis to investigate the relationship between mental effort and the testing effect. We found that participants rated higher mental effort during retrieval practice than during restudy $(t(67)=1.97, p=.05, d=.18)$. There was no correlation between effort beliefs and mental effort during retrieval practice $(r=-.04, p=.76)$ or restudy $(r=.06, p=.66)$, which suggests that effort beliefs were not related to the amount of effort invested during the use of either strategy. From this we conclude that the additional mental effort invested for retrieval practice was probably intrinsic to the strategy itself. However, a regression analysis showed that higher mental effort during retrieval practice did not predict a 
higher test score $(F(1,58)=.10, p=.75)$, which suggests that mental effort alone did not explain the testing effect.

\section{JOLs}

Hypothesis 2 predicted that students would have higher JOLs after restudy than after retrieval practice. We found that participants' JOLs were the same across both strategies $(t(62)=.78, p=.44)$.

Table 3.1. Means (and Standard Deviations) of the Variables Measured in Experiment 1

\begin{tabular}{lllll}
\hline & Retrieval practice & Restudy & $t$ & $p$ \\
\hline Initial learning performance $(\mathrm{n}=68)$ & $64.15(24.26)$ & & & \\
Immediate test performance $(\mathrm{n}=68)$ & $47.61(27.43)$ & $38.97(29.97)$ & $2.92^{* *}$ & .01 \\
Delayed test performance $(\mathrm{n}=60)$ & $31.67(22.72)$ & $26.25(21.43)$ & $1.99^{*}$ & .05 \\
Mental effort $(\mathrm{n}=68)$ & $5.94(1.35)$ & $5.68(1.51)$ & $1.97^{*}$ & .05 \\
JOLs $(\mathrm{n}=63)$ & $48.51(22.67)$ & $50.10(24.45)$ & -.78 & .44 \\
\hline
\end{tabular}

Performance and JOLs are expressed as percentages. Initial learning performance indicates the test performance when participants were tested for the first time when learning the imagename pairs from retrieval practice units (which means learning round 3 in this study). JOLs $=$ Judgments of Learning.

$* p \leq .05,{ }^{* *} p \leq .01$

\section{Retrieval Practice Beliefs}

Hypothesis 3 predicted that students who had experienced the testing effect would significantly change their beliefs about retrieval practice. While 25 students obtained a higher score after retrieval practice (retrieval benefit), the scores of 21 students remained the same after retrieval practice and after restudy (same score), and yet another 14 students obtained a higher score after restudy (restudy benefit). Figure 3.3a displays participants' retrieval practice beliefs before and after individual feedback, illustrating that students who had benefited from retrieval practice positively changed their retrieval practice beliefs $(t(24)=4.26, p<.001, d=.56)$. This was not the case for students who had obtained the same score $(t(20)=1.43, p=.17)$, nor for those who had benefited from restudy $(t(13)=-.69, p=.50)$. 


\section{Retrieval Practice Decisions}

Hypothesis 4 predicted that students who had experienced the testing effect would more often select retrieval practice compared to those who had not. Figure $3.3 \mathrm{~b}$ depicts participants' retrieval practice choice before and after receiving the individual feedback. We grouped participants based on the strategy they benefited from. Consequently, we found an interaction effect between the groups and retrieval practice decisions that was statistically significant $\left(F(2,57)=8.42, p<.001, \eta_{p}^{2}=.23\right)$. More specifically, the retrievalbenefit group revealed a significant increase in retrieval practice choice after receiving feedback $(p<.01)$; the same-score group showed no difference in strategy choice between the two measurements $(p=.90)$; and the restudy-benefit group significantly reduced retrieval practice choice after feedback $(p=.01)$, meaning that they more often chose restudy.
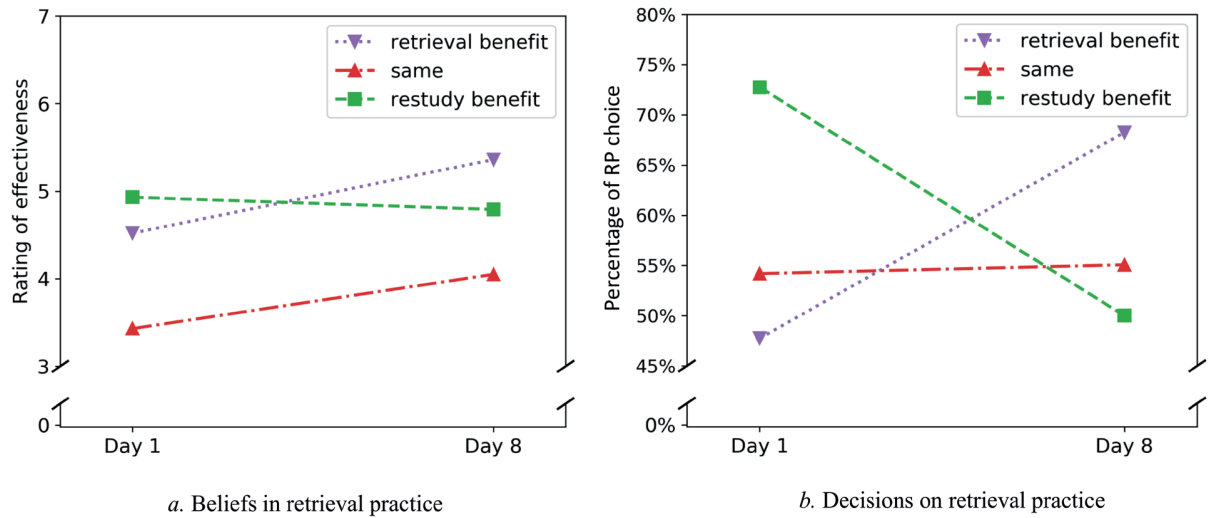

Figure 3.3. $a$. Participants' retrieval practice beliefs rated on a 7-point Likert scale before (Day 1) and after (Day 8) individual feedback, $b$. The percentage of retrieval practice (RP) choice of each participant group (retrieval-benefit, same-score, and restudy-benefit group) before (Day 1) and after (Day 8) individual feedback.

Before receiving individual feedback (Day 1), all of the participants were expected to choose the same amount of retrieval practice. However, Figure 3.3b indicates that the restudy-benefit group chose more retrieval practice than the others at Day 1. Considering the small sample size of this group, it could be due to one or two students not giving good faith responses which leads to this unstable result. There is a big confidence interval for this group, 95\% CI $[56.13,89.40]$ (see the Appendix 3.1). 


\section{Discussion}

With the overarching aim to promote retrieval practice use, Experiment 1 served two main purposes: 1) to investigate the effect of experiencing the benefit of retrieval practice by receiving individual performance feedback showing retrieval practice outperforms restudy; and 2) to explore the relationship between mental effort and the testing effect. Our results indeed showed that retrieval practice has a benefit compared to restudy, confirming Hypothesis 1. We also found that participants invested more mental effort during retrieval practice than during restudy. Yet, as in Endres and Renkl's study (2015), in our experiment mental effort alone could not explain the testing effect. These results contradict Rowland's previous finding that effortful processing during retrieval practice contributed to the testing effect (2014). Considering our small sample size, which resulted in an even smaller retrieval-benefit group $(n=25)$, perhaps a larger sample would have produced more stable results.

Another finding is that we could not confirm Hypothesis 2 predicting that students would have higher JOLs after restudy than after retrieval practice. This seems to conflict with the results of previous studies in which restudy led to feelings of fluency (Kornell \& Son, 2009; Roediger III \& Karpicke, 2006b). We will therefore examine this more in detail in Experiment 2.

Next, our results confirmed Hypothesis 3 predicting that students who had experienced the testing effect would significantly change their retrieval practice beliefs. Students rated retrieval practice as more effective after they had experienced the testing effect, suggesting that the feedback on actual learning outcomes showing the testing effect significantly impacted not only students' retrieval practice decisions, but also their beliefs.

Moreover, we found that, after receiving feedback on actual learning outcomes for retrieval practice and restudy, students who had experienced the testing effect chose retrieval practice more often than those who had not benefited from retrieval practice, confirming Hypothesis 4. Students who had obtained the same or a higher score after restudy, however, still continued to use their previous strategy and chose restudy more often, even though we explained the advantage of retrieval practice in the individual feedback. Hence, consistent with previous studies (DeWinstanley \& Bjork, 2004; Einstein et al., 2012), our findings suggest that individual performance feedback significantly impacts students' retrieval practice decisions, provided they actually benefited from 
the strategy. Without intervention, students intend to use retrieval practice only when they are certain they will answer correctly (Kornell \& Bjork, 2007; Vaughn \& Kornell, 2019). In our study, almost half of the participants benefited from retrieval practice even without knowing whether their answer was correct or not during retrieval practice. Although learning strategy decisions were made on the item-level and the individual performance feedback was global (i.e., across all items after each strategy), this feedback may make students aware of the global mismatch between their perceived learning and actual learning. This global awareness may have influenced decisions on the item-level, which means learners are more inclined to test themselves also on items where they were uncertain of the correct answer. This may also explain why individual performance feedback increased retrieval practice choice only for those who experienced the benefit of retrieval practice.

Nevertheless, a study by Ariel and Karpicke (2018) showed that students may not need to experience the actual benefits of retrieval practice to increase its use. In their study, general instruction stressing the mnemonic benefits of retrieval practice over restudy promoted the use of retrieval practice, even in the long term. Indeed, according to Donker et al. (2014), such general instruction about why and how to use certain learning strategies is a prerequisite for applying learning strategies. However, we agree with Fishbein and Ajzen (1975a) that having this knowledge does not warrant its application in real life. It seems that Ariel and Karpicke's findings do not agree with Fishbein and Ajzen (1975), nor with our results from Experiment 1. We started from the assumption that individual feedback would be more promising than general instruction because the former might enhance students' perceived utility of retrieval practice by demonstrating its actual utility. At the same time, with knowledge gained from the general instruction, university students could still consider retrieval practice as not useful to them, since "knowledge" can be interpreted in many ways (Schommer, 1990). As the perceived utility of a certain learning strategy influences a shift to this strategy (Berger \& Karabenick, 2011; Escribe \& Huet, 2005), general instruction may not be sufficiently powerful to impact retrieval practice decisions. In conclusion, these findings seem to suggest that individual feedback may be more powerful than general instruction in influencing future retrieval practice decisions. 


\section{Experiment 2}

In Experiment 2, we aimed to measure two interventions, specifically the provision of individual performance feedback showing the actual testing effect and general instruction about the testing effect (hereinafter referred to as "general feedback"), in terms of their short-term and long-term effect on increasing retrieval practice choice. Since we wanted to investigate the long-term effects as well, Experiment 2 spanned three days that were again separated by a 7-day interval (Day 1, Day 8, and Day 15). The rest of the procedure was roughly similar to that of Experiment 1, the only difference being that on Day 8, after the delayed test, we divided participants into two groups: group one received feedback on their individual performance; group two received general feedback explaining how retrieval practice was superior to restudy. The learning strategy decisions procedure continued as in Experiment 1 and was repeated On Day 15. In addition to retesting Hypotheses 1 and 2 from Experiment 1, we hypothesized that:

5. Individual feedback would promote the use of retrieval practice among students who had experienced the testing effect, in both the short and long term, and that the general feedback would not (retrieval practice decisions);

6. Compared with the general-feedback group, participants from the individual-feedback group who had experienced the testing effect would consider retrieval practice as more useful (perceived utility). 


\section{Method}

\section{Participants}

Participants were 124 university students ( $M$ age $=20.3 \mathrm{yrs}, S D=2.6,71 \%$ female). We determined the sample size based on the effect size of the testing effect from Experiment 1 $(d=.25)$, meaning that we needed 101 students to achieve a power of at least .80. We oversampled since we expected a high drop-out rate due to the long duration of the study (three weeks). The demographic structure was similar to that of Experiment 1.

\section{Memory Materials}

In addition to the 18 units of Experiment 1, we used another four units in Experiment 2 to measure participants' learning strategy decisions on Day 15.

\section{Design}

We used a mixed two-factor design for Experiment 2, combining a between-subjects factor (individual vs. general feedback) with the same within-subjects factor as in Experiment 1 (retrieval practice vs. restudy). This means that participants either received individual feedback or general feedback. Similar to Experiment 1, for the within-subjects factor, each participant studied half of units 1-10 in the restudy condition, the other half in the retrieval practice condition. For units 11-18 and the newly added four units on Day 15, participants were free to choose one of the strategies.

\section{Measures}

\section{Retrieval Practice Decisions}

We used the same method as in Experiment 1 to measure participants' retrieval practice decisions in the short (Day 8) and long (Day 15) term. We again calculated the percentage of retrieval practice choice on these respective days.

\section{Perceived utility}

Instead of measuring participants' retrieval practice beliefs on Day 1 and 8, we measured their perceived utility on Day 1 and 15 by asking the question "To what extent do you think self-testing is useful in helping you memorize the anatomic image-name pairs?", 
to be scored on a 7-point rating scale ( 1 = extremely useless, 7 = extremely useful). The other variables were measured in the same way as described in Experiment 1.

\section{Procedure}

As mentioned, the experiment spanned three days: Day 1, Day 8, and Day 15. On Day 1, the procedure was identical to Day 1 of Experiment 1, except that participants rated perceived utility rather than retrieval practice beliefs. On Day 8, all participants took a delayed test, after which they were divided into two groups: individual-feedback group and general-feedback group. As in Experiment 1, the individual-feedback group received individual performance feedback, whereas the general-feedback group received general feedback. The individual feedback was identical to the feedback in Experiment 1, the only difference being that the last sentence now read "because this strategy enhances longterm memory (>2 days) best” (changed from: "because this strategy enhances long-term memory [ $>1$ week] best"). The general feedback differed from the individual feedback in that it presented the average rate at which retrieval practice was found superior to restudy, as calculated from the studies by Grimaldi and Karpicke (2014) and Roediger III and Karpicke (2006b), instead of providing students' actual learning outcomes. Figure 3.4 details the general feedback that the general-feedback group received. The rest of Day 8 was the same as Day 8 of Experiment 1. On Day 15, we measured performance on the image-name pairs studied on Day 8 (this performance will not be reported). Then, the two groups completed another learning strategy decisions phase with four new units. Similar to the learning strategy decisions phase 1 and 2 in Experiment 1, participants were asked to select a strategy for each pair for continuing study after learning the second round of each image-name pair. Hence, in learning rounds 3 and 4 they used the chosen strategy to study each pair. The experiment ended with participants rating the perceived utility scale again. 
Educational researchers have found that self-testing is generally a more effective learning strategy than restudying for enhancing learning performance (scores) and long-term memory.

The score of items that students studied by self-testing is about 16.33\% higher than the score of items that they studied by restudying. See a visual depiction of these results in the figure below. Based on scientific research results, we highly recommend that you use self-testing, because this strategy enhances long-term memory ( $>2$ days) best.

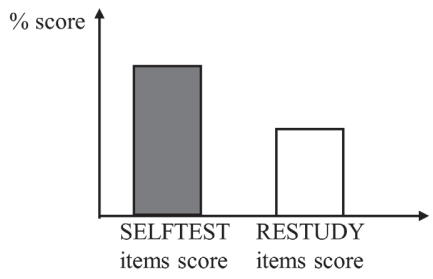

Figure 3.4. General feedback in Experiment 2.

\section{Data Analysis}

The data analysis methods were similar to those of Experiment 1. We used pairedsamples t-tests to analyze how each feedback condition influenced students' decisions in the short term and long term compared to their decisions at the baseline of Day 1. Repeated-measures ANOVAs were used to measure retrieval practice utility as perceived by the general-feedback group and the participants from the individual-feedback group who had actually experienced the testing effect. 


\section{Results}

Three participants dropped out of the Day 8 measurement and another 3 dropped out of the Day 15 measurement. We removed all JOL data of one participant because this participant gave incorrect answers to the JOLs-related questions. See Table 3.2 for a summary of the results.

\section{Testing Effect and Mental Effort}

As in Experiment 1, Hypothesis 1 predicted the testing effect which was confirmed again $(t(120)=3.53, p<.001, d=.36)$. There was no significant difference in invested mental effort between retrieval practice and restudy $(t(123)=.80, p=.42)$, which was not consistent with the results from Experiment 1. Furthermore, mental effort during retrieval practice could not predict the test score after retrieval practice $(F(1,179)=1.10$, $p=.30$ ). These results again suggest that effortful processing does not directly contribute to the testing effect.

\section{JOLs}

As in Experiment 1, Hypothesis 2 predicted that students would provide higher JOLs after restudy than after retrieval practice. We found that students had significantly higher JOLs after restudy than after retrieval practice $(t(122)=5.25, p<.001, d=.33)$, which was not consistent with the results from Experiment 1. 
Table 3.2. Means (and Standard Deviations) of the Variables Measured in Experiment 2

\begin{tabular}{|c|c|c|c|c|}
\hline & Retrieval practice & Restudy & $t$ & $p$ \\
\hline Initial learning performance $(n=124)$ & $60.84(22.50)$ & & & \\
\hline Immediate test performance $(n=124)$ & $41.23(26.34)$ & $35.28(24.18)$ & $2.86^{*}$ & .01 \\
\hline Delayed test performance $(n=121)$ & $29.75(21.67)$ & $22.42(19.02)$ & $3.53^{* * * *}$ & .00 \\
\hline Mental effort $(n=124)$ & $5.83(1.44)$ & $5.76(1.45)$ & .80 & .42 \\
\hline JOLs $(\mathrm{n}=123)$ & $44.44(21.04)$ & $51.45(21.47)$ & $-5.25^{* * * *}$ &.$\circ 0$ \\
\hline \multicolumn{5}{|l|}{ Perceived utility (retrieval benefit, $\mathrm{n}=31$ ) } \\
\hline Before feedback & $5.55(1.31)$ & & \multirow{2}{*}{.71} & \multirow{2}{*}{.48} \\
\hline After feedback & $5.74(1.15)$ & & & \\
\hline \multicolumn{5}{|l|}{ Perceived utility (restudy benefit, $\mathrm{n}=13$ ) } \\
\hline Before feedback & $5.92(.90)$ & & \multirow{2}{*}{$-2.80^{*}$} & \multirow{2}{*}{.02} \\
\hline After feedback & $5.08(1.51)$ & & & \\
\hline \multicolumn{5}{|l|}{ Perceived utility (same score, $\mathrm{n}=17$ ) } \\
\hline Before feedback & $5.53(1.51)$ & & \multirow{2}{*}{-1.29} & \multirow{2}{*}{.22} \\
\hline After feedback & $5.06(1.68)$ & & & \\
\hline \multicolumn{5}{|c|}{ Perceived utility (general feedback, $n=60$ ) } \\
\hline Before feedback & $5.81(1.28)$ & & \multirow{2}{*}{$-2.21^{*}$} & \multirow[b]{2}{*}{.03} \\
\hline After feedback & $5.39(1.67)$ & $J$ & & \\
\hline
\end{tabular}

Performance and JOLs are expressed as percentages. Initial learning performance indicates the test performance when participants were tested for the first time when learning the image-name pairs from retrieval practice units (which means learning round 3 in this study). JOLs = Judgments of Learning; retrieval benefit = students whose scores were higher after retrieval practice than after restudy; restudy benefit = higher scores after restudy.

${ }^{*} p \leq .05,{ }^{* *} p \leq .01,{ }^{* * *} p \leq .001$

\section{Retrieval Practice Decisions}

Hypothesis 5 predicted that individual feedback would promote retrieval practice use among students who had experienced the testing effect, in both the short and long term, and that general feedback would not. In the group that received individual feedback, 31 students had gained a retrieval benefit, 17 students had obtained the same score, and 13 
students had gained a restudy benefit. Based on these results, we divided students into three corresponding subgroups: a retrieval-benefit, same-score, and restudy-benefit group, respectively. Figure 3.5 depicts the average percentage of retrieval practice choice at baseline (Day 1) and in the short term (Day 8) and the long term (Day 15) by students from the general-feedback group and the three individual-feedback subgroups. In the short term, both the general-feedback group $(t(59)=2.43, p=.02, d=.29)$ and the retrieval-benefit group $(t(30)=2.26, p=.03, d=.34)$ chose retrieval practice more often on Day 8 compared to Day 1 at baseline. In the long term, however, only the retrievalbenefit group chose retrieval practice more often on Day 15 compared to the baseline $(t(30)=2.49, p=.02, d=.44)$, which was not the case for the general-feedback group $(t(58)=1.80, p=.08)$. More specifically, the percentage of retrieval practice choice on Day 15 slightly dropped for the general-feedback group while for the retrieval-benefit group it slightly increased, although there was no statistical difference in retrieval practice choice on Day 15 between these two groups $(t(88)=.68, p=.50)$. Hence, our results could not confirm the short-term effect predicted by Hypothesis 5 , but they did confirm the predicted long-term effect.

For the same-score group, we found that neither in the short $(t(16)=.23, p=.82)$ nor in the long term $(t(15)=-.16, p=.88)$ the feedback affected retrieval practice decisions. For the restudy-benefit group, the feedback did not affect retrieval practice decisions in the short $(t(12)=.00, p=1)$ nor in the long $(t(11)=.28, p=.79)$ term. The short-term effect was not consistent with our finding from Experiment 1 that participants who had benefited from restudy chose restudy more often on Day 8. Given the small sample of the restudy-benefit group in both experiments, it is difficult to reach a unified conclusion although participants who benefited from restudy might have displayed a tendency to choose restudy more often. Note that individual feedback in general did not have an impact on retrieval practice decisions. When students were not split up into the three subgroups, individual feedback did not influence retrieval practice decisions both in the short term $(t(60)=1.67, p=.10)$ and in the long term $(t(58)=1.70, p=.09)$. Moreover, when the individual-feedback group was not split up according to learning strategy benefit, there was no difference between the two types of feedback in increasing the retrieval practice choice in the short term $(t(119)=.65, p=.52)$ nor the long term $(t(116)=.04, p=.97)$. 


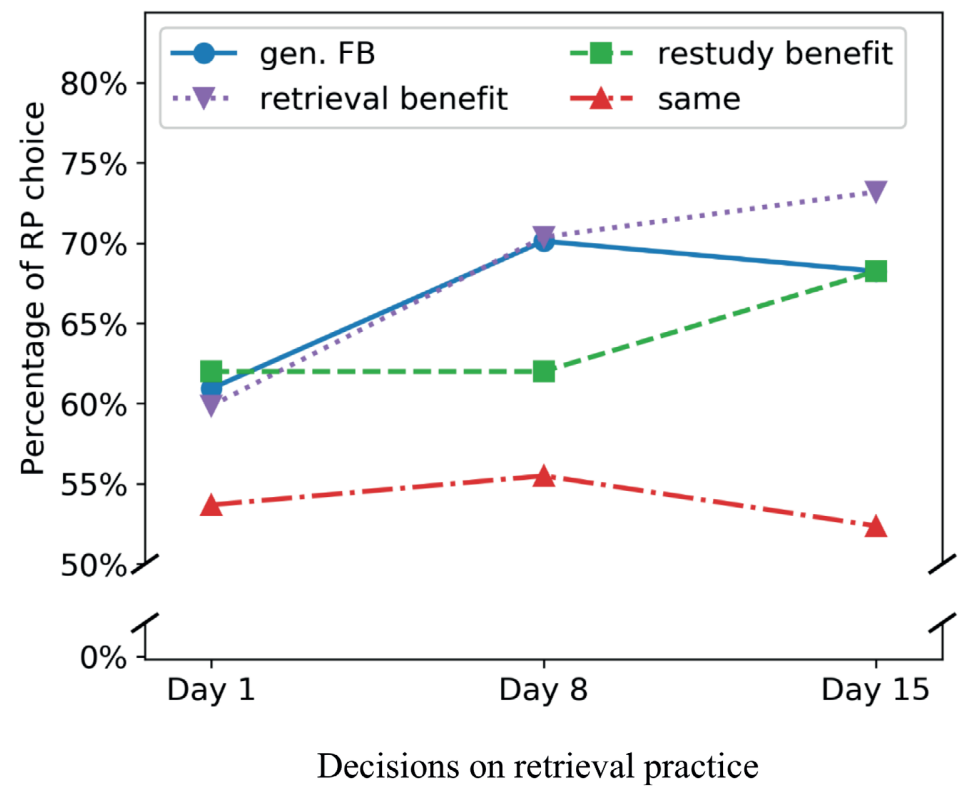

Figure 3.5. The percentage of retrieval practice (RP) choice of each participant group (retrieval-benefit, same-score, restudy-benefit group, and gen.FB) before (Day 1) and after the two types of feedback in both the short (Day 8) and long (Day 15) term. "Gen. FB" = general-feedback group.

\section{Perceived Utility}

Repeated-measures ANOVAs did not confirm Hypothesis 6, which predicted that participants from the individual-feedback group who had experienced the testing effect would consider retrieval practice as more useful than would those from the generalfeedback group, $(F(1,88)=3.45, p=.07)$, although there was a tendency in the expected direction. We explored the perceived utility rating for restudy-benefit and same-score groups. The results showed that the utility of retrieval practice as perceived by the restudy-benefit participants decreased significantly before and after the individual feedback $(t(11)=-2.80, p=.02, d=-.68)$. In the same-score group, by contrast, perceived utility did not change before or after the individual feedback $(t(16)=-1.29, p=.22)$. Combined, these results suggest that feedback on individual performance impacted perceived utility but only to a limited extent. 


\section{Discussion}

In Experiment 2, we measured whether and how the provision of individual or general feedback about the benefits of retrieval practice would impact the use of retrieval practice in the short and long term. Additionally, we measured JOLs and the relationship between the testing effect and mental effort. We confirmed both Hypothesis 1 that retrieval practice would outperform restudy and Hypothesis 2 that students would provide higher JOLs after restudy than after retrieval practice, which we will discuss in the next section.

We also found that both types of feedback inspired students from generalfeedback and retrieval-benefit groups to engage in retrieval practice more often in the short term, partially dismissing Hypothesis 5. Not surprisingly, however, only individual feedback led to an enhanced use of retrieval practice in the long term, provided that participants had actually experienced the testing effect. More details will be discussed in the next section.

Furthermore, Hypothesis 6 was not confirmed, which predicted that participants from the individual-feedback group who had experienced the testing effect would consider retrieval practice as more useful than would the general-feedback group. Since the general-feedback group who had not received any actual performance feedback gave lower utility ratings on Day 15 than Day 1, we might presume that the image-name pairs were too difficult. Students might have thought that whichever strategy they chose, it would not help them learn. This could also explain why students from the individualfeedback group who had experienced the testing effect did not give significantly higher utility ratings. We therefore suggest to investigate in future research how individual performance feedback impacts perceived utility and subsequent retrieval practice decisions by choosing tasks of medium difficulty. Although individual performance feedback did not significantly impact perceived utility, students from the individualfeedback group who had experienced the testing effect did choose retrieval practice more often. Hence, contrary to Rokeach's finding (1973) that perceived utility influences an individual's behavior, our results suggest that being informed about the results of a certain behavior (i.e., higher scores after retrieval practice) has a stronger influence on subsequent behavior (i.e., choosing retrieval practice) than perceived utility has. 


\section{General Discussion}

Across two experiments, the present study investigated how the provision of individual performance feedback showing that retrieval practice outperforms restudy affects students' retrieval practice decisions. We found such individual feedback to significantly impact students' retrieval practice decisions in both the short and long term, provided they actually benefited from retrieval practice. In addition, this study confirmed the testing effect, by demonstrating the mnemonic advantage of retrieval practice as predicted by Hypothesis 1 in both Experiments 1 and 2 .

Unlike previous studies that involved images (e.g., Carpenter, 2009; Coppens et al., 2011; Jacoby et al., 2010) or word pairs (e.g., Ariel \& Karpicke, 2018), however, we did not obtain a large effect size: across both experiments, only about half of the students benefited from retrieval practice. A potential reason could be that, in order to control for prior knowledge, we selected students who were not familiar with human anatomy. Although low prior knowledge is an advantage in certain learning conditions (Kalyuga, 2007; Mayer \& Gallini, 1990), little prior knowledge may have constrained students' elaborative semantic processing during study, in turn stifling the benefits of retrieval practice (Carpenter et al., 2016). Lack of prior knowledge may also increase task difficulty, further hindering students benefit from retrieval practice. In our study, students' initial learning was lower than $65 \%$ across two experiments (see the initial learning performance in Tables 3.1 and 3.2), which indicates that the task they received was, indeed, difficult. In his meta-analysis (2014), Rowland explained that the reliable testing effect was found if students' initial learning is in between 50\%-75\%, and greater retrieval benefit if it is higher than $75 \%$, otherwise students may benefit more from restudy. This also explains why about $26 \%$ of the students benefited from restudy, a finding that is echoed in previous studies.

Effortful processing is a contested explanation for the testing effect (Roediger III \& Karpicke, 2006a; Rowland, 2014). In Kirk-Johnson and colleagues' study (2019), for instance, participants reported that retrieval practice was effort-demanding. However, our data did not provide a strong indication that participants invest more mental effort during retrieval practice than during restudy. These findings echo those of Endres and Renkl (2015), who also measured invested mental effort. Our argument in the Introduction section stated that retrieval practice requires more mental effort. The way to phrase the mental effort question is important because students respond differently 
when asking them for the effort "invested" or the effort "required" (Koriat, Nussinson, \& Ackerman, 2014). We therefore invite future researchers to rephrase the mental effort scale or to measure mental effort objectively by collecting physiological data, for instance using eye trackers. This may provide a better basis for investigating the relationship between mental effort and the testing effect.

We were able to confirm Hypothesis 2 which predicted that students would have higher JOLs after restudy than after retrieval practice in Experiment 2, but not in Experiment 1. This inconsistency may be due to the fact that we asked participants how many pairs out of four they would remember, instead of a percentage like most other studies did. The measurement (o to 4) may make it difficult to distinguish the difference between the two strategies. Despite the potential difficulty, we could still confirm hypothesis 2 after increasing the sample size in Experiment 2. The finding from Experiment 2 resonates with previous studies about feelings of fluency during restudy (Ariel \& Karpicke, 2018; Bjork et al., 2013; Kornell \& Son, 2009; Roediger III \& Karpicke, 2006b). Learners mistook these feelings for "learning" causing them to have higher perceptions of learning after restudy than after retrieval practice and they are not aware of this, in turn hindering the future use of retrieval practice (Kirk-Johnson et al., 2019). Providing feedback about the perceived learning as well as the actual learning may make students realize the mismatching of the perceived learning and the actual learning. Showing this mismatching may have a stronger influence on retrieval practice decisions than only showing the actual learning as we did. This could therefore be an interesting topic of future studies.

The results from Experiment 2 showed that both individual and general feedback caused students (i.e., general-feedback and retrieval-benefit groups) to choose retrieval practice more often in the short term. In the long term, however, only individual feedback made students engage in retrieval practice more often, provided they had actually experienced the testing effect, confirming Hypothesis 5 about the long-term impact of individual feedback on retrieval practice decisions. As previous studies (Carpenter et al., 2017; DeWinstanley \& Bjork, 2004; Dobson \& Linderholm, 2015; Einstein et al., 2012) were already keen to point out, learners use a certain strategy more often if they have noticed the actual benefits of that strategy. Our results indeed suggest that experiencing the testing effect, by observing that retrieval practice outperforms restudy, significantly impacts subsequent retrieval practice decisions in both the short and long term. The individual feedback may have opened students' eyes to the fact that their actual learning 
did not match their perceived learning (Dobson \& Linderholm, 2015), in turn inducing them to base learning strategy decisions on their objective rather than subjective learning (Kirk-Johnson et al., 2019).

However, our results also showed that individual feedback did not have an impact on improving students' choice for retrieval practice, when including students who had benefited from restudy and students who had the same score. Considering only about half of the students from the individual-feedback group experienced the testing effect, this result could have been expected. With more students benefitting from retrieval practice like most of the memory studies showed, we would expect that the individual feedback will have a stronger impact than general feedback on improving the use of retrieval practice. Moreover, our study only showed students individual feedback once. The results of the general-feedback group implicate that the restudy-benefit and samescore groups would benefit more from the general feedback, at least in the short term. However, repeated reinforcement is needed to change behavior (Bai \& Podlesnik, 2017). With more students repeatedly seeing that they obtain higher scores after retrieval practice than after restudy, individual feedback may show its superiority. Comparing the effect on individual and general feedback across multiple sessions could be an interesting direction for future studies. Moreover, studies show that students seek feedback about correct answers after retrieval practice (e.g., Dunlosky \& Rawson, 2015). This implies that providing feedback about correct answers may make retrieval practice more appealing. Future studies could combine individual performance feedback and feedback about correct answers to explore a more effective learning strategy intervention.

As mentioned, the general feedback was not able to promote the use of retrieval practice in the long term. Worse still, the group receiving general feedback in Experiment 2 considered retrieval practice even less useful after having tried the strategy. Since this group had only received instruction about the testing effect and no information about their actual test results, they may have appreciated that retrieval practice is an effective learning strategy and tested its use in the short term. When reconsidering its utility after a while, they may have concluded that retrieval practice was not applicable to them, because in absence of objective learning results they based their judgments on perceived learning. As a result, these students kept their original poor perceptions of the strategy's utility, reverting to their previous strategy in the long term. This finding that general feedback did not impact retrieval practice decisions in the long term does not agree with a study by Ariel and Karpicke (2018). In this study, the instruction explained 
that students should successfully retrieve each Lithuanian-English pair at least three times before the final test, which was administered 45 minutes after initial learning. The clearly quantified times of using retrieval practice (three times) and the relatively short interval between the initial learning phase and the final test (45 mins) may have directed and motivated students to use retrieval practice. These features might have caused a long-term effect in use of retrieval practice, which were not present in our study. However, the final test was conducted only 45 minutes after the initial learning in this study. Since spaced retrieval practice works better than crammed retrieval practice, it will be interesting to measure the effect of Ariel and Karpicke's general instruction when there is a longer time interval between the initial learning and the final test (e.g., a 7-day interval).

Our study has some limitations. First, the image-name pairs used were difficult to memorize. The fact that a relatively large group of students did not experience the testing effect could be a result of this. More importantly, it may also play an essential role in influencing initial learning, and further influencing retrieval practice decisions. However, to make our two experiments comparable, we did not change tasks when we conducted Experiment 2. We suggest that future studies should investigate how task characteristics and initial learning impact learning strategy decisions, by manipulating task difficulty and by using multiple learning strategy decision rounds. Second, as stated before, the way we phrased the mental effort question might have misled participants to judge the effort required by retrieval practice and restudy. We therefore welcome rephrasing the mental effort question or the use of alternative methods, such as the ones previously suggested, to measure mental effort in future studies. Third, all participants received either individual or general feedback across the two experiments. We did not compare results to a no feedback group. The task experience from using retrieval practice and restudy may increase the choice of retrieval practice even without receiving feedback, although previous research in this area (e.g., Karpicke, 2009; Kirk-Johnson et al., 2019) shows that this is not a likely explanation. These studies show that students perceive retrieval practice as less effective than restudy as stated in the Introduction section. However, to measure the extent of the performance feedback effect, it is advisable to include a control group without feedback in future research.

Our study was the first to use individual performance feedback that showed the benefits of retrieval practice to change learning behavior. Moreover, such feedback showed significant promise as a tool to promote retrieval practice use among students 
who had benefited from this strategy. We found that experiencing the benefit of retrieval practice by witnessing its actual learning effects significantly enhanced its use. Educational practitioners seeking to promote the use of certain strategies may want to make their students directly experience the benefits of these strategies as this has been proven to be an effective intervention.

\section{Conclusion}

The present study was the first to underscore the value of individual performance feedback showing the benefits of retrieval practice as a tool to promote its use. Experiencing the testing effect, by receiving individual performance feedback showing that retrieval practice outperforms restudy, impacts students' subsequent retrieval practice decisions, not only in the short but also in the long term. Rather than being impacted by the general instructions we give them, students will choose the learning strategy they benefited from. 


\section{References}

Ariel, R., \& Karpicke, J. D. (2018). Improving self-regulated learning with a retrieval practice intervention. Journal of Experimental Psychology: Applied, 24(1), 43.

Bai, J. Y., \& Podlesnik, C. A. (2017). No impact of repeated extinction exposures on operant responding maintained by different reinforcer rates. Behavioural Processes, 138, 29-33.

Berger, J.-L., \& Karabenick, S. A. (2011). Motivation and students' use of learning strategies: Evidence of unidirectional effects in mathematics classrooms. Learning and Instruction, 21(3), 416-428.

Bjork, R. A., Dunlosky, J., \& Kornell, N. (2013). Self-Regulated Learning: Beliefs, Techniques, and Illusions. Annual Review of Psychology, 64(1), 417-444. doi:10.1146/annurev-psych-113011-143823

Blackwell, L. (2003). Psychological mediators of student achievement during the transition to junior high school: The role of implicit theories.

Carpenter, S. K. (2009). Cue strength as a moderator of the testing effect: the benefits of elaborative retrieval. Journal of Experimental Psychology: Learning, Memory, and Cognition, 35(6), 1563.

Carpenter, S. K., \& DeLosh, E. L. (2005). Application of the testing and spacing effects to name learning. Applied Cognitive Psychology: The Official Journal of the Society for Applied Research in Memory and Cognition, 19(5), 619-636.

Carpenter, S. K., Lund, T. J., Coffman, C. R., Armstrong, P. I., Lamm, M. H., \& Reason, R. D. (2016). A classroom study on the relationship between student achievement and retrieval-enhanced learning. Educational Psychology Review, 28(2), 353-375.

Carpenter, S. K., Rahman, S., Lund, T. J., Armstrong, P. I., Lamm, M. H., Reason, R. D., \& Coffman, C. R. (2017). Students' use of optional online reviews and its relationship to summative assessment outcomes in introductory biology. CBE—Life Sciences Education, 16(2), ar23.

Clark, D. A., \& Svinicki, M. (2015). The effect of retrieval on post-task enjoyment of studying. Educational Psychology Review, 27(1), 51-67.

Coppens, L. C., Verkoeijen, P. P., \& Rikers, R. M. (2011). Learning Adinkra symbols: The effect of testing. Journal of Cognitive Psychology, 23(3), 351-357.

DeWinstanley, P. A., \& Bjork, E. L. (2004). Processing strategies and the generation effect: Implications for making a better reader. Memory \& Cognition, 32(6), 945-955.

Dobson, J. L., \& Linderholm, T. (2015). Self-testing promotes superior retention of anatomy and physiology information. Advances in Health Sciences Education, 20(1), 149-161.

Donker, A. S., De Boer, H., Kostons, D., Van Ewijk, C. D., \& van der Werf, M. P. (2014). Effectiveness of learning strategy instruction on academic performance: A meta-analysis. Educational Research Review, 11, 1-26. 
Dunlosky, J., \& Rawson, K. A. (2015). Do students use testing and feedback while learning? A focus on key concept definitions and learning to criterion. Learning and Instruction, 39, 32-44.

Einstein, G. O., Mullet, H. G., \& Harrison, T. L. (2012). The testing effect: Illustrating a fundamental concept and changing study strategies. Teaching of Psychology, 39(3), 190-193.

Endres, T., \& Renkl, A. (2015). Mechanisms behind the testing effect: an empirical investigation of retrieval practice in meaningful learning. Frontiers in Psychology, 6, 1054.

Escribe, C., \& Huet, N. (2005). Knowledge accessibility, achievement goals, and memory strategy maintenance. British Journal of Educational Psychology, 75(1), 87-104.

Finn, B., \& Tauber, S. K. (2015). When confidence is not a signal of knowing: How students' experiences and beliefs about processing fluency can lead to miscalibrated confidence. Educational Psychology Review, 27(4), 567-586.

Fishbein, M., \& Ajzen, I. (1975a). Intention and Behavior: An introduction to theory and research. In: Addison-Wesley, Reading, MA.

Geller, J., Toftness, A. R., Armstrong, P. I., Carpenter, S. K., Manz, C. L., Coffman, C. R., \& Lamm, M. H. (2018). Study strategies and beliefs about learning as a function of academic achievement and achievement goals. Memory, 26(5), 683-690.

Grimaldi, P. J., \& Karpicke, J. D. (2014). Guided retrieval practice of educational materials using automated scoring. Journal of Educational Psychology, 106(1), 58.

Hartwig, M. K., \& Dunlosky, J. (2012). Study strategies of college students: Are self-testing and scheduling related to achievement? Psychonomic Bulletin \& Review, 19(1), 126-134.

Hattie, J., Biggs, J., \& Purdie, N. (1996). Effects of learning skills interventions on student learning: A meta-analysis. Review of Educational Research, 66(2), 99-136.

Jacoby, L. L., Wahlheim, C. N., \& Coane, J. H. (2010). Test-enhanced learning of natural concepts: Effects on recognition memory, classification, and metacognition. Journal of Experimental Psychology: Learning, Memory, and Cognition, 36(6), 1441.

Kalyuga, S. (2007). Expertise reversal effect and its implications for learner-tailored instruction. Educational Psychology Review, 19(4), 509-539.

Karpicke, J. D. (2009). Metacognitive control and strategy selection: Deciding to practice retrieval during learning. Journal of Experimental Psychology: General, 138(4), 469.

Karpicke, J. D., \& Roediger III, H. L. (2007). Expanding retrieval practice promotes short-term retention, but equally spaced retrieval enhances long-term retention. Journal of Experimental Psychology: Learning, Memory, and Cognition, 33(4), 704.

Kirk-Johnson, A., Galla, B. M., \& Fraundorf, S. H. (2019). Perceiving effort as poor learning: The misinterpreted-effort hypothesis of how experienced effort and perceived learning relate to study strategy choice. Cognitive Psychology, 115, 101237. 
Koriat, A. (1997). Monitoring one's own knowledge during study: A cue-utilization approach to judgments of learning. Journal of Experimental Psychology: General, 126(4), 349.

Koriat, A., Nussinson, R., \& Ackerman, R. (2014). Judgments of learning depend on how learners interpret study effort. Journal of Experimental Psychology: Learning, Memory, and Cognition, $40(6), 1624$.

Kornell, N., \& Bjork, R. A. (2007). The promise and perils of self-regulated study. Psychonomic Bulletin \& Review, 14(2), 219-224.

Kornell, N., \& Son, L. K. (2009). Learners' choices and beliefs about self-testing. Memory, 17(5), 493-501.

Mayer, R. E., \& Gallini, J. K. (1990). When is an illustration worth ten thousand words? Journal of Educational Psychology, 82(4), 715.

McDaniel, M. A., Anderson, J. L., Derbish, M. H., \& Morrisette, N. (2007). Testing the testing effect in the classroom. European Journal of Cognitive Psychology, 19(4-5), 494-513.

Paas, F. G. (1992). Training strategies for attaining transfer of problem-solving skill in statistics: A cognitive-load approach. Journal of Educational Psychology, 84(4), 429.

Pyc, M. A., \& Rawson, K. A. (2010). Why testing improves memory: Mediator effectiveness hypothesis. Science, $330(6002), 335-335$.

Rawson, K. A., \& Dunlosky, J. (2012). When is practice testing most effective for improving the durability and efficiency of student learning? Educational Psychology Review, 24(3), 419-435.

Roediger III, H. L., \& Karpicke, J. D. (2006a). The power of testing memory: Basic research and implications for educational practice. Perspectives on Psychological Science, 1(3), 181-210.

Roediger III, H. L., \& Karpicke, J. D. (2006b). Test-enhanced learning: Taking memory tests improves long-term retention. Psychological Science, 17(3), 249-255.

Rokeach, M. (1973). The nature of human values: Free press.

Rowland, C. A. (2014). The effect of testing versus restudy on retention: A meta-analytic review of the testing effect. Psychological Bulletin, 140(6), 1432.

Runquist, W. N. (1983). Some effects of remembering on forgetting. Memory \& Cognition, 11(6), 641-650.

Schommer, M. (1990). Effects of beliefs about the nature of knowledge on comprehension. Journal of Educational Psychology, 82(3), 498.

Schwartz, B. L., Benjamin, A. S., \& Bjork, R. A. (1997). The inferential and experiential bases of metamemory. Current Directions in Psychological Science, 6(5), 132-137. 
Toppino, T. C., LaVan, M. H., \& Iaconelli, R. T. (2018). Metacognitive control in self-regulated learning: Conditions affecting the choice of restudying versus retrieval practice. Memory \& Cognition, 46(7), 1164-1177.

Tullis, J. G., Finley, J. R., \& Benjamin, A. S. (2013). Metacognition of the testing effect: Guiding learners to predict the benefits of retrieval. Memory \& Cognition, 41(3), 429-442.

Vaughn, K. E., \& Kornell, N. (2019). How to activate students' natural desire to test themselves. Cognitive Research: Principles and Implications, 4(1), 35.

Yan, V. X., Bjork, E. L., \& Bjork, R. A. (2016). On the difficulty of mending metacognitive illusions: A priori theories, fluency effects, and misattributions of the interleaving benefit. Journal of Experimental Psychology: General, 145(7), 918. 


\section{Appendix 3.1}

Means and 95\% CIs for figures

\begin{tabular}{|c|c|c|c|}
\hline & Day 1 & Day 8 & Day 15 \\
\hline \multicolumn{4}{|c|}{ Learning strategy beliefs (Figure $3.3 \mathrm{a}$ ) } \\
\hline $\begin{array}{l}\text { Retrieval-benefit } \\
\text { group }\end{array}$ & $\begin{array}{l}4.52(1.74), \\
95 \% \text { CI }[3.87,5.18]\end{array}$ & $\begin{array}{l}5.36(1.22), \\
95 \% \text { CI }[4.80,5.92]\end{array}$ & \\
\hline $\begin{array}{l}\text { Same-score } \\
\text { group }\end{array}$ & $\begin{array}{l}3.43 \text { (1.75), } \\
95 \% \text { CI }[2.71,4.14]\end{array}$ & $\begin{array}{l}4.05(1.63), \\
95 \% \text { CI }[3.44,4.66]\end{array}$ & \\
\hline $\begin{array}{l}\text { Restudy-benefit } \\
\text { group }\end{array}$ & $\begin{array}{l}4.93(1.21), \\
95 \% \text { CI }[4.05,5.80]\end{array}$ & $\begin{array}{l}4.79 \text { (1.31), } \\
95 \% \text { CI }[4.04,5.53]\end{array}$ & \\
\hline \multicolumn{4}{|c|}{ Learning strategy decisions in Exp 1 (Figure 3.3b) } \\
\hline $\begin{array}{l}\text { Retrieval-benefit } \\
\text { group }\end{array}$ & $\begin{array}{l}47.75(31.14) \\
95 \% \text { CI }[35.30,60.20]\end{array}$ & $\begin{array}{l}68.28(30.02), \\
95 \% \text { CI }[54.98,81.52]\end{array}$ & \\
\hline $\begin{array}{l}\text { Same-score } \\
\text { group }\end{array}$ & $\begin{array}{l}54.17(36.03), \\
95 \% \text { CI }[40.59,67.75]\end{array}$ & $\begin{array}{l}55.06(37.01), \\
95 \% \text { CI }[40.59,69.53]\end{array}$ & \\
\hline $\begin{array}{l}\text { Restudy-benefit } \\
\text { group }\end{array}$ & $\begin{array}{l}72.77(21.17) \\
95 \% \text { CI }[56.13,89.40]\end{array}$ & $\begin{array}{l}50.00(32.24), \\
95 \% \mathrm{CI}[32.27,67.73]\end{array}$ & \\
\hline \multicolumn{4}{|c|}{ Learning strategy decisions in Exp 2 (Figure 3.5) } \\
\hline $\begin{array}{l}\text { Retrieval-benefit } \\
\text { group }\end{array}$ & $\begin{array}{l}59.88(29.26), \\
95 \% \text { CI }[49.15,70.61]\end{array}$ & $\begin{array}{l}70.36(31.83), \\
95 \% \text { CI }[58.69,82.04]\end{array}$ & $\begin{array}{l}73.19(31.26), \\
95 \% \text { CI }[61.72,84.65]\end{array}$ \\
\hline $\begin{array}{l}\text { Same-score } \\
\text { group }\end{array}$ & $\begin{array}{l}53.91(31.94) \\
95 \% \text { CI }[36.89,70.93]\end{array}$ & $\begin{array}{l}58.20(39.18) \\
95 \% \text { CI }[37.33,79.08]\end{array}$ & $\begin{array}{l}52.34(37.63) \\
95 \% \mathrm{CI}[32.29,72.40]\end{array}$ \\
\hline $\begin{array}{l}\text { Restudy-benefit } \\
\text { group }\end{array}$ & $\begin{array}{l}67.19(34.35), \\
95 \% \text { CI }[45.36,89.01]\end{array}$ & $\begin{array}{l}64,58 \text { (26.29), } \\
95 \% \text { CI }[47.88,81,29]\end{array}$ & $\begin{array}{l}68.23(34.79), \\
95 \% \text { CI }[46.12,90.34]\end{array}$ \\
\hline $\begin{array}{l}\text { General-feedback } \\
\text { group }\end{array}$ & $\begin{array}{l}61.04(33.02), \\
95 \% \text { CI }[52.51,69.57]\end{array}$ & $\begin{array}{l}68.44(31.44), \\
95 \% \text { CI }[60.32,76.56]\end{array}$ & $\begin{array}{l}67.08(34.69), \\
95 \% \mathrm{CI}[58.12,76.04]\end{array}$ \\
\hline
\end{tabular}





\section{Chapter 4}

\section{Why Students Do (or Do Not) Choose Retrieval}

Practice: Their Perceptions of Mental Effart During Task Performance Matter

This chapter is under revision as Hui, L., de Bruin, A. B., Donkers J. (2021). Why Students Do (or Do Not) Use Retrieval Practice:

Abstract

Although retrieval practice is a more effect learning trategy than restudy, students oftentimes prefer the latter duriy se regorning. Previous studies have investigated this suboptimal d sion level. The present study, however, focused on the learning task level: A perceived mental effort and perceived learning during task performance in uentroarng strategy decisions. Participants rated their mental effort and 10 ing $\Lambda$ memorizing anatomical image-name tasks, choosing either retrieval actid res for each task. Moreover, the actual learning after each strate yas asured or each participant and presented as feedback. The results suggested tha hased perceived mental effort was directly related to reduced

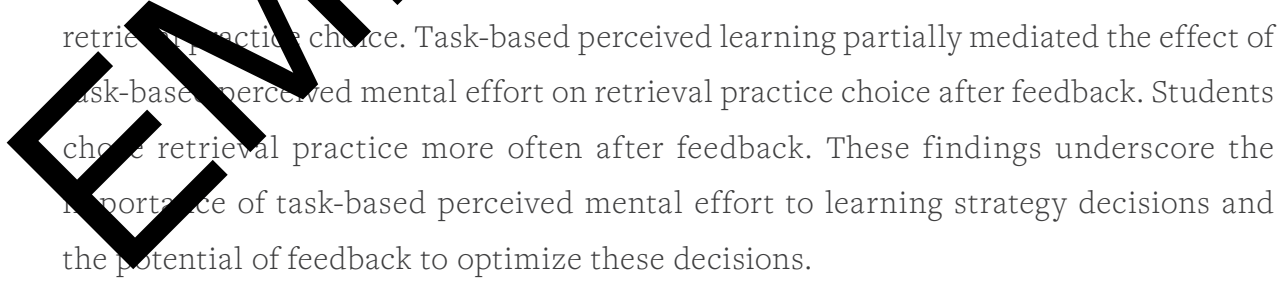
Keywords: retrieval practice, perceived learning, perceived mental effort, feedback 


\section{Chapter 5}

\section{Self-Regulation of Flow: Creating "Seemingly}

Effortless" Learning

This chapter is submitted as Hui, L., Rovers. S. F., van Merriënboer, J. J., Don S S, J., \& de uin, A. B. (2021). Self-Regulation of Flow: Creating "Seemingly Effortless" Carning Many ript
submitted for publication.

\section{Abstract}

During self-regulated learning, students ray regte learning-related factors to increase the chances of reaching flow stat In this st e, people completely focus on an activity without self-consciousp os, igut nental effort. Being in flow state leads to an optimal learning ex riend werning performance. While conditions that promote flow have been well do ribed, it is unclear if and how students can selfregulate learning-related fary their chances of encountering flow. In this review, we analyze bich f ors known to promote flow can be self-regulated and how those fact can to reach a flow state. We found that factors from four cluster an regul ed: (1) metacognitive strategies such as timely feedback seeking, (2) b a e bu challenge and skill, (3) motivation, and (4) attention. To incre ch nof encountering flow, students should (1) actively seek feedback Ased on grnms goals, reflect on their learning and apply appropriate cognitive and me Cognitiv learning strategies, (2) choose challenging tasks based on their current (3) set clear goals and stay committed to them, and (4) control the learning env.nment to enhance focused attention by reducing distraction. This self-regulation process takes effort but may influence the way students interpret this effort. They may perceive that the effort they put into an activity is minimal because they interpret effort as valuable to achieve their goals. As a result, flow is only a seemingly effortless state, which may be regulated by the way effort is interpreted.

Keywords: flow, self-regulation, mental effort, metacognitive strategy, balance of challenge and skill, attention 


\section{Chapter 6}

General Discussion 
This dissertation has investigated how to foster self-regulated learning in higher education by helping students to engage in more effective learning strategies and by identifying known factors that can be self-regulated to facilitate flow. Five studies were conducted to answer this central question. This General Discussion section summarizes the main findings from these studies and addresses the theoretical considerations, strengths and limitations, and practical implications of these findings. At the end, the main conclusion is presented.

\section{Main Findings}

The first study (Chapter 2) investigated whether a behavioral-change strategy (the use of narratives) can stimulate students' intention to switch to effective learning strategies and to enhance their awareness of desirable difficulties more than a didactical approach can. The results showed that narratives and didactic communication did not differ in their change of erroneous beliefs and stimulation of intentions to change. However, more students in the narrative group became aware of the importance of desirable difficulties (i.e., that effective learning strategies require more effort and are more difficult but benefit learning in the long run). These results help to answer the central question by revealing that the use of narratives can enhance the uptake of effective learning strategies. Being aware of desirable difficulties may help students to accept the perceived effort from using effective learning strategies and have a more goal-driven perspective when judging effort (i.e., higher perceived effort means higher learning performance). Knowing that the extra effort is valuable may also motivate students to regulate their effort towards desirable difficulties. This may enhance the use of effective but effortful learning strategies.

In Chapter 3, findings from the second and third study were reported. The second study investigated whether giving individual feedback on actual learning outcomes enhanced the use of retrieval practice. The third study compared the short-term and long-term effects of providing individual feedback and general feedback about the testing effect on the use of retrieval practice. Students who had experienced the benefits of retrieval practice chose this strategy more often after receiving individual feedback. General feedback only enhanced the use of retrieval practice in the short term, whereas individual feedback increased the short- and long-term use of retrieval practice in 
students who had experienced its benefits. Moreover, students gave higher judgments of learning after restudy than after retrieval practice, but the perceived mental effort of the two strategies were not statistically different. This may be due to the goal-driven perspective of the effort judgment (we might have unintentionally nudged students towards a goal-driven interpretation of effort by asking them about the mental effort they actively invested during restudy and retrieval practice). These results help to answer the central question because they show that individual feedback can promote the use of retrieval practice. Students were inclined to choose the learning strategy they benefited from and were not influenced by general feedback on demonstrating the retrieval practice benefit.

The fourth study (Chapter 4) investigated the effects of individual feedback on enhancing the use of retrieval practice. It also investigated how factors at the task level influenced learning strategy decisions. Similar to results of the second and third studies, students who had benefited from retrieval practice chose this strategy more often after receiving individual feedback. In addition, the perceived mental effort at the learning task level directly influenced the decision to use retrieval practice before and after individual feedback. More specifically, higher perceived mental effort at the task level reduced the uptake of retrieval practice. Unexpectedly, perceived learning at the task level did not influence learning strategy decisions before individual feedback was received. After individual feedback was received, learning strategy decisions were only partially affected by perceived learning - the perceived mental effort at the task level still had the dominant effect on these decisions. Moreover, students perceived better learning after restudy than after retrieval practice and they perceived lower mental effort during restudy than during retrieval practice. This study demonstrated a fundamental problem in students' learning-strategy decisions. It indicated that students adopt a data-driven perspective when deciding which learning strategy to use - when they experience high effort, they relapse to a strategy that requires less cognitive engagement, such as restudy.

The fifth study (Chapter 5) was a literature review to investigate which factors known to promote flow can be self-regulated by students, and how these factors can be regulated to facilitate the occurrence of flow. Four main factors were identified that can be regulated by students to increase occurrence of flow: (1) metacognitive strategies such as seeking timely feedback, (2) balance between challenge and skill, such as how difficult a task is, (3) motivation, such as being persistent on clear goals, and (4) attention, such as to what extent students focus on learning. Flow-facilitating strategies included 
seeking feedback on learning goals, applying appropriate learning strategies, selecting challenging tasks based on current skill level, setting clear goals and staying committed, and reducing distraction in the learning environment to enhance focused attention. Students can apply these flow-facilitating strategies to self-regulate their learning and increase their chance of achieving flow. This self-regulation process requires effort, but students may interpret this effort as worthy because it helps them to achieve their goals. In this way, self-regulation reduces perceived effort and learners may even feel that task performance and learning is "effortless". This confirms the importance of how effort is interpreted. This study worked from the solution (an optimal self-regulated learning state) back to the problem (not using effective but effortful learning strategies) and showed that students can self-regulate entering an "effortless" flow state, and that this may give students more mental resources to apply effortful learning strategies.

Overall, this dissertation shows how higher-education students can optimize their self-regulated learning by using more effective learning strategies and by self-regulating certain factors to facilitate flow as follows. Showing students narratives of peers who switched to and benefited from effective learning strategies helped students to become aware of desirable difficulties; they realized that effective learning strategies take effort but that this effort is worth it because it improves learning outcomes. Individual feedback on learning outcomes increased the uptake of retrieval practice in students who benefited from it, despite the high mental effort involved. In other words, students were willing to use effortful learning strategies if they visibly enhanced their performance and if these helped them achieve their learning goals. Thus, individual feedback may create a goal-driven perspective of learning, indicating that learners are willing to invest effort if they benefit from doing so or if doing so is in line with their goals. Without intervention, students are more likely to take a data-driven perspective when making learning strategy decisions - the high perceived mental effort of the learning task reduces the chance of choosing an effortful learning strategy such as retrieval practice.

Finally, the self-regulation of flow facilitators may lead to a goal-driven interpretation of effort and a seemingly effortless state during learning since the investment of effort is fully in line with the students' goals. With a goal-driven perspective, learners may use effortful learning strategies and put extra effort into achieving their goals; and they do not experience this effort as such because the effort is fully in line with reaching their goals. Therefore, flow regulation may be a particularly important element in optimizing self-regulated learning. 


\section{Theoretical Considerations}

This dissertation contributes to our knowledge of self-regulated learning by showing the importance of perceived mental effort. Perceived mental effort from learning strategies and learning tasks affects which learning strategies the student decides to use. Perceived mental effort of learning tasks was found, for the first time to our knowledge, to be crucial for making learning strategy decisions. This empirical finding is in line with several recent theoretical articles indicating the potential impact of perceived mental effort of learning tasks on self-regulated learning (Scheiter et al., 2020; Seufert, 2020; van Gog et al., 2020). Nelson's metacognition model (Nelson, 1990) and de Bruin et al.'s effort monitoring and regulation framework (de Bruin, Roelle, Carpenter, Baars, \& EFG-MRE, 2020) suggest that students control and regulate their learning (e.g., making learning strategy decisions) based on cues from the meta level, such as perceived learning. Perceived learning is generated using cues from the object level, such as perceived mental effort of learning tasks. However, I have shown that students do not use cues in line with these models. Perceived learning did not affect learning strategy decisions; instead, perceived mental effort directly impacted learning strategy decisions and high perceived mental effort reduced the chances of the student choosing an effective but effortful strategy. Future studies could further investigate (for example by using think aloud) which cues students use to make learning strategy decisions and why. More importantly, future studies should determine how to increase the use of more valid cues during selfregulated learning.

How mental effort should be measured is another important question (Baars et al., 2020; Koriat et al., 2014; Scheiter et al., 2020). Students were often asked to rate their mental effort subjectively (perceived mental effort) and these subjective metacognitive judgments may have been biased (Scheiter et al., 2020). How metacognitive judgment of mental effort is measured might affect whether students perceive their effort as data-driven or goal-driven (Koriat, 2018; Koriat et al., 2014). Data-driven effort is passively experienced effort required for learning tasks and high data-driven effort is being interpreted as learning less. In contrast, goal-driven effort is actively invested effort in the learning tasks and high goal-driven effort is being interpreted as learning more (Seufert, 2018, 2020). These types of effort are comparable to ineffective and effective learning strategies since they consider learners as passive or active information processors, respectively (Biwer et al., 2020). In Chapters 3 and 4, students were asked 
to rate their mental effort by using "invested effort" or "required effort", respectively. Asking for "invested effort" and "required effort" might have led to different results, since "invested effort" is actively produced while "required effort" is experienced passively (Klepsch \& Seufert, 2021). This echoes previous findings (Koriat, 2018; Koriat et al., 2014) that the interpretation of goal- or data-driven mental effort affects how that effort is evaluated.

In the context of self-regulated learning, different evaluations of mental effort caused by goal- or data-driven effort perspectives are important because they influence how students control and self-regulate their mental effort and their learning (de Bruin et al., 2020; Koriat, 2018). All models of self-regulated learning consider self-regulated learning to be goal-driven and self-regulation to be goal-directed (Panadero, 2017). Yet, students seem to be more data-driven than these models assume (Baars et al., 2020; Koriat et al., 2014; Panadero, 2017). Students with a data-driven perspective avoid the use of effortful but effective learning strategies because of the high cognitive load, without acknowledging the positive effects of these strategies on learning. Learners view this effort as a cost, so are more likely to save their effort, reducing their learning performance even further (Kurzban, Duckworth, Kable, \& Myers, 2013). This reflects a lack of awareness of desirable difficulties. Changing the students' perspective on mental effort to a goal-driven one would help them to see effort as an investment, further stimulate students to actively engage in effortful learning strategies, and improve their learning performance.

This dissertation has revealed ways to help students switch from a data-driven to a goal-driven perspective when interpreting effort. First, the individual feedback on learning performance encouraged students to continue using an effective but effortful learning strategy if it had benefited them before. Essentially, students who achieved higher scores after investing the extra effort by using a more effort-demanding strategy were further motivated to engage this strategy more often in subsequent studies - a typical goal-driven behavior. This finding is in line with previous work on agenda-based regulation (about how students allocate their study time), which found that students allocate more time to their studies if they anticipate gaining rewards and achieving learning goals (Ariel et al., 2009). If individuals see the potential reward, they might engage effort in a task, such as working harder to achieve career goals (Kurzban et al., 2013). 
Second, hearing about a peer's positive learning results after using effective but effortful learning strategies increased the awareness of desirable difficulties. These peer narratives may also help learners switch to a goal-driven perspective when judging effort because they interpret the high perceived mental effort of using effective learning strategies as valuable (Inzlicht, Shenhav, \& Olivola, 2018; Reber \& Greifeneder, 2017).

Third, the self-regulation of flow facilitators (e.g., using metacognitive strategies) may also help learners switch to a goal-driven perspective when judging effort. Although students put vast effort into learning during flow regulation, this active regulation process (e.g., choosing to focus on the task at hand and pursuing their goals) makes them feel that their effort is valuable and acceptable and that their perceived effort is reduced or even absent (Swann et al., 2019; Swann et al., 2016). This “effortless" state has a positive effect on their learning process and may increases their perceived mental resources, making them willing to engage in effortful learning strategies. In this way, flow regulation can regulate how much effort is invested by helping the student to interpret effort from a goal-driven perspective.

These three potential strategies for switching from a data-driven to a goal-driven perspective when judging effort both encourage learners to add value to effort during regulation. However, there are two dimensions to effort regulation. The first dimension is to accept effort by receiving individual feedback and becoming aware of desirable difficulties. The second dimension is to reduce effort by regulating flow facilitators in order to perceive having more mental resources to engage in more effortful learning strategies. This dissertation stresses the importance of regulating how effort is judged/ perceived to promote the use of effective but effortful learning strategies. The regulation of flow nicely fits with the theoretical model "effort monitoring and regulation", which integrates cognitive load theory and self-regulated learning theory (de Bruin et al., 2020). To explore this model, authors of ten articles in a special issue in Educational Psychology Review (2020, issue 4) discussed the relationship between regulating mental effort and self-regulated learning and stressed the importance of monitoring and regulating effort during self-regulated learning. Along the same line, this dissertation not only shows how students monitor and control their learning by using effort as a cue when choosing learning strategies, but also provides practical strategies for regulating effort. In agreement with the findings of Eitel, Endres, and Renkl (2020), Seufert (2020), and van Gog et al. (2020), this dissertation shows the importance of task-based mental effort and the importance of students choosing medium-difficult learning tasks that are 
balanced with their knowledge for effective effort regulation. Choosing challenging tasks that match the current skill level (the "zone of proximal development") (Vygotsky, 1980) may be a key starting point for regulating effort and optimizing self-regulated learning.

The research on effort regulation reported in this dissertation was performed before or during the studies reported in the special issue. Like the findings reported in this special issue, the results of this dissertation also provide a useful basis for future research. However, the influence of mental effort on self-regulated learning is not fully appreciated and requires further study, as stated by van Gog et al. in the special issue: "what we currently know very little about, is to what extent students consider mental effort when making regulation decisions" (van Gog et al., 2020, p. 1060). Future studies should continue investigating how mental effort influences monitoring and regulation and how to regulate effort by accepting effort and reducing (perceived) effort. In addition, future work should determine how to optimize interpretation of effort to foster self-regulated learning. To answer these questions, we must investigate how learners judge their effort and how this judgment is biased. We must also explore objective measurements of mental effort and cognitive load since these are fundamental for research on effort regulation and self-regulated learning. Qualitative studies could be performed to investigate what cues students use to judge effort with goal-driven and data-driven perspectives. Based on these results, researchers could go on to explore unbiased ways of measuring mental effort. Researchers could also create tasks of different difficulties to manipulate mental effort at the objective level and show how objective mental effort influences perceived mental effort and regulation decisions.

\section{Strengths and Limitations}

A strength of this dissertation is that it tried to change ineffective learning strategies from a behavior-change perspective using narratives. After years of using certain learning strategies, students have established learning behaviors (Fiorella, 2020) and changing from these ineffective learning strategies to more effective ones requires a change in behavior. Chapter 2 demonstrated how a behavioral change technique, namely, the use of narratives, can help students become aware of desirable difficulties.

The second strength is that the studies reported in this dissertation addressed perceived learning versus actual learning for the first time by providing individual 
performance feedback. Learners use ineffective learning strategies because of the perceived learning versus actual learning paradox. This means they perceive poor learning after using effective learning strategies but better learning after using ineffective learning strategies, when in fact it is the other way around. Since this paradox is generated from subjective and individual experiences, it can only be addressed by giving individual feedback on actual learning performance to show that effective strategies improve test scores. These findings emphasize the importance of the learners' own experiences in changing their learning behaviors.

The third strength of this dissertation is that it has built on previous suggestions that task-based factors, including task-based perceived mental effort and perceived learning, influence learning strategy decisions (Karpicke, 2009; Son \& Metcalfe, 2000; Vaughn \& Kornell, 2019). The study described in Chapter 4 measured whether and to what extent task-based factors influence learning strategy decisions. After participants worked on a task, their task-based perceived mental effort, task-based perceived learning, and choice of learning strategy were immediately recorded. In this way, I measured selfregulated learning in real time. This study provides a fundamental basis for future studies on self-regulated learning and on promoting uptake of effective learning strategies in ecologically valid settings.

The fourth strength of this work is that it took this area of research in a more practical direction. Like self-regulated learning, flow experience is shaped by the interactions between a person and their environment (Nakamura \& Csikszentmihalyi, 2014). The study in Chapter 5 focused on which and how facilitators of flow can be self-regulated. In this dissertation, flow was conceptualized as a goal-driven and selfregulated seemingly effortless state. In flow regulation processes, learners value their effort because exerting effort challenges them and brings them enjoyment (Inzlicht et al., 2018). Although exerting effort to self-regulate flow facilitators cannot guarantee a flow state, this novel perspective of valuing effort to reduce perceived effort indicates that a new research line for self-regulated learning and effort regulation exists. Future studies could measure how much the regulation of flow facilitators increases the chance of achieving flow and increases the uptake of effective but effortful learning strategies in a flow state.

There are also some limitations to this work. The perceived learning versus actual learning paradox demonstrates a mismatch between perceived learning and actual learning and has attracted attention over the last years (Biwer et al., 2020; Kirk-Johnson et al., 2019). 
A recent study reported how this paradox impeded the use of effective learning strategies (Biwer et al., 2020). In Chapters 3 and 4, I investigated whether addressing the perceived learning versus actual learning paradox increases retrieval practice uptake. However, only the actual learning was included in the individual feedback and there was no option to directly compare the mismatch between perceived learning and actual learning. Since students reported higher perceived learning after restudy than after retrieval practice, showing the mismatch may have increased the intervention effect. Future studies could present information about perceived learning and actual learning at the same time to promote the uptake of effective learning strategies.

An awareness of desirable difficulties is essential for using effortful but effective learning strategies and is essential for regulating effort in self-regulated learning (Bjork et al., 2013; Carpenter, Endres, \& Hui, 2020; de Bruin et al., 2020). Another limitation of this dissertation is that it only investigated how to gain awareness of desirable difficulties without measuring how and to what extent this awareness helps the regulation of effort by engaging effective but effortful learning strategies. Future studies could conduct experiments to measure the relationship between this awareness and the proactive creation of learning conditions that create desirable difficulties, which is the use of effective but effortful learning strategies.

\section{Practical Implications}

The primary practical aim of this dissertation was to help students self-regulate their learning so that they choose effective learning strategies and increase their chances of achieving a flow state. This aim focused on showing students how to learn, that is how to be an efficient self-regulated learner. The core of education can be described by an ancient Chinese phrase: “授人以鱼不如授人以渔”, which means “Give a man a fish and you feed him for a day. Teach a man to fish and you feed him for a lifetime”. This Chinese phrase emphasizes that teaching students how to learn is much more important than only teach them knowledge. This is essential, since students in higher education have more information to choose from, more freedom in what, how and where they study. For these students, self-regulated learning skills are required. Nowadays, it is essential to be a lifelong learner to adapt to the fast-changing world. Knowing how to learn and being able to learn after leaving university is important for this. 
One way to teach how to learn and to optimize learning behavior is in-depth training, such as the Study Smart project at Maastricht University. This project works on increasing students' use of effective learning strategies by explaining what desirable difficulties and different learning strategies are and by allowing students to practice effective learning strategies (Biwer et al., 2020). Another way of informing students how to learn and how to change learning behavior is to provide small and simple interventions to create new habits and gradually help individuals to become engaged in new behaviors (Fogg, 2019). For example, starting with a small intervention that gets students using retrieval practice and then slowly using it more often until they form other effective self-regulated behaviors. This dissertation explored two practical and easy-to-use interventions narratives and individual feedback - that showed students how to learn by engaging in more effective learning strategies (see Table 6.1).

Table 6.1 shows how to apply two practical and easy-to-use interventions, who can apply them, and how the effect of existing interventions can be increased. As shown in step 1 of Table 6.1, the use of narratives leads to awareness of desirable difficulties. Students will understand that the high effort required in using effective learning strategies is worthwhile because it leads to high learning gains. Although awareness of desirable difficulties cannot guarantee that students will use effective learning strategies, it at least raises their attention and may be a first step to taking action. As shown in step 2 of Table 6.1, feedback on individual performance enhanced the use of effective learning strategies; it addressed the perceived learning versus actual learning paradox by showing that desirable difficulties exist and that students learn more after using effective learning strategies. The combination of narratives and repeated presentation of individual feedback showed the value of effortful strategies and reinforced behaviors that increase the use of effective learning strategies (Table 6.1, step 3). In step 4, I propose combining in-depth training and small interventions as these could reinforce each other; the small interventions immediately show students how effective certain learning strategies can be and the in-depth training shows how to use strategies in ecologically valid settings and provides a chance to reflect on different strategies. Institutes and educational practitioners can follow the steps in Table 6.1 to foster self-regulated learning. 
Table 6.1. Interventions of fostering self-regulated learning by increasing effective learning strategy uptake.

\begin{tabular}{|c|c|c|c|}
\hline Step & Method & How to apply & Who can apply \\
\hline 1 & $\begin{array}{l}\text { Narratives } \\
\text { to increase } \\
\text { awareness } \\
\text { of desirable } \\
\text { difficulties }\end{array}$ & $\begin{array}{l}\text { Let role models (persons similar to the } \\
\text { target group are preferable) explain how they } \\
\text { struggled at first when applying effective } \\
\text { learning strategies (i.e., retrieval practice), } \\
\text { how they felt they did not learn that much } \\
\text { compared with ineffective learning strategies } \\
\text { (i.e., restudy), and finally describe how they } \\
\text { obtained positive results after using effective } \\
\text { learning strategies. }\end{array}$ & $\begin{array}{l}\text { Institutes and } \\
\text { educational } \\
\text { practitioners; } \\
\text { students }\end{array}$ \\
\hline 2 & $\begin{array}{l}\text { Individual } \\
\text { feedback } \\
\text { to increase } \\
\text { the uptake } \\
\text { of effortful } \\
\text { but effective } \\
\text { strategies }\end{array}$ & $\begin{array}{l}\text { Study with both effective and ineffective } \\
\text { strategies. Then test long-term retention. } \\
\text { Immediately compare the scores after } \\
\text { ineffective and effective strategy use to see } \\
\text { that effective strategies not only require } \\
\text { more effort but also lead to more learning. }\end{array}$ & $\begin{array}{l}\text { Institutes and } \\
\text { educational } \\
\text { practitioners; } \\
\text { students }\end{array}$ \\
\hline 3 & $\begin{array}{l}\text { Narratives } \\
+ \text { (repeated) } \\
\text { individual } \\
\text { feedback }\end{array}$ & $\begin{array}{l}\text { Step 3a: apply narratives as in step } 1 \\
\text { Step } 3 \text { b: repeatedly apply individual feedback } \\
\text { as in step } 2\end{array}$ & $\begin{array}{l}\text { Institutes and } \\
\text { educational } \\
\text { practitioners; } \\
\text { students }\end{array}$ \\
\hline 4 & $\begin{array}{l}\text { In-depth } \\
\text { training + small } \\
\text { interventions }\end{array}$ & $\begin{array}{l}\text { Step 4a: explain different learning strategies } \\
\text { in-depth (how students use them, why } \\
\text { they are effective or not, why students do } \\
\text { or do not use them) and explain desirable } \\
\text { difficulties from a scientific perspective } \\
\text { Step 4b: apply narratives (using a peer role } \\
\text { model to explain desirable difficulties as in } \\
\text { step 1) } \\
\text { Step 4c: give individual feedback as in step } 2 \\
\text { Step 4d: encourage discussion and reflection } \\
\text { on the experience of desirable difficulties } \\
\text { and stress the value of exerting effort in self- } \\
\text { regulated learning }\end{array}$ & $\begin{array}{l}\text { Institutes and } \\
\text { educational } \\
\text { practitioners }\end{array}$ \\
\hline
\end{tabular}


Table 6.1. (Continued)

\begin{tabular}{llll}
\hline Step Method & How to apply & Who can apply \\
\hline \multirow{4}{*}{$\begin{array}{l}\text { In-depth } \\
\text { training + small }\end{array}$} & Step 5a: same as in step 4 & \\
& Step 5b: choose a challenge-skill balanced & \\
interventions + & Step 5d: keep attention focused by reducing & educational \\
flow regulation & distractions from the learning environment & practitioners, \\
& Step 5e: apply suitable (and effortful) & and students \\
& learning strategies students learned from in- & \\
& depth training & \\
& &
\end{tabular}

This dissertation has contributed guidelines that promote the occurrence of flow by analyzing facilitators of flow that can be self-regulated and flow-facilitating strategies. These flow-facilitating strategies can guide students step by step in regulating their learning and can help teachers to support their students. To increase the chance of reaching a flow state, students can first choose a challenge-skill balanced task, then set up a clear goal and be persistent about reaching it, then control their learning environment to maintain focus, and then apply suitable learning strategies. These simple interventions and flow regulation strategies can enrich the effect of in-depth learning strategy training programs, as shown in the last row of Table 6.1. The combination of these methods may have the best effect on optimizing self-regulated learning. 


\section{Conclusion}

This dissertation demonstrates the importance of perceived mental effort in selfregulated learning and provides a new perspective on self-regulated learning. Students often take data-driven perspectives to make learning strategy decisions, and this stops them from using effortful but effective learning strategies. Providing individual performance feedback and supporting students to self-regulate facilitators of flow may help them create a goal-driven perspective. Students with a goal-driven perspective will be more inclined to invest effort and pursue their goals by becoming engaged in effective and effortful learning strategies. Being aware of desirable difficulties may also help students to take a goal-driven perspective on judging effort when making learningstrategy decisions. Furthermore, narratives and individual performance feedback could be used by educational practitioners and students to promote the use of effective learning strategies and to optimize self-regulated learning. 


\section{References}

Ariel, R., Dunlosky, J., \& Bailey, H. (2009). Agenda-based regulation of study-time allocation: when agendas override item-based monitoring. Journal of Experimental Psychology: General, 138(3), 432.

Baars, M., Wijnia, L., de Bruin, A., \& Paas, F. (2020). The relation between students' effort and monitoring judgments during learning: A meta-analysis. Educational Psychology Review.

Biwer, F., Oude Egbrink, M. G., Aalten, P., \& de Bruin, A. B. (2020). Fostering Effective Learning Strategies in Higher Education-A Mixed-Methods Study. Journal of Applied Research in Memory and Cognition.

Bjork, R. A., Dunlosky, J., \& Kornell, N. (2013). Self-Regulated Learning: Beliefs, Techniques, and Illusions. Annual Review of Psychology, 64(1), 417-444. doi:10.1146/annurev-psych-113011-143823

Carpenter, S. K., Endres, T., \& Hui, L. (2020). Students' use of retrieval in self-regulated learning: Implications for monitoring and regulating effortful learning experiences. Educational Psychology Review, 1-26.

de Bruin, A. B., Roelle, J., Carpenter, S. K., Baars, M., \& EFG-MRE. (2020). Synthesizing cognitive load and self-regulation theory: a theoretical framework and research agenda. Educational Psychology Review, 1-13.

Eitel, A., Endres, T., \& Renkl, A. (2020). Self-management as a bridge between cognitive load and self-regulated learning: The illustrative case of seductive details. Educational Psychology Review, 1-15.

Fiorella, L. (2020). The Science of Habit and Its Implications for Student Learning and Well-being. Educational Psychology Review, 1-23.

Fogg, B. J. (2019). Tiny habits: the small changes that change everything: Eamon Dolan Books.

Inzlicht, M., Shenhav, A., \& Olivola, C. Y. (2018). The effort paradox: Effort is both costly and valued. Trends in Cognitive Sciences, 22(4), 337-349.

Karpicke, J. D. (2009). Metacognitive control and strategy selection: Deciding to practice retrieval during learning. Journal of Experimental Psychology: General, 138(4), 469.

Kirk-Johnson, A., Galla, B. M., \& Fraundorf, S. H. (2019). Perceiving effort as poor learning: The misinterpreted-effort hypothesis of how experienced effort and perceived learning relate to study strategy choice. Cognitive Psychology, 115, 101237.

Klepsch, M., \& Seufert, T. (2021). Making an Effort Versus Experiencing Load. Frontiers in Education, 6(56). doi:10.3389/feduc.2021.645284

Koriat, A. (2018). Agency attributions of mental effort during self-regulated learning. Memory \& Cognition, 46(3), 370-383. 
Koriat, A., Nussinson, R., \& Ackerman, R. (2014). Judgments of learning depend on how learners interpret study effort. Journal of Experimental Psychology: Learning, Memory, and Cognition, $40(6), 1624$.

Kurzban, R., Duckworth, A., Kable, J. W., \& Myers, J. (2013). An opportunity cost model of subjective effort and task performance. The Behavioral and Brain Sciences, 36(6).

Nakamura, J., \& Csikszentmihalyi, M. (2014). The concept of flow. In Flow and the foundations of positive psychology (pp. 239-263): Springer.

Nelson, T. O. (1990). Metamemory: A theoretical framework and new findings. In Psychology of Learning and Motivation (Vol. 26, pp. 125-173): Elsevier.

Panadero, E. (2017). A review of self-regulated learning: Six models and four directions for research. Frontiers in Psychology, 8, 422.

Reber, R., \& Greifeneder, R. (2017). Processing fluency in education: How metacognitive feelings shape learning, belief formation, and affect. Educational Psychologist, 52(2), 84-103.

Scheiter, K., Ackerman, R., \& Hoogerheide, V. (2020). Looking at mental effort appraisals through a metacognitive lens: Are they biased? Educational Psychology Review, 1-25.

Seufert, T. (2018). The interplay between self-regulation in learning and cognitive load. Educational Research Review, 24, 116-129.

Seufert, T. (2020). Building Bridges Between Self-Regulation and Cognitive Load-an Invitation for a Broad and Differentiated Attempt. Educational Psychology Review, 1-12.

Son, L. K., \& Metcalfe, J. (2000). Metacognitive and control strategies in study-time allocation. Journal of Experimental Psychology: Learning, Memory, and Cognition, 26(1), 204.

Swann, C., Jackman, P. C., Schweickle, M. J., \& Vella, S. A. (2019). Optimal experiences in exercise: A qualitative investigation of flow and clutch states. Psychology of Sport and Exercise, 40, 87-98.

Swann, C., Keegan, R., Crust, L., \& Piggott, D. (2016). Psychological states underlying excellent performance in professional golfers:“Letting it happen” vs."making it happen”. Psychology of Sport and Exercise, 23, 101-113.

van Gog, T., Hoogerheide, V., \& van Harsel, M. (2020). The role of mental effort in fostering selfregulated learning with problem-solving tasks. Educational Psychology Review, 1-18.

Vaughn, K. E., \& Kornell, N. (2019). How to activate students' natural desire to test themselves. Cognitive Research: Principles and Implications, 4(1), 35.

Vygotsky, L. S. (1980). Mind in society: The development of higher psychological processes: Harvard university press. 



\section{Appendices}

Summary

Nederlandse Samenvatting

Impact Chapter

Acknowledgements

SHE Dissertation Series

ICO Dissertation Series 


\section{Summary}

This dissertation describes five studies that investigated how to foster self-regulated learning. These studies showed that self-regulated learning can be promoted by encouraging students to use more effective learning strategies and identified flowfacilitating factors that can be self-regulated to facilitate the occurrence of flow. The General Introduction (Chapter 1) first describes what effective learning strategies are, discusses current research on how to enhance their use, and then briefly presents theory about flow - a seemingly effortless flow state. Rather than using effective but effortful learning strategies (e.g., retrieval practice), learners often prefer ineffective but less effortful strategies (e.g., restudy). To enhance academic success and to prepare our students to be lifelong learners, we must help them use more effective learning strategies despite the higher investment of mental effort. We must also show them how to reach a "flow state" when using these strategies, so they experience learning as inherently enjoyable and rewarding, without noticing the effort invested.

Five studies were conducted to determine how students can optimize their selfregulated learning, either by promoting the uptake of more effective learning strategies or by self-regulating factors that lead to a flow state. These five studies are reported in Chapters 2-5. The four research questions (RQs) guiding these respective chapters were:

RQ1: Does a behavior change intervention using narrative communication influence the intention to wield more effortful and effective learning strategies? (Chapter 2)

RQ2: Does the provision of individual feedback on actual learning outcomes increase the uptake of an effortful and effective learning strategy, namely retrieval practice? (Chapter 3 )

RQ3: What role do factors at the learning task level - perceived effort and perceived learning - play in students' learning strategy decisions both before and after receiving individual feedback on actual learning outcomes ?(Chapter 4)

RQ4: Which factors known to promote flow can be self-regulated by learners, and how can these factors be self-regulated? (Chapter 5)

In Chapter 2, an experimental study was conducted to investigate whether a behavioralchange strategy (the use of narratives) can stimulate students' intention to switch to 
effective learning strategies and to enhance their awareness of desirable difficulties more than a didactical approach can. Videos on promoting learning-strategy change were recorded, using either a narrative or a didactic approach. One group watched narrative videos, one group watched didactic videos, and a control group watched irrelevant videos. Students' intentions to change from less effective to more effective learning strategies and their awareness of desirable difficulties were measured and compared. The results showed that narratives and didactic communication did not differ in their change of erroneous beliefs and stimulate intentions to change. However, more students in the narrative group than in the didactic group became aware of the importance of desirable difficulties for long-term learning. This awareness of desirable difficulties may motivate students to regulate their effort as they realize that putting in the extra effort is valuable. This demonstrates the potential of narratives on promoting the use of effortful but effective learning strategies.

Two experimental studies are reported in Chapter 3. In the first experiment, participants studied one series of anatomical image-name pairs by retrieval practice and another series by restudy. In subsequent studies of new image-name pairs, participants were free to choose either retrieval practice or restudy for each pair. After a 7-day interval, a test was administered, and participants were informed of their test result after each learning strategy (individual feedback). Then, participants studied new anatomical image-name pairs and were again free to choose which learning strategy to use. In the second experiment, another experimental group was added who received general feedback on how much more effective retrieval practice was than restudy in previous experiments. The effects of giving individual feedback versus general feedback in short- and long-term use of retrieval practice were compared. In the first experiments, students who had experienced the learning benefits of retrieval practice chose this strategy more often after receiving individual feedback. In the second experiment, general feedback only enhanced the use of retrieval practice in the short term, whereas individual feedback increased the use of retrieval practice both in the short and long term, at least for students who had experienced its benefits. These experiments showed that individual feedback can promote the use of retrieval practice for students who had experienced its benefits. Students are inclined to choose the learning strategy they have benefited from, rather than being influenced by general feedback about the benefits of retrieval practice. 
In Chapter 4, in addition to providing individual feedback as in Chapter 3, students rated the perceived mental effort it took to learn each anatomical image-name pair as well as the perceived learning of each pair. Then, they chose either retrieval practice or restudy to further study each pair. With these data, models were built to measure how students' perceptions about the learning tasks - perceived mental effort and perceived learning at the learning task level - influence their learning strategy decisions and how these decisions change after receiving individual feedback on the learning outcomes of each strategy. In agreement with earlier chapters, students who benefited from retrieval practice chose this strategy more often after receiving feedback. In addition, perceived mental effort at the learning task level was directly related to retrieval practice decisions before and after feedback. More specifically, higher task-based perceived mental effort directly reduced retrieval practice uptake. Unexpectedly, perceived learning at the task level had no influence on learning strategy decisions before receiving feedback and had only partial influence after receiving feedback. This showed that task-based perceived mental effort had the dominant effect on learning strategy decisions and revealed a fundamental problem in students' learning-strategy decision making: students adopt a data-driven perspective when deciding which learning strategy to use. This means that, when they experience high effort, they lapse back into ineffective learning strategies that require less cognitive engagement, such as restudy.

Chapter 5 reviewed flow-promoting factors that can be self-regulated by learners. It also investigated how these factors can be regulated to reach a flow state during learning. To increase the chance of reaching a flow state, four clusters of factors can be regulated: (1) metacognitive strategies such as seeking feedback in a timely manner, (2) balance between challenge and skill, (3) motivation, such as being persistent on clear goals, and (4) attention, such as focusing on learning. Specific flow-facilitating strategies based on these factors included (1) seeking and reflecting on feedback about learning goals and applying appropriate cognitive and metacognitive learning strategies, (2) choosing challenging tasks that match current skill level, (3) setting clear goals and staying committed, and (4) reducing distraction in the learning environment to enhance focused attention. These practical regulation strategies facilitate flow and help students improve their learning experience and learning performance.

Chapter 6 provides an overarching discussion of the five studies presented in the dissertation. Students decide which learning strategy to use from a data-driven perspective and this prevents them from using effortful but effective learning strategies. 
Providing individual performance feedback and helping students self-regulate flow facilitators may help them switch from a data-driven to a goal-driven perspective. Students with a goal-driven perspective will be more inclined to invest effort and pursue their goals by becoming engaged in effective learning strategies. Being aware of desirable difficulties may also help students to take a goal-driven perspective when judging effort and making learning strategy decisions. Furthermore, educational practitioners and students could use narratives and individual performance feedback to promote the use of effective learning strategies and to optimize self-regulated learning. 


\section{Nederlandse Samenvatting}

Dit proefschrift beschrijft vijf studies waarin werd onderzocht hoe zelfregulerend leren kan worden bevorderd. Deze studies lieten zien dat zelfregulerend leren kan worden bevorderd door studenten aan te moedigen effectievere leerstrategieën te hanteren. Daarbij maakten de studies de flowbevorderende factoren inzichtelijk die zelfgereguleerd kunnen worden met als doel gemakkelijker in een flow terecht te komen. De algemene inleiding (Hoofdstuk 1) beschrijft eerst wat effectieve leerstrategieën zijn, bespreekt bestaand onderzoek over hoe het gebruik ervan kan worden bevorderd en presenteert vervolgens kort de theorie over "flow", oftewel een staat van flow die weinig moeite lijkt te kosten. In plaats van gebruik te maken van leerstrategieën die effectief zijn maar veel moeite kosten (bijv. retrieval practice*), geven studenten vaak de voorkeur aan strategieën die ineffectief zijn maar minder inspanning vereisen (bijv. restudy of het studeren herhalen). Om het studierendement te vergroten en onze studenten voor te bereiden op een leven lang leren, moeten we hen helpen om effectievere leerstrategieën te hanteren, ook al vereisen deze een grotere mentale inspanning. Ook moeten we ze laten zien hoe zij bij het gebruik van deze strategieën in een "staat van flow" kunnen geraken, zodat zij het leren op zich als prettig en zinvol ervaren, zonder dat zij in de gaten hebben hoeveel moeite ze erin steken.

Er werden vijf studies verricht om erachter te komen hoe studenten hun zelfregulerend leren kunnen optimaliseren, enerzijds door het gebruik van effectievere leerstrategieën te bevorderen, anderzijds door hen te helpen de factoren die tot een staat van flow leiden zelf te reguleren. Deze vijf studies worden in Hoofdstuk 2-5 beschreven. De vier onderzoeksvragen (OV) die in de desbetreffende hoofdstukken centraal stonden, waren:

OV1: Heeft een op gedragsverandering gerichte interventie waarbij gebruik wordt gemaakt van narratieve communicatie invloed op het voornemen om leerstrategieën te gebruiken die meer inspanning vereisen en effectiever zijn? (Hoofdstuk 2);

OV2: Verhoogt het geven van persoonlijke feedback op daadwerkelijke leerresultaten het gebruik van retrieval practice, een effectieve leerstrategie die veel inspanning vereist? (Hoofdstuk 3);

OV3: Welke rol spelen leertaakgebonden factoren, namelijk perceived effort en perceived learning (d.w.z. hoeveel moeite de taak heeft gekost en hoeveel 
de student ervan heeft geleerd in zijn/haar beleving), bij het kiezen van een leerstrategie zowel vóór als nadat studenten persoonlijke feedback hebben ontvangen op hun daadwerkelijke leerresultaten? (Hoofdstuk 4);

OV4: Welke factoren waarvan bekend is dat zij een flowstaat bevorderen kunnen studenten zelf reguleren en hoe kunnen deze factoren zelfgereguleerd worden? (Hoofdstuk 5).

In Hoofdstuk 2 werd een experimentele studie verricht om te onderzoeken of een op gedragsverandering gerichte interventie (het gebruik van narratieven) studenten meer prikkelt om over te stappen op effectieve leerstrategieën en hun bewuster maakt van wenselijke moeilijkheden (desirable difficulties) dan een didactische aanpak dat doet. Er werden twee verschillende video's opgenomen met het doel om verandering van leerstrategie te promoten, waarbij een narratieve dan wel een didactische aanpak werd gehanteerd. Eén groep bekeek de narratieve video's, één groep bekeek de didactische video's, en een controlegroep bekeek irrelevante video's. Vervolgens maten en vergeleken wij het voornemen van studenten om van minder effectieve op meer effectieve leerstrategieën over te stappen, alsmede de mate waarin zij zich van wenselijke moeilijkheden bewust waren. De resultaten lieten zien dat er geen verschil was tussen narratieven en de didactische manier van communiceren ten aanzien van het veranderen van verkeerde aannames. Ook bevorderden ze beide het voornemen om van strategie te veranderen. Wel werden meer studenten uit de narratieve groep dan uit de didactische groep zich bewust van het belang van wenselijke moeilijkheden voor het leren op de lange termijn. Dit besef van wenselijke moeilijkheden kan studenten mogelijk motiveren om hun inzet te reguleren, omdat zij inzien dat meer inspanning loont. Dit toont aan dat narratieven het gebruik van leerstrategieën die veel inspanning vereisen maar effectief zijn, kunnen bevorderen.

In Hoofdstuk 3 worden er twee experimentele studies beschreven. In het eerste experiment bestudeerden de participanten een reeks anatomische afbeelding-naamparen door gebruik te maken van retrieval practice en een andere reeks met behulp van restudy. In de daaropvolgende periode voor het bestuderen van nieuwe afbeelding-naamparen mochten de participanten zelf kiezen welke van de twee strategieën ze wilden gebruiken voor elk paar. Na een tussenperiode van zeven dagen werd een toets afgenomen en kregen de participanten te horen wat hun toetsuitslag was na het gebruik van elke leerstrategie (persoonlijke feedback). Vervolgens bestudeerden de participanten nieuwe anatomische afbeelding-naamparen en mochten zij opnieuw kiezen welke leerstrategie 
ze wilden gebruiken. In het tweede experiment werd een derde experimentele groep toegevoegd; deze groep ontving de algemene feedback dat retrieval practice in voorgaande experimenten veel effectiever was gebleken dan restudy. We vergeleken de gevolgen van het geven van persoonlijke versus algemene feedback voor het gebruik van retrieval practice op de korte en lange termijn. In het eerste experiment kozen de studenten die de leerwinst van retrieval practice hadden ervaren vaker voor deze strategie nadat zij persoonlijke feedback hadden ontvangen. In het tweede experiment zorgde de algemene feedback alleen op de korte termijn voor een toename in het gebruik van retrieval practice, terwijl de persoonlijke feedback het gebruik van retrieval practice zowel op de korte als op de lange termijn deed toenemen, althans voor die studenten die het voordeel ervan hadden ervaren. Deze experimenten lieten zien dat persoonlijke feedback het gebruik van retrieval practice kan bevorderen voor de studenten die het voordeel ervan hebben ervaren. Studenten zijn eerder geneigd om de leerstrategie te kiezen waar zij baat bij hebben gehad dan dat zij zich laten leiden door algemene feedback over de voordelen van retrieval practice.

In Hoofdstuk 4 ontvingen studenten niet alleen persoonlijke feedback zoals in Hoofdstuk 3, maar gaven zij ook aan hoeveel mentale inspanning er in hun beleving voor nodig was om elk anatomisch afbeelding-naampaar uit het hoofd te leren (perceived mental effort) en hoeveel zij meenden van elk paar te hebben geleerd (perceived learning). Daarna kozen zij ofwel retrieval practice dan wel restudy om elk paar verder te bestuderen. Op basis van de aldus verkregen data, stelden we modellen op waarmee we konden meten hoe de percepties van studenten ten aanzien van de leertaken (leertaakgebonden perceived mental effort en perceived learning) hun leerstrategiekeuzes beïnvloedden en hoe hun keuzes veranderden na het ontvangen van persoonlijke feedback op de behaalde leerresultaten per strategie. In overeenstemming met de voorgaande hoofdstukken kozen de studenten die baat hadden gehad bij retrieval practice vaker voor deze strategie na het ontvangen van feedback. Daarnaast hield leertaakgebonden perceived mental effort direct verband met de keuze voor retrieval practice voor en na feedback. Dat wil zeggen dat een grotere taakgebonden mentale inspanning, zoals de studenten dat ervoeren, het gebruik van retrieval practice direct verminderde. Verrassend was dat leertaakgebonden perceived learning geen invloed had op de leerstrategiekeuzes vóór het ontvangen van feedback en slechts een gedeeltelijke invloed had na het ontvangen van feedback. Dit toonde aan dat taakgebonden perceived mental effort richtinggevend was bij het maken van leerstrategiekeuzes en onthulde tevens een fundamenteel probleem in de manier 
waarop studenten tot de keuze van een leerstrategie komen: bij het kiezen van een leerstrategie nemen zij een datagerichte houding aan. Dit betekent dat wanneer zij veel inspanning ervaren, zij terugvallen in ineffectieve leerstrategieën zoals restudy die minder cognitieve betrokkenheid vereisen.

Hoofdstuk 5 zette de flowbevorderende factoren op een rij die studenten zelf kunnen reguleren. Het onderzocht ook hoe deze factoren zelfgereguleerd kunnen worden om tijdens het leren een flowstaat te bereiken. Om de kans op het bereiken van een flowstaat te vergroten, kunnen er vier groepen factoren worden gereguleerd, namelijk: 1) metacognitieve strategieën, zoals het tijdig vragen om feedback; 2) afstemmen van de moeilijkheidsgraad op competentie; 3) motivatie, zoals het consequent nastreven van duidelijke doelen; en 4) aandacht, deze moet gericht zijn op het leren. Op basis van deze factoren werden de volgende specifieke flowbevorderende strategieën onderscheiden: 1) om feedback over leerdoelen vragen, hierop reflecteren en passende cognitieve en metacognitieve leerstrategieën toepassen; 2) uitdagende taken kiezen die passen bij het huidige competentieniveau; 3) duidelijke doelen stellen en deze blijven nastreven; en 4) afleiding in de leeromgeving verminderen om gerichte aandacht te vergroten. Deze praktische regulatiestrategieën bevorderen flow en helpen studenten om hun leerervaring en -prestaties te verbeteren.

Hoofdstuk 6 geeft een overkoepelende bespreking van de vijf studies die in dit proefschrift werden gepresenteerd. Studenten kiezen de leerstrategie die ze willen gebruiken vanuit een datagericht perspectief en dit weerhoudt hen ervan om inspannende maar effectieve leerstrategieën te hanteren. Door hun persoonlijke feedback te geven op hun prestaties en hen te helpen om flowbevorderende factoren zelf te reguleren, kunnen we ze wellicht stimuleren om hun datagerichte houding om te vormen tot een doelgerichte opstelling. Studenten met een doelgerichte opstelling zullen meer geneigd zijn om zich in te spannen en hun doelen na te streven door effectieve leerstrategieën te hanteren. Ook het zich bewust worden van wenselijke moeilijkheden kan studenten helpen om een doelgerichte houding aan te nemen bij het inschatten van de te investeren energie en het kiezen van een leerstrategie. Ten slotte zouden onderwijskundigen en studenten zich van narratieven en persoonlijke feedback op prestaties kunnen bedienen om het gebruik van effectieve leerstrategieën te bevorderen en zelfregulerend leren te optimaliseren. 


\section{Impact Chapter}

\section{Societal Impact}

Teaching students how to learn is more important than giving them knowledge. Likewise, being able to learn and knowing how to learn is important for successful learning. This is particularly relevant for students in higher education who have more information to choose from and more freedom in what, how, and where they study. This is also important throughout life as we all need to be able to learn to adapt to the fast-changing world. This dissertation focuses on "how to learn" and the reported findings will benefit students, teachers, and educational institutes.

Being able to learn involves having self-regulated learning skills and being capable to use effective but effortful learning strategies is an important aspect of these skills. Many students struggle to study effectively by engaging in appropriate learning strategies and do not know how to manage their effort. For example, when they try to memorize a book chapter, they often read the chapter again and again (restudy), but this is an ineffective learning strategy. They rarely opt to use effective but effortful learning strategies, such as self-testing to enhance their memory. Students are sometimes aware of which strategies are effective and which are not (McAndrew, Morrow, Atiyeh, \& Pierre, 2016), but still do not always choose effective learning strategies because of the added effort involved. They are not aware that this extra effort is worth it because it greatly improves the learning outcome - in other words, they lack awareness of desirable difficulties. Awareness of these desirable difficulties is important to enhance the use of effective learning strategies. Narratives (stories about personal experiences) that explain how using effective learning strategies is difficult and effortful but worth the effort because of their effectiveness help students become aware of desirable difficulties.

Students may be willing to put in extra effort if it helps them to pass exams or get high scores. They could motivate themselves to use more effective learning strategies by evaluating how these strategies improve their learning - for example by studying with effective but effortful and ineffective but effortless strategies and then comparing their effects on long-term retention. When they see that effective strategies not only require more effort but also lead to higher learning gains they might be inclined to switch to these strategies.

This dissertation also suggests practical regulation strategies that might help students enter a seemingly effortless flow state during learning. First, students should 
choose challenging tasks that are not too difficult but not too easy - in other words, these tasks should fall in their "zone of proximal development" (Nakamura \& Csikszentmihalyi, 2014). Second, students should establish clear goals for learning these tasks and be persistent about these goals. Third, before studying the chosen tasks, students should choose a learning environment that is not distracting, such as a quite spot in the library. They should remove all distractions (such as their phone with social media apps) from their learning environment to increase their concentration and focus only on the learning tasks at hand. Fourth, students should actively engage in effective learning strategies, such as self-testing to increase learning, and actively engage in reflection to further direct their learning.

Not only students but also teachers and educational institutes might benefit from the small and simple interventions explored in this dissertation. Teachers and educational institutes often inform students how to learn through intense and in-depth training such as the Study Smart project at Maastricht University (https://www.studysmartpbl. com/). Small and simple interventions can also establish new habits (Fogg, 2019) that gradually help students engage in new learning behaviors. Teachers and educational institutes could provide narratives about changing ineffective learning strategies and show how effective but effortful learning strategies can affect learning performance through individual feedback to show students how to learn. This combination of in-depth training with narratives and individual performance feedback may help to promote the use of effective learning strategies.

Teachers and educational institutes typically use one effective learning strategy, testing, as an assessment tool, often without realizing that it is also an effective strategy for learning and long-term retention. Testing enhances long-term knowledge more than restudying does and has attracted the attention of institutes and educational practitioners in recent years. This may be why the "Beoordelingskader Accreditatiestelsel Hoger Onderwijs Nederland 2018" [the Assessment Framework for the Dutch Higher Education Accreditation System 2018] stressed that assessment should support students' own learning processes. Teachers and educational institutes could introduce more lowstakes tests into their curriculum to make regular testing a part of the learning processes. Moreover, assigning tasks that are balanced with the learners' current skill level might help regulate effort and optimize self-regulated learning. Teachers and educational institutes could adapt their instructions to each student so the right level of support and 
guidance is offered based on the student's knowledge. This is also called differentiated instruction or personalized learning.

\section{Scientific Impact}

This dissertation has contributed to our understanding of how students monitor and control their learning (self-regulated learning), especially how they make learning strategy decisions. I developed two experimental paradigms to investigate how to increase the uptake of effective learning strategies: narrative communication and individualized performance feedback on actual learning. Individualized performance feedback addresses the perceived learning versus actual learning paradox (i.e., students perceive that they learn more from ineffective learning strategies than from effective ones, when in fact it is the other way around). These two approaches have enriched our knowledge of self-regulated learning by introducing behavioral change strategies and by focusing on the main reason for low uptake of effective learning strategies. Future studies could apply either one or even combine the two approaches to further investigate how to enhance self-regulated learning skills by increasing the uptake of effective learning strategies.

This dissertation described for the first time that it is the mental effort students perceive during learning a task (perceived mental effort) and not how well they think they learned (perceived learning) that dominates their decisions on which learning strategy to use. If they experience high effort from learning a task, they relapse to a strategy that is less effortful and less effective, such as restudy, and if they experience less effort, they are inclined to use an effortful and effective learning strategy, such as testing themselves. This finding shows the importance of perceived mental effort during self-regulated learning. Although it is the first and only experimental study to reach this conclusion, this finding is supported by two theoretical articles published around the same time (Dunlosky, Badali, Rivers, \& Rawson, 2020; van Gog et al., 2020). In these two articles, the authors emphasized the potential importance of perceived mental effort in self-regulated learning. However, one experiment cannot confirm this theory and future studies are needed to further investigate the role of perceived mental effort in self-regulated learning. 


\section{Dissemination of Results}

Results from this dissertation have been published in international peer-reviewed journals with a broad readership in the field of educational sciences and educational psychology. The results have also been presented at international conferences, including the conferences of the European Association for Research on Learning and Instruction (EARLI) in 2019 and 2021, the International Cognitive Load Theory Conferences in 2019 and 2021, the annual meeting of the American Educational Research Association in 2020, and the EARLI SIG 16 Metacognition in 2021. 


\section{References}

Dunlosky, J., Badali, S., Rivers, M. L., \& Rawson, K. A. (2020). The Role of Effort in Understanding Educational Achievement: Objective Effort as an Explanatory Construct Versus Effort as a Student Perception. Educational Psychology Review, 1-13.

Fogg, B. J. (2019). Tiny habits: the small changes that change everything: Eamon Dolan Books.

McAndrew, M., Morrow, C. S., Atiyeh, L., \& Pierre, G. C. (2016). Dental student study strategies: Are self-testing and scheduling related to academic performance? Journal of Dental Education, $80(5), 542-552$.

Nakamura, J., \& Csikszentmihalyi, M. (2014). The concept of flow. In Flow and the foundations of positive psychology (pp. 239-263): Springer.

van Gog, T., Hoogerheide, V., \& van Harsel, M. (2020). The role of mental effort in fostering selfregulated learning with problem-solving tasks. Educational Psychology Review, 1-18. 
Impact Chapter 


\section{Acknowledgements}

On 12 September 2017, I arrived in Maastricht, a completely unfamiliar city to me, for my PhD project. Except for planning to do a good PhD and build my own theoretical model, I had no idea what would happen. I did not expect that this city and the lovely people I would meet here would completely change my life. I often have the feeling that I am the luckiest person in the world, which I never felt before I came to Maastricht. Here, I would like to express my gratitude and thanks to my family, friends, and colleagues.

My supervision team, Anique, Jeroen, and Jeroen, make me feel I am lucky the most. Anique, I am always amazed how you get things done efficiently. And I am inspired by the way you think. No matter what kind of trouble I run into, the first door I will knock on is yours because I know you will have the perfect solution. I want to think like you think. You are a role model and the person I look up to both in work and in life. Jeroen, you have explained statistics repeatedly until I understood and have taught me coding with endless patience. I have enjoyed every moment sitting with you talking about Chinese food and culture. Jeroen, I am always wondering how you store so much knowledge in your brain and how you are so wise. Although you have already achieved so much, you still work very hard; I have noticed you working late in the evenings and at weekends. When I am lazy and unmotivated, I often tell myself: if Jeroen still works so hard, I have no reason to not work hard! This motivates me. If someday technology allows us to send knowledge and wisdom between brains like emails, I want yours. I often feel that I do not deserve such a wonderful supervision team. Four years of patient guidance and constant support have made me a stronger person. With the knowledge you have given me and your way of thinking, I feel there is nothing I cannot learn and there are no difficulties I cannot overcome. Anique, you once wrote to me "if you put your mind to it, you will make it work". I have built up this ability in Maastricht after meeting my supervision team! Thanks to all of you, the fortune of my life!

Our SRL lab members, Sanne, Felicitas, Lucy, Jonas, Karol, Erdem, Hector, and Wisnu - you often patiently listen to my problems and provide down to earth advice at our bi-weekly meetings and also any time after our meeting. The discussions at our meetings have inspired me so much and I have learned so much from you. You make me enjoy being a researcher and make me feel I am lucky to be close to smart people and learn from them. 
Thanks to my colleague, Jimmy. You spent so much time helping me record videos and set up my most difficult experiment. Without you, I would never have started collecting my data and would never have finished my PhD. Danielle, thank you so much for inviting me to join your family during the Easter. You have a lovely family and everyone was so kind to me; I really enjoyed spending time with your family.

My old roomies, Carolin, Andrea, Lorette, Joy and Stephanie. You know my struggles and sorrows the most, thank you so much for being there for me all the time. Without you, how could I make it at my lowest moment! Thank you, my angels! My new roomies, Eveline, Erdem, Fatemeh, Derk, Fury, we spent so little time together because of COVID, but I enjoyed every moment with you and I had so much fun with you! Thank you for the joy you brought to me.

Many thanks to all the PhD students in our department, Juliet, Samantha, Lianne, Suzanne, Serge, HQ, Sanne, Cindy, Emmaline, Guy, Anique, Michelle, Yuanyuan, Hao. Thanks for making it a wonderful and comfortable place to work.

Thanks to our secretary team, Nicky, Lilian, Audrey, Hennie and Eveline, for all their support over these years. Special thanks to Nicky and Lilian - your help made me feel I had a new family when I just arrived in Maastricht.

感谢家人对我求学期间的支持! 惠梓祺, 惠思祺, 姑姑希望你们能通过努力读 书, 成为一个思想独立、经济独立的人, 成为一个有能力做对的事情的人, 而不是迫于 生计和匮乏的能力做大家都做的事情! 希望你们能铭记龙应台告诫儿子的话: 孩子, 我要求你读书用功, 不是要你跟别人比成绩。而是因为, 我希望你将来会有选择的权 利, 选择有意义, 有时间的工作, 而不是被迫谋生。当你的工作在你心中有意义, 你就 有成就感; 当你的工作给你时间, 不剥夺你的生活, 你就有尊严。

Martin, Ursula, Joachim, Jenessa, thank you for welcoming me as part of your family. To me, family are those you feel comfortable and safe with and who you feel like you can be yourself around. That is the way I feel in this family. I enjoy spending time with you and looking forward to getting to know all of you better.

Last but not the least, Matthias. I would like to say you are a beautiful surprise Maastricht brought to me. It took me a while to realize that I have a boyfriend, I am engaged, and we are married because I often do not know what I did to deserve someone like you. Maybe because Maastricht turned me a lucky person, that makes me deserve you! I cannot wait to explore the future with you. 


\section{SHE Dissertation Series}

The SHE Dissertation Series publishes dissertations of PhD candidates from the School of Health Professions Education (SHE) who defended their PhD theses at Maastricht University. The most recent ones are listed below. For more information go to: https:// she.mumc.maastrichtuniversity.nl

Schillings, M. (06-07-2021) Talking about feedback: Face-to-face peer dialogue about written feedback

Wilbur, K. (05-07-2021) NO WHERE | NOW HERE: Context and Competency Expectations in Workplace-Based Training

Bendermacher, G. (02-07-2021) Navigating from Quality Management to Quality Culture

Ahmed Khan, R. (29-06-2021) Assessing curriculum viability in Undergraduate Medical Education

Chim, H.Q. (30-03-2021) Physical Activity Behavior and Learning in Higher Education

Dominguez, L.C. (23-02-2021) Persistence in surgical training: The role of job crafting and leadership

Bindels, E. (22-02-2021) DOING WELL, GETTING BETTER; Facilitating physicians' reflection on their professional performance

Iqbal, Z. (15-12-2020) All stakeholders matter in faculty development: Designing entrustable professional activities for small group facilitation

Tran, QT. (09-12-2020) Nationwide implementation of medical skills training laboratories in a developing country: studies from Vietnam

Pacifico, J. (30-11-2020) Making the Implicit Explicit: Uncovering the Role of the Conceptions of Teaching and Learning and the Perceptions of the Learning Climate in Postgraduate Medical Training.

Nishigori, H. (17-11-2020) Why do doctors work for patients? Medical professionalism in the era of neoliberalism

Oudkerk Pool, A. (06-11-2020) Competency-based portfolio assessment - Unraveling stakeholder perspectives and assessment practices

Geel van, K. (05-11-2020) Lifelong learning in radiology: all eyes on visual expertise

Stammen, L. (16-10-2020) Pursuing - High-Value, Cost-Conscious Care - The Role of Medical Education

Meulen van der, M. (15-10-2020) Assessment of physicians' professional performance using questionnaire-based tools 
Matsuyama, Y. (05-10-2020) Contextual attributes fostering self-regulated learning in a teachercentered culture: learner's professional identity formation is a trigger

Rovers, S. (16-09-2020) Growing knowledge, supporting students' self-regulation in problembased learning

Bourgeois-Law, G. (03-09-2020) Conceptualizations of remediation for practicing physicians

Giuliani, M. (19-05-2020) A Critical Review of Global Curriculum Development, Content and Implementation in Oncology

Schreurs, S. (20-03-2020) Selection for medical school; the quest for validity

Schumacher, D. (19-03-2020) Resident Sensitive Quality Measures: Defining the Future of PatientFocused Assessment

Sehlbach, C. (21-02-2020) To be continued.... Supporting physicians' lifelong learning

Kikukawa, M. (17-12-2019) The situated nature of validity: Exploring the cultural dependency of evaluating clinical teachers in Japan

Kelly, M. (10-12-2019) Body of knowledge. An interpretive inquiry into touch in medical education

Klein, D. (06-11-2019) The performance of medical record review as an instrument for measuring and improving patient safety

Bollen, J. (01-11-2019) Organ donation after euthanasia: medical, legal and ethical considerations

Wagner-Menghin, M. (25-09-2019) Self-regulated learning of history-taking: looking for predictive cues

Wilby, K. (02-07-2019) When numbers become words: Assessors' processing of performance data within OSCEs

Szulewski, A. (20-06-2019) Through the eyes of the physician: Expertise development in resuscitation medicine

McGill, D. (29-05-2019) Supervisor competence as an assessor of medical trainees; Evaluating the validity and quality of supervisor assessments

Van Rossum, T. (28-02-2019) Walking the tightrope of training and clinical service; The implementation of time variable medical training 


\section{ICO Dissertation Series}

In the ICO Dissertation Series dissertations are published of graduate students from faculties and institutes on educational research within the ICO Partner Universities: Eindhoven University of Technology, Leiden University, Maastricht University, Open University of the Netherlands, Radboud University Nijmegen, University of Amsterdam, University of Antwerp, University of Ghent, University of Groningen, University of Twente, Utrecht University, Vrije Universiteit Amsterdam, and Wageningen University, and formerly Tilburg University (until 2002). The University of Groningen, and the Erasmus University Rotterdam have been 'ICO ‘Network partner' in 2010 and 2011. From 2012 onwards, these ICO Network partners are full ICO partners, and from that period their dissertations will be added to this dissertation series. The most recent ones (2019 - Jan.2021) are listed below:

Wijnen, M. (O1-02-2019) Introduction of problem-based learning at the Erasmus School of Law: Influences on study processes and outcomes. Rotterdam: Erasmus University Rotterdam

Dobbelaer, M.J. (22-02-2019) The quality and qualities of classroom observation systems. Enschede: University of Twente

Van der Meulen, A.N. (28-02-2019) Social cognition of children and young adults in context. Amsterdam: Vrije Universiteit Amsterdam

Schep, M. (06-03-2019) Guidance for guiding. Professionalization of guides in museums of art and history. Amsterdam: University of Amsterdam

Jonker, H.M. (09-04-2019) Teachers' perceptions of the collaborative design and implementation of flexibility in a blended curriculum. Amsterdam: University of Amsterdam

Wanders, F. H. K. (03-05-2019). The contribution of schools to societal participation of young adults: The role of teachers, parents, and friends in stimulating societal interest and societal involvement during adolescence. Amsterdam: University of Amsterdam

Schrijvers, M.S.T. (03-05-2019) The story, the self, the other. Developing insight into human nature in the literature classroom. Amsterdam: University of Amsterdam

Degrande, T. (08-05-2019) To add or to multiply? An investigation of children's preference for additive or multiplicative relations. Leuven: KU Leuven.

Filius, R.M. (23-05-2019) Peer feedback to promote deep learning in online education. Unravelling the process. Utrecht: Utrecht University

Woldman, N. (24-05-2019) Competence development of temporary agency workers. Wageningen: Wageningen University 
Donszelman, S. (06-06-2019) Doeltaal-leertaal didactiek, professionalisering en leereffecten. Amsterdam: Vrije Universiteit Amsterdam

Van Oeveren, C.D.P. (12-06-2019) ITHAKA gaf je de reis. Amsterdam: Vrije Universiteit Amsterdam

Agricola, B.T. (21-06-2019) Who's in control? Finding balance in student-teacher interactions. Utrecht: Utrecht University

Cuyvers, K. (28-08-2019), Unravelling medical specialists self -regulated learning in the clinical environment. Antwerp: University of Antwerp

Vossen, T.E. (04-09-2019) Research and design in STEM education. Leiden: Leiden University

Van Kampen, E. (05-09-2019) What's CLIL about bilingual education? Leiden: Leiden University

Henderikx, M.A. (06-09-2019) Mind the Gap: Unravelling learner success and behaviour in Massive Open Online Courses. Heerlen: Open University of the Netherlands

Liu, M. (13-09-2019) Exploring culture-related values in Chinese student teachers' professional self-understanding and teaching experiences. Utrecht: Utrecht University

Sun, X. (13-09-2019) Teacher-student interpersonal relationships in Chinese secondary education classrooms. Utrecht: Utrecht University

Wu, Q. (02-10-2019) Making Construct-Irrelevant Variance Relevant: Modelling item position effects and response behaviors on multiple-choice tests. Leuven: KU Leuven

Jansen, R.S. (11-10-2019) Dealing with autonomy: Self-regulated learning in open online education. Utrecht: Utrecht University

Van Ginkel, S.O. (23-10-2019) Fostering oral presentation competence in higher education. Wageningen: Wageningen University

Van der Zanden, P. (05-11-2019) First-year student success at university: Domains, predictors, and preperation in secondary education. Nijmegen: Radboud University Nijmegen

De Bruijn, A.G.M. (14-11-2019) The brain in motion: Effects of different types of physical activity on primary school children's academic achievement and brain activation. Groningen: University of Groningen

Hopster-Den Otter, D. (28-11-2019) Formative assessment design: A balancing act. Enschede: University of Twente

Harmsen, R. (10-12-2019) Let's talk about stress. Beginning secondary school teachers' stress in the context of induction programmes. Groningen: University of Groningen

Post, T. (11-12-2019) Fostering inquiry-based pedagogy in primary school: a longitudinal study into the effects of a two-year school improvement project. Enschede: University of Twente

Ackermans, K. (20-12-2019) Designing Video-Enhanced Rubrics to Master Complex Skills. Heerlen: Open University of the Netherlands 
Li, N (08-01-2020) Analyzing online in-service teacher training courses in China. Eindhoven: Eindhoven University of Technology

Figueroa Esquivel, F. (13-02-2020) Early childhood multidimensional development. A rapid and non-linear roller coaster. Groningen: University of Groningen

De Leeuw, R.R. (27-02-2020) Through the eyes of the beholder. Unfolding social participation “from within' the classroom. Groningen: University of Groningen

Schreurs, S. (20-03-20) Selection for medical school. The quest for validity. Maastricht: Maastricht University

Nugteren, M.L. (12-06-2020) What do I know and where do I go? The effects of guidance on task selection. Utrecht: Utrecht University

Wijns, N. (01-07-2020) On the hunt for regularities: An investigation of children's early patterning competencies. Leuven: KU Leuven

Duijzer, A.C.G. (25-08-2020) Reasoning about graphs in primary mathematics education. Utrecht: Utrecht University

Dijkema, S. (25-08-2020) Ready for takeoff? The relation between the type of teacher training program and daily teaching practices of Dutch beginning primary school teachers. Groningen: University of Groningen

Slot, E.M. (11-09-2020) Characterizing adolescents' interest: understanding multiplicity and dynamics in persons, objects and contexts. Utrecht: Utrecht University

Ping, C. (24-09-2020) Understanding Teacher Educators' Professional Learning. Eindhoven: Eindhoven University of Technology

Van Rijswijk, M.M. (16-10-2020) Experiences of continuity and discontinuity in student teachers' development. Utrecht: Utrecht University

Rovers, S.F.E. (16-09-2020) Growing knowledge; Supporting students' self-regulation in problembased learning Maastricht: Maastricht University

Langeloo, A. (17-09-2020) Multilingual and monolingual children in kindergarten classrooms: Exploring teacher-child interactions and engagement as learning opportunities. Groningen: University of Groningen

Sekeris, E. (06-10-2020) Unravelling computational estimation development in 5- to 7-year-olds Leuven: KU Leuven

Ter Beek, M. (29-10-2020) Supporting reading comprehension in history education: The use and usefulness of a digital learning environment Groningen: University of Groningen

Peppen, L.M. (25-09-2020) Fostering Critical Thinking. Generative processing strategies to learn to avoid bias in reasoning Rotterdam: Erasmus University Rotterdam 
Van Geel, K., (05-11-2020) Lifelong learning in radiology: All eyes on visual expertise Maastricht: Maastricht University

Donker, M.H. (20-11-2020) In DEPTh: Dynamics of Emotional Processes in Teachers - An exploration of teachers' interpersonal behavior and physiological responses Utrecht: Utrecht University

Janssen, E.M. (13-11-2020) Teaching Critical Thinking in Higher Education: Avoiding, Detecting, and Explaining Bias in Reasoning Utrecht: Utrecht University

Van den Broek, E.W.R. (09-10-2020) Language awareness in foreign language education. Exploring teachers' beliefs, practices and change processes Nijmegen: Radboud University Nijmegen

Kasch, J.A. (09-10-2020) Scaling the unscalable? Interaction and support in open online education Heerlen: Open University of the Netherlands

Otten, M. (30-10-2020) Algebraic reasoning in primary school: A balancing act Utrecht: Utrecht University

De Vrind, E. (25-11-2020) The SpeakTeach method, Towards self-regulated learning of speaking skills in foreign languages in secondary schools: an adaptive and practical approach Leiden: Leiden University

Tacoma, S.G. (15-11-2020) Automated intelligent feedback in university statistics education Utrecht: Utrecht University

Boonk, L.M. (04-12-20202) Exploring, measuring, and evaluating parental involvement in vocational education and training Heerlen: Open University of the Netherlands

Kickert, R. (04-12-2020) Raising the bar: Higher education students' sensitivity to the assessment policy Rotterdam: Erasmus University Rotterdam

Van der Wal, N.J. (09-12-2020) Developing Techno-mathematical Literacies in higher technical professional education Utrecht: Utrecht University 
